\title{
Understanding low-temperature first-stage ignition delay: Propane
}

Shamel S. Merchant ${ }^{\dagger}$, C. Franklin Goldsmith ${ }^{\ddagger \perp}$, Aäron G. Vandeputte ${ }^{\dagger}$, Michael P. Burke ${ }^{\ddagger \S}$, Stephen J. Klippenstein ${ }^{\ddagger}$ and William H. Green ${ }^{\dagger} *$

${ }^{\dagger}$ Department of Chemical Engineering, Massachusetts Institute of Technology, 77 Massachusetts Avenue, Cambridge, MA 02139, USA

${ }^{\ddagger}$ Chemical Sciences and Engineering Division, Argonne National Laboratory, Argonne, IL 60439, USA

${ }^{\perp}$ School of Engineering, Brown University, Providence, RI 02912, USA

${ }^{\S}$ Department of Mechanical Engineering, Department of Chemical Engineering and Data Sciences Institute, Columbia University, New York, NY 10027

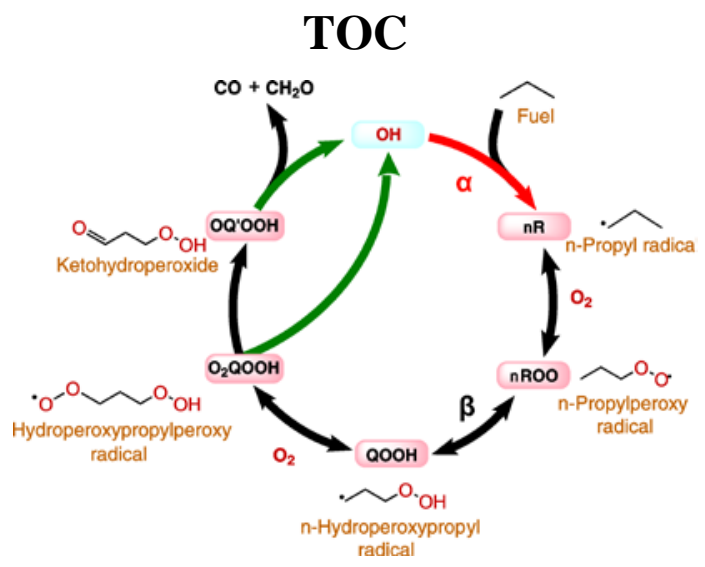

\begin{abstract}
The low-temperature auto-ignition of fuels is a complex process, occurring in multiple stages with distinct chemical processes governing each stage. The conversion from alkyl radical to chain branching products, which occurs through successive $\mathrm{O}_{2}$ additions followed by thermal decomposition of the products, is at the core of the auto-ignition process. Our detailed
\end{abstract}


understanding of this central process continues to evolve, with recent theoretical kinetics studies providing a particularly comprehensive description of the radical oxidation process for propane. In this study, we employ this improved description in a detailed numerical and analytical exploration of the first-stage ignition delay for low-temperature auto-ignition of propane, which may be considered as a prototype for larger alkane fuels. The traditional first-stage of ignition can be divided into two stages (stage-1A and stage-1B). During stage-1A, the concentration of radicals grows exponentially, and both $\mathrm{OH}$ and $\mathrm{HO}_{2}$ are important in the consumption of the fuel and generation of alkyl radicals. Stage- $1 \mathrm{~A}$ ends when the concentration of $\mathrm{HO}_{2}$ is sufficiently high that the chain-terminating bimolecular reaction $\mathrm{HO}_{2}+\mathrm{HO}_{2}$ becomes competitive with other $\mathrm{HO}_{2}$ reactions including $\mathrm{HO}_{2}+$ fuel, thus slowing the $\mathrm{HO}_{2}$ concentration rise such that is no longer key contributor to fuel consumption. During stage-1B, increasing temperature and growing side reactions with secondary chemistry reduce the positive feedback and the concentrations of ketohydroperoxide species stop growing exponentially. The end of this stage is associated with the maximum in ketohydroperoxide, after which it is depleted. We present simple analytical approximations for the time it takes to complete these two sub-stages. These expressions clarify which rate constants control first-stage ignition, and they quantify how the ignition is influenced by mixture composition, temperature and pressure. The analysis is also extended to longer alkane fuels and is shown to provide fairly reliable predictions of the firststage ignition delay.

KEYWORDS: propane, low temperature combustion, peroxy chemistry, first-stage ignition delay. 


\section{Introduction}

Low temperature $(600-800 \mathrm{~K})$ ignition delay is among the most important chemical properties of ground transportation fuels; it is the basis of the octane rating system for gasoline and the cetane rating system for diesel [1-3], and it is critical in new engine concepts like homogenous charge compression ignition (HCCI), premixed charge compression ignition (PCCI), and reactivity controlled compression ignition (RCCI) [4, 5]. Low-temperature autoignition is also a highly complex phenomenon; it exhibits non-Arrhenius (sometimes even nonmonotonic) temperature behavior, and it has strong sensitivities to modest changes in fuel structure and pressure. Models aimed at a complete description of the ignition process, typically involve hundreds of species and thousands of reactions, thereby complicating the analysis and obscuring the essential chemistry. Here we present a different perspective which allows a simple analysis of what is important during the first stage of ignition.

To facilitate understanding, several prior authors have also attempted to identify the ratecontrolling processes to focus attention on what controls pre-ignition chemistry. These analyses have proven helpful in clarifying which reactions are most important; we note in particular significant papers in this vein by Gibson et al. [6], Keck and Hu [7], Griffiths [8], Westbrook [9], Peters et al. [10], Kazakov et al. [11], Zhao and Law [12] , and Beeckman et al. [13]. Many of the recent studies like [11] base their analysis on the Curran et al. n-heptane model, first published in 1998 [14]. Other recent studies [10-12] base their analysis on skeletal models for nheptane $[10,15]$.

However, as demonstrated by Kazakov et al. [11], different conclusions regarding the controlling chemistry can be drawn using different models that employ different rate coefficients 
and thermochemistry, especially when they involve simplifications in generating the skeletal scheme. Therefore, it would appear valuable to use a detailed model that is as fundamentally sound as possible in order to draw reliable conclusions regarding the controlling chemistry for low-temperature oxidation.

Since the time of development of the models employed in previous studies, our fundamental understanding of low-temperature oxidation processes has significantly improved. For example, due to limited understanding at the time of their study, several critical reactions were not included in the detailed model of Curran et al.[14], and subsequent model studies have each retained some of these shortcomings. Three important examples include (i) the very important concerted reactions of the type $\mathrm{RO}_{2} \rightleftharpoons \mathrm{HO}_{2}+$ alkene, where $\mathrm{RO}_{2}$ is an alkylperoxy radical [16-19], (ii) molecular elimination of carboxylic acids and aldehydes from ketohydroperoxides [20-25], and (iii) the interception of vibrationally excited free radicals by $\mathrm{O}_{2}$ $[26,27]$. The thermochemistry and elementary rate coefficients for many peroxy radicals have also been significantly revised during the last few years [28-37]. Also, there have been tremendous methodological advances for computing the pressure-dependence of rate-coefficients [38-41], but few large mechanisms consider pressure-dependence in a consistent way. Only a small fraction of the many reactions in these mechanisms have been measured experimentally or computed theoretically, so most rate coefficients are approximated from rough estimates; this crude approach is particularly true for peroxide chemistry, where the multiplicity of possible isomers and pathways is commonly replaced with a single lumped irreversible pathway and an empirically adjusted rate coefficient [14, 42, 43]. Detailed mechanisms for large fuel systems such as heptane and gasoline surrogate mechanisms still lack the fidelity to accurately capture 
the time for first stage ignition delay and pressure rise rate as shown recently by Sarathy et al. [44] and Campbell et al.[45].

For propane, the number of intermediates is small enough to permit detailed exploration (e.g. five distinct isomers on the $\mathrm{C}_{3} \mathrm{H}_{7} \mathrm{O}_{2}$ potential energy surface (PES), and five distinct isomers on the $\mathrm{C}_{3} \mathrm{H}_{7} \mathrm{O}_{4}$ PES), and mechanisms for propane oxidation have been developed in which all of the reactions are represented by reversible elementary rate coefficients, e.g. by Healy et al. [46]. A recent study of Hughes et al. [47] presented a global uncertainty analysis for low temperature autoignition of propane, which highlighted a number of the key reactions and species. Goldsmith et al. [30] performed high-level quantum calculations on most of the species and reactions involved in the low-temperature ignition of propane, and made predictions of the pressure-dependent rate coefficients. A follow-up study explored the global uncertainty in the predicted rate coefficients for the $n$-propyl $+\mathrm{O}_{2}$ reaction [48]. Here we use a comprehensive detailed propane mechanism drawn from the prior studies, which provide a secure basis for analysis.

As has been discussed in the literature $[9,10]$, ignition chemistry depends dramatically on both the temperature and the pressure of the initial state, with remarkably different species and reactions being important at 650,800 , and $1100 \mathrm{~K}$. The chemistry of low-temperature ignition goes through several distinct stages, which are driven largely by the temperature changes during the process. It is often possible to experimentally discern two distinct stages in the ignition process [49]. The end of the first-stage is marked by a small increase in temperature (e.g. $\Delta \mathrm{T}$ of 10-100 K), followed by a second induction period before the more violent "hot" or "explosive" ignition. When the ignition is initiated at low temperature, the first-stage is typically much longer 
in duration than the second stage, see for example the experimental data in Figure 1. Consequently, accurate prediction of the final ignition delay time for those conditions requires accurate prediction of the first-stage ignition delay.

Although detailed kinetic models have been developed for the low-temperature oxidation of a many fuels, our understanding of low-temperature ignition chemistry is far from complete. Simple changes to the fuel structure can have significant impact on ignition delay, and these effects are not reproduced in all models. Our goal in the present work is to elucidate the chemistry occurring during the first-stage of ignition. Rather than merely catalogue all the reactions, however, we aim to simplify the process first by identifying the most important reactions and second by quantifying the effects of these reactions on the first-stage ignition delay in a manner that is both illuminating and practical for combustion chemists and engineers alike. To that end, we present simple algebraic formulae for estimating the duration of the first-stage ignition in propane, and we demonstrate how these formulae can be extended to cover larger, more complex fuels. 


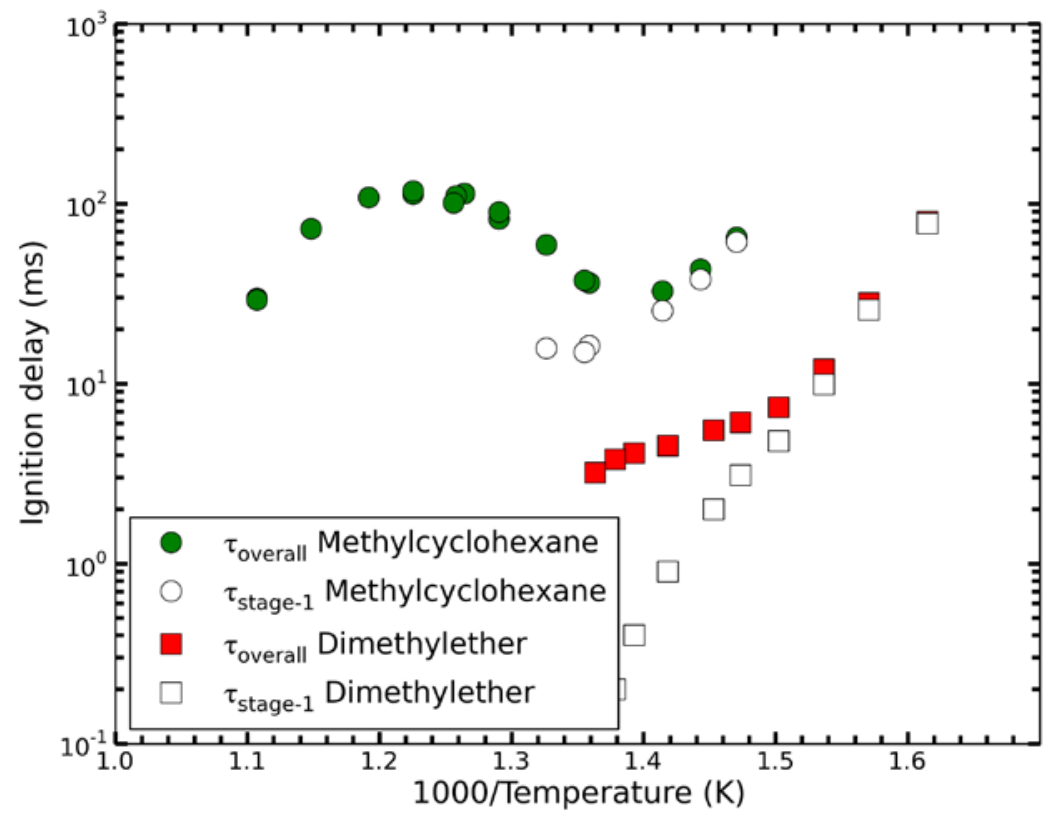

Figure 1: Experimental measured overall (filled symbols) and first-stage (open symbols) ignition delays in a rapid compression machine $(\mathrm{RCM})$ for methylcyclohexane $(\mathrm{MCH})$ [50] and dimethylether $(\mathrm{DME})[51]$ at $P_{0}=15 \mathrm{bar}, \varphi(\mathrm{MCH})=$ 1 and $\varphi(\mathrm{DME})=0.75$. For low temperatures the measured first-stage ignition delay is almost equal to the overall measured ignition delay. For higher temperatures the later stages of ignition contribute more to the overall ignition delay.

\section{Propane as an archetype for low temperature peroxy ignition pathways}

Low temperature ignition of alkanes is governed by a complex set of reactions that involve alkylperoxy radicals. Zádor et al. [52] recently presented a thorough review of this topic, and only a brief summary is provided here. Figure 2 shows a schematic mechanism for low temperature alkane oxidation and auto-ignition chemistry, adapted from [52]. The alkyl radical, $\mathrm{R}$, reacts with molecular oxygen to form an energetically excited adduct, $\mathrm{RO}_{2}^{\dagger}$, which can undergo collisional stabilization, isomerization, or decomposition into bimolecular products.

At low temperatures and normal or high pressures, the $\mathrm{R}+\mathrm{O}_{2}$ reaction leads primarily to $\mathrm{RO}_{2}$. The $\mathrm{RO}_{2}$ radical under these conditions will mainly undergo isomerization to form hydroperoxyalkyl radical, QOOH. However as the temperature is increased the branching ratio to QOOH decreases with a significant fraction of $\mathrm{RO}_{2}$ radicals instead converted to $\mathrm{HO}_{2}+$ alkene, 
which is often effectively terminating because $\mathrm{HO}_{2}$ is largely non-reactive at low to moderate temperatures. Higher temperatures also cause the $\mathrm{R}+\mathrm{O}_{2} \rightleftharpoons \mathrm{RO}_{2}$ equilibrium to shift towards the reactants. Consequently, the production of $\mathrm{RO}_{2}$ and $\mathrm{QOOH}$ effectively ceases and the energetically excited adduct, $\mathrm{RO}_{2}{ }^{\dagger}$, either returns back to $\mathrm{R}+\mathrm{O}_{2}$ or decomposes to alkene $+\mathrm{HO}_{2}$. The cumulative effect is the negative temperature coefficient (NTC) regime, where the ignition delay actually increases with increasing temperature.

All of the above reactions are at best chain propagating. For a radical driven auto-ignition to occur, however, the total number of radicals must increase. Two pathways can lead to chain branching. In the first pathway, $\mathrm{RO}_{2}$ abstracts an $\mathrm{H}$ atom from the parent fuel molecule $(\mathrm{RH})$, leading to formation of alkylhydroperoxide, $\mathrm{ROOH}$, which decomposes to an alkyloxy radical (RO) and $\mathrm{OH}$. This pathway is thought to be the main source of radicals at very low temperatures and high densities - e.g. in oxidation of liquid hydrocarbons [53].

The second chain-branching pathway involves QOOH. In the gas-phase the unimolecular isomerization reaction $\mathrm{RO}_{2} \rightleftharpoons \mathrm{QOOH}$ is often faster than the bimolecular reaction $\mathrm{RO}_{2}+\mathrm{RH} \rightarrow$ $\mathrm{ROOH}+\mathrm{R}$. The QOOH radical can then undergo addition with a second $\mathrm{O}_{2}$ molecule to form a hydroperoxyalkylperoxy radical, $\mathrm{O}_{2} \mathrm{QOOH}$, which rapidly decomposes to a ketohydroperoxide $\left(\mathrm{OQ}^{\prime} \mathrm{OOH}\right)$ and $\mathrm{OH}$ at most conditions. As in the alkylhydroperoxide, the $\mathrm{O}-\mathrm{O}$ bond in the ketohydroperoxide is quite weak (typically $\sim 40 \mathrm{kcal} / \mathrm{mol}$ ), and this species often decomposes to form ketoalkyloxy radical (OQ'O) $+\mathrm{OH}$. Consequently, the reaction sequence $\mathrm{R}+2 \mathrm{O}_{2} \rightarrow \mathrm{RO}_{2}+$ $\mathrm{O}_{2} \rightarrow \mathrm{QOOH}+\mathrm{O}_{2} \rightarrow \mathrm{O}_{2} \mathrm{QOOH} \rightarrow \mathrm{OQ}^{\prime} \mathrm{OOH}+\mathrm{OH} \rightarrow \mathrm{OQ}^{\prime} \mathrm{O}+2 \mathrm{OH}$ is chain branching, since three radicals are formed $\left(O Q^{\prime} \mathrm{O}+2 \mathrm{OH}\right)$ for every one radical consumed $(\mathrm{R})$. 
For chain branching to be fast, the concentration of QOOH needs to be sufficiently high. However, at low temperatures, the $\mathrm{RO}_{2} \rightleftharpoons \mathrm{QOOH}$ equilibrium favors $\mathrm{RO}_{2}$, while at high temperatures the $\mathrm{R}+\mathrm{O}_{2} \rightleftharpoons \mathrm{RO}_{2}$ equilibrium favors $\mathrm{R}+\mathrm{O}_{2}$, so there is a limited temperature regime in which QOOH concentrations will be sufficiently high. QOOH is formed by intramolecular $\mathrm{H}$ transfer reaction from a peroxy radical. Although there may be several possible intramolecular $\mathrm{H}$ transfer reactions for a given $\mathrm{RO}_{2}$, the energetically most favorable reactions involve either a six- or seven-membered ring, so the most relevant QOOH radicals are those with the HOO- group in the gamma or delta position, relative to the radical site. $n$-Propyl is the smallest alkyl radical that has the key six-member ring transition state (e.g. to form the $\gamma$-QOOH, 3-hydroperoxypropyl from $n$-propylperoxy). As a result the $n$-propyl radical exhibits all the key features of ignition of larger alkyl radicals, such as second $\mathrm{O}_{2}$ addition, and propane is considered as a combustion archetype [30, 37, 54].

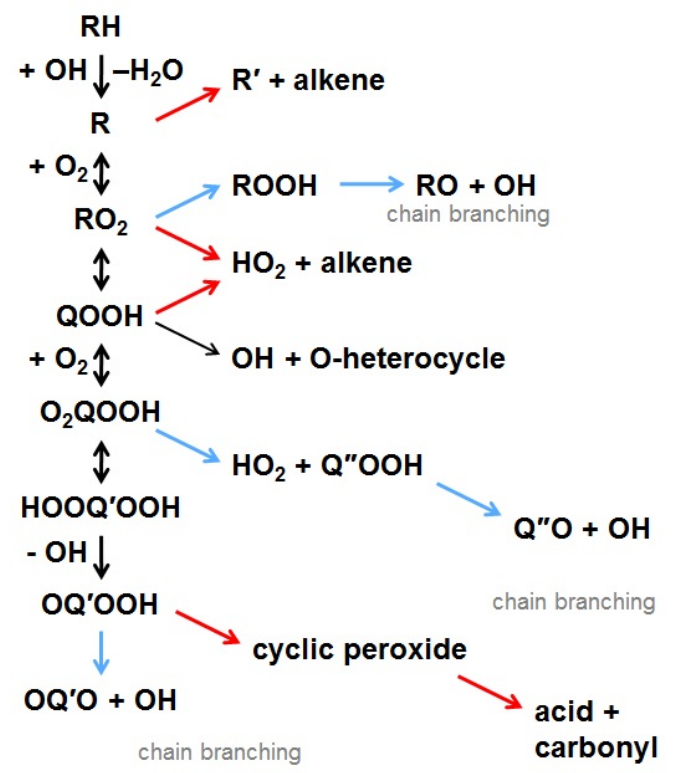

Figure 2: Schematic mechanism for the low temperature alkane oxidation and autoignition chemistry adapted from the work of Zádor et al. [52], including the Korcek reaction [24]. The pathways shown by a blue arrow lead to additional OH radicals (chain branching) while the pathways indicated by a red arrow lead to chain termination. Some of the intermediates may not live long enough to thermalize, they may not even be stationary points on the PES [30]. 


\section{Propane kinetic model}

The chemical kinetic mechanism that is used in this study is a combination of several previously published mechanisms. The core of the mechanism is based upon the high-level ab initio calculations for $\mathrm{C}_{3} \mathrm{H}_{7}+\mathrm{O}_{2}, \mathrm{C}_{3} \mathrm{H}_{7} \mathrm{O}_{2}+\mathrm{O}_{2}$, and $\mathrm{C}_{3} \mathrm{H}_{6} \mathrm{O}_{3}$ decomposition kinetics of Goldsmith et al [30]. The hydrogen/oxygen sub-mechanism was taken from Li et al. [55]. The rest of the mechanism was taken from Dooley et al [56], which itself was the union of four previous mechanisms: the $\mathrm{CH}_{2} \mathrm{O} / \mathrm{CH}_{3} \mathrm{OH}$ mechanism of $\mathrm{Li}$ et al. [57]; the $\mathrm{CH}_{3} \mathrm{OCH}_{3}$ mechanism of Zhao et al. [58]; the $\mathrm{C}_{1}-\mathrm{C}_{4}$ mechanism of Healy et al.[59]; and the methyl-ester mechanism of Fisher et al. [60]. The Korcek reaction was included in the full model with the rate coefficient adopted from calculations by Jalan et al. [24], however in line with the conclusion from Goldsmith et al.[25] $\mathrm{OH}+\mathrm{OQ}^{\prime} \mathrm{O}$ is the only significant product channel from OQ'OOH decomposition above $600 \mathrm{~K}$. The fraction of $\mathrm{nR}+\mathrm{O}_{2}+\mathrm{O}_{2}$ that directly proceeds to $\mathrm{OH}+$ OQ’OOH via a non-Boltzmann kinetic sequence was calculated by Burke et al. [27] to be less than $1 \%$ at similar conditions to those investigated here $(10 \mathrm{~atm}$ and $\mathrm{T}<800 \mathrm{~K})$. Thus, those sequences were not included in the full model.

The full propane model employed here as a basis of our simple analysis is provided in supporting information. All model simulations presented in this work are performed using Chemkin Pro [61].

\section{Low temperature oxidation of propane}

A detailed schematic for the initial stage of the oxidation of propane is presented in Figure 3. The oxidation is initiated by hydrogen abstractions by $\mathrm{O}_{2}$. The resulting $\mathrm{nR}\left(\mathrm{nC}_{3} \mathrm{H}_{7}\right)$ and $\mathrm{iR}$ $\left(\mathrm{iC}_{3} \mathrm{H}_{7}\right)$ radicals will react with the oxygen leading to their respective peroxy radicals $\left(\mathrm{nRO}_{2}\right.$ and 
$\mathrm{iRO}_{2}$ ). The $\mathrm{nRO}_{2}$ can undergo a facile isomerization via a six-membered ring transition state to a QOOH radical which will go on to react with a second oxygen molecule to form an $\mathrm{O}_{2} \mathrm{QOOH}$ radical. This radical will decompose to give one $\mathrm{OH}$ radical and ketohydroperoxide, $\mathrm{OQ}^{\prime} \mathrm{OOH}$, which itself decomposes to a second $\mathrm{OH}$ and $\mathrm{OQ}^{\prime} \mathrm{O}$ radical. The OQ'O radical decomposes to $\mathrm{CH}_{2} \mathrm{O}$ and vinoxy, $\mathrm{CH}_{2} \mathrm{CHO}$, which reacts with a third $\mathrm{O}_{2}$ molecule to form $\mathrm{CO}, \mathrm{CH}_{2} \mathrm{O}$ and a third $\mathrm{OH}$ radical. This overall sequence starting with $\mathrm{nRO}_{2}$ thus releases three reactive $\mathrm{OH}$ radicals. By contrast, $\mathrm{iRO}_{2}$ cannot undergo a six-membered isomerization and instead mostly decomposes to give $\mathrm{C}_{3} \mathrm{H}_{6}+\mathrm{HO}_{2}$.

The main chain-branching mechanism is the cyclic pathway, shown in black. Reactions that produce $\mathrm{OH}$ are shown in blue, and pathways that consume $\mathrm{OH}$ are shown in red. Pathways that divert flux away from the central chain-branching mechanism, such as the formation of $\mathrm{iC}_{3} \mathrm{H}_{7}$ from $\mathrm{C}_{3} \mathrm{H}_{8}$, the formation of $\mathrm{C}_{3} \mathrm{H}_{6}+\mathrm{HO}_{2}$ from $\mathrm{nRO}_{2}$, reactions of $\mathrm{OH}$ and $\mathrm{nRO}_{2}$ with $\mathrm{XH}$ (e.g. $\mathrm{CH}_{2} \mathrm{O}$ and $\mathrm{HO}_{2}$ ), and the Korcek pathway from $\mathrm{OQ}^{\prime} \mathrm{OOH}$, are each shown with a dotted line. Whether or not the system is explosive (supercritical) depends on whether the $\mathrm{OH}$ production is larger than the $\mathrm{OH}$ consumption, i.e. is there net postive feedback, such that an initially small concentration of radicals is exponentially amplified. Note that to a good approximation both of these rates are linear in $\mathrm{OH}$ concentrations during the early stages of ignition. For propane, over the temperature range from $500 \mathrm{~K}$ to $700 \mathrm{~K}$ two of the steps in the positive feedback in Figure 3 are particularly lossy, they are labeled as $\alpha$ and $\beta$. We define these two important ratios as follows: 


$$
\begin{gathered}
\alpha=\frac{\text { net rate of } \mathrm{OH}+\mathrm{C}_{3} \mathrm{H}_{8} \rightarrow \mathrm{nR}+\mathrm{H}_{2} \mathrm{O}}{\text { total consumption rate of } \mathrm{OH}} \\
\beta=\frac{\text { net rate of } \mathrm{nRO}_{2} \rightarrow \mathrm{QOOH}}{\text { total consumption of } \mathrm{nRO}_{2}}
\end{gathered}
$$

The values of the branching ratios $\alpha$ and $\beta$ depend on the temperature, pressure and the composition of the reactive system. If there are no losses, $3 \mathrm{OH}$ radicals are later generated for each $\mathrm{OH}$ entering the cycle. Considering the losses of $\mathrm{OH}$ characterized by $\alpha$ and $\beta$, the gain ( $f_{\mathrm{OH}}$ ) in $\mathrm{OH}$ is defined as:

$$
f_{\mathrm{OH}}=3 \alpha \beta
$$

There is positive feedback and the $\mathrm{OH}$ concentration grows rapidly if $f_{\mathrm{OH}}>1$, while values lower than 1 indicate that the $\mathrm{OH}$ concentration will diminish with time.

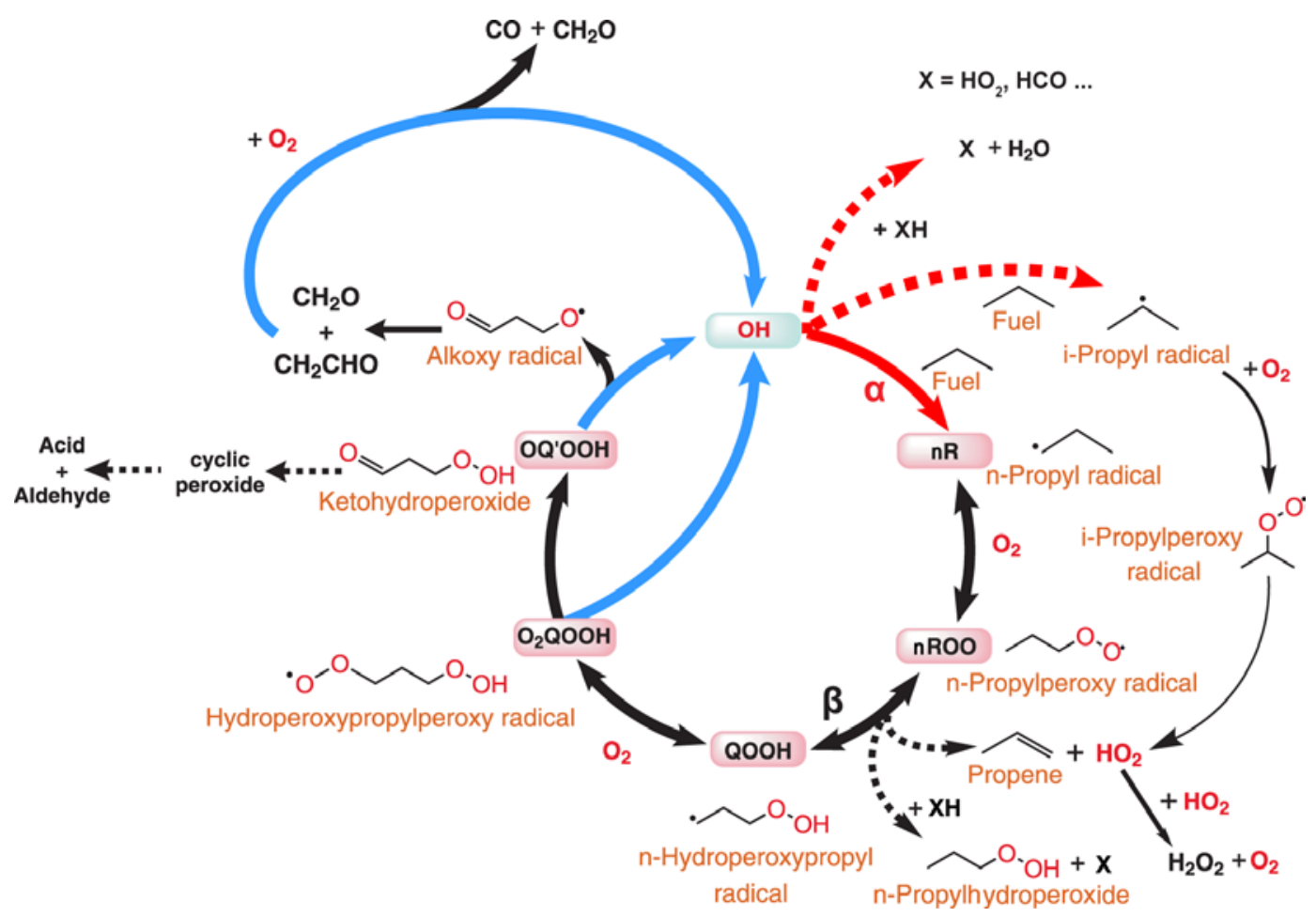

Figure 3: Schematic of major reaction pathways during the first-stage of propane ignition. Reactions shown in blue lead to formation of $\mathrm{OH}$ radicals while those in red consume $\mathrm{OH}$ radicals. The reactions shown by dotted lines divert radicals away from the main chain branching pathway and delay the first-stage ignition. During stage- $1 \mathrm{~A}, \mathrm{HO}_{2}$ radicals reacts with 
the fuel accelerating the chemistry, but later much of it recombines reducing the concentration of radicals. Note: For clarity some well-skipping pathways and reactions of $\mathrm{HO}_{2}$ are omitted from the figure.

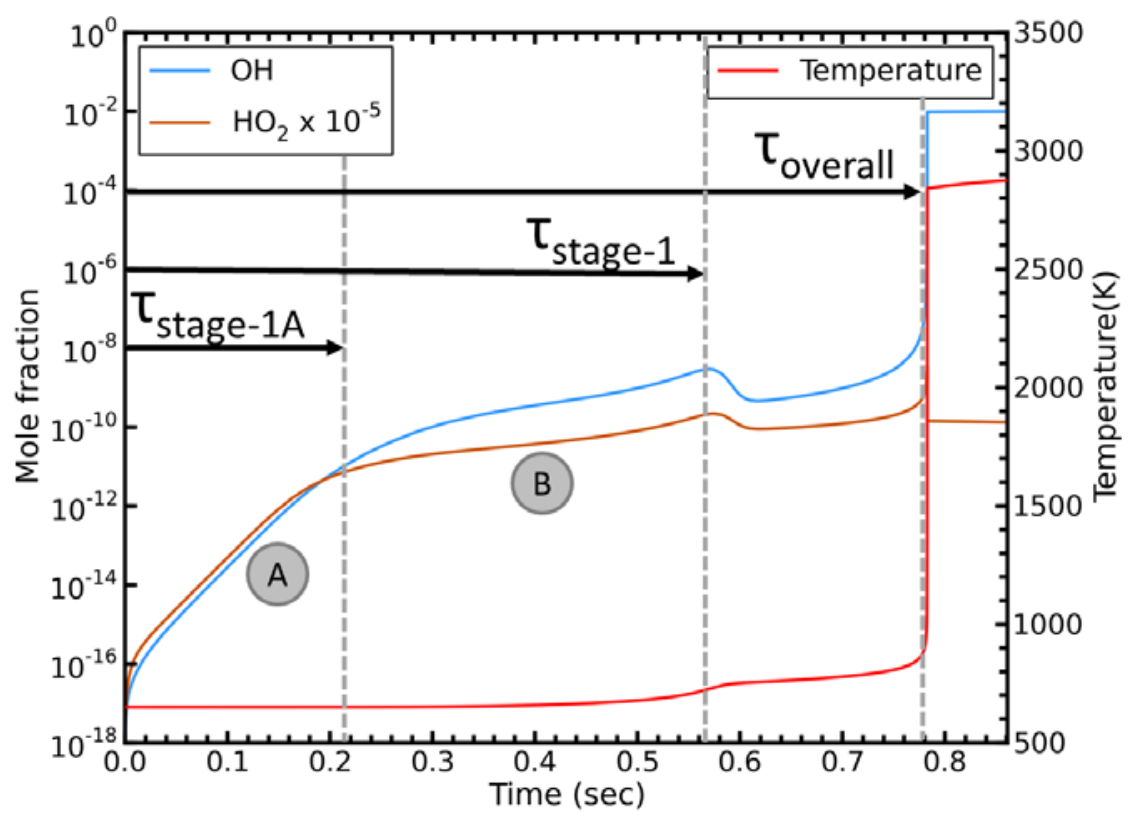

Figure 4: $\mathrm{OH}$ and $\mathrm{HO}_{2}$ mole fraction profile (on semi-log scale) and temperature profile for isochoric (constant-volume) adiabatic simulation for a stoichiometric mixture of propane and air initially at $P_{0}=10$ bar and $T_{0}=650 \mathrm{~K}$. $\tau_{\text {overall }}$ is the overall ignition delay of the fuel. $\tau_{\text {stage- } 1}$ is the first-stage ignition delay of the fuel, the time when the temperature (or pressure) of the system makes a small jump prior to the main ignition event. The first-stage ignition delay can be further divided into two stages $\mathrm{A}$ and $\mathrm{B}$ that are characterized by different time constants for the exponential rise of the $\mathrm{OH}$ concentration. $\tau_{\text {stage-1A }}$ is the time when the early exponential rise in $\mathrm{OH}$ concentration ends.

Figure 4 shows the simulated temperature evolution and $\mathrm{OH}$ and $\mathrm{HO}_{2}$ concentration for an isochoric (constant-volume), adiabatic system containing a stoichiometric mixture of propane and air (at a representative low-temperature condition of $\varphi=1, P_{0}=10 \mathrm{bar}$, and $T_{0}=650 \mathrm{~K}$ ). As seen in Figure 4, the temperature increases in two stages, with a small rise at $0.56 \mathrm{~s}$ and a much larger rise at $0.78 \mathrm{~s}$. Though not readily apparent from the temperature profile, the $\mathrm{OH}$ and $\mathrm{HO}_{2}$ profiles demonstrate that the first-stage itself can be divided into two stages, denoted stage-1A and stage-1B. 
The first noticeable time scale $\tau_{\text {stage-1A }}$ (see Figure 4) corresponds to a distinct change in the slope of the $\mathrm{OH}$ rise (dln[OH]/dt). $\tau_{\text {stage-1A }}$ marks the end of stage- $1 \mathrm{~A}$ and the beginning of stage1B. This time scale is usually not observed experimentally, since there is little or no change in the temperature and the $\mathrm{OH}$ concentrations are still too low to be detected. Both in stage- $1 \mathrm{~A}$ and 1B an exponential build-up of radicals is observed. The different exponential rise rate observed between stage- $1 \mathrm{~A}$ and $1 \mathrm{~B}$ is mainly due to reactions involving $\mathrm{HO}_{2}$ radicals. At early times (on the order of 10's and 100's of milliseconds), essentially every $\mathrm{OH}$ and $\mathrm{HO}_{2}$ formed reacts with the fuel. Since $\mathrm{OH}$ and $\mathrm{HO}_{2}$ are formed in comparable amounts, they each contribute comparably to fuel consumption during Stage-1A. In this period, the $\mathrm{HO}_{2}$ concentration is about 5 orders of magnitudes higher than $\mathrm{OH}$ (see Figure 4). Consequently, even though the rate coefficients for fuel $+\mathrm{OH}$ are about five orders of magnitude larger than the rate coefficients for fuel $+\mathrm{HO}_{2}$ at these conditions, $\mathrm{HO}_{2}$ nonetheless is responsible for a significant percentage of the total fuel consumption in stage-1A, as illustrated by the red bars in Figure 5 .

The concentration of $\mathrm{HO}_{2}$ radicals continues to build until the rate of the recombination reaction, $\mathrm{HO}_{2}+\mathrm{HO}_{2} \rightarrow \mathrm{H}_{2} \mathrm{O}_{2}+\mathrm{O}_{2}$, becomes one of the dominant $\mathrm{HO}_{2}$ consumption channels (see Figure 6). This happens at around $\sim 0.2 \mathrm{~s}$ for the conditions presented in Figure 4 and just precedes the observed kink in the $\mathrm{OH}$ concentration profile which indicates the start of stage-1B. At this point the exponential growth rate of $\mathrm{HO}_{2}$ concentration decreases significantly and the fuel $+\mathrm{HO}_{2}$ reactions become relatively unimportant (see Figure 5). Similar behavior will be observed for all fuels that produce significant amounts of $\mathrm{HO}_{2}$ (e.g. propane, iso-butane, alcohols). 


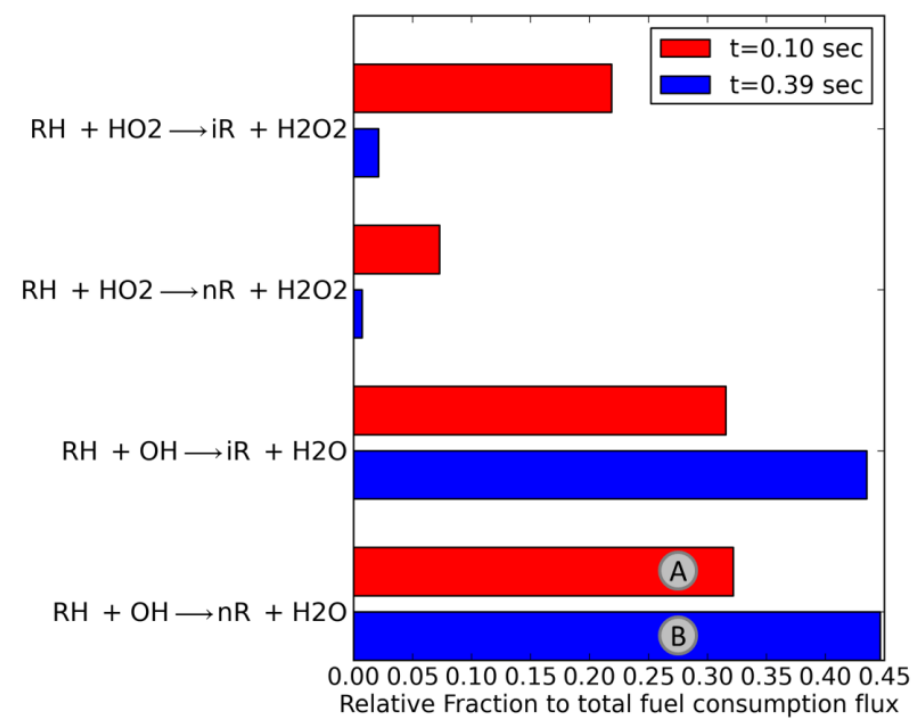

Figure 5: Fraction of propane consumed by each reaction during stage- $1 \mathrm{~A}(0.1 \mathrm{~s})$ and stage- $1 \mathrm{~B}(0.39 \mathrm{~s})$. $\mathrm{HO}_{2}$ reaction with the fuel is significant during stage-1A, but negligible during stage-1B.

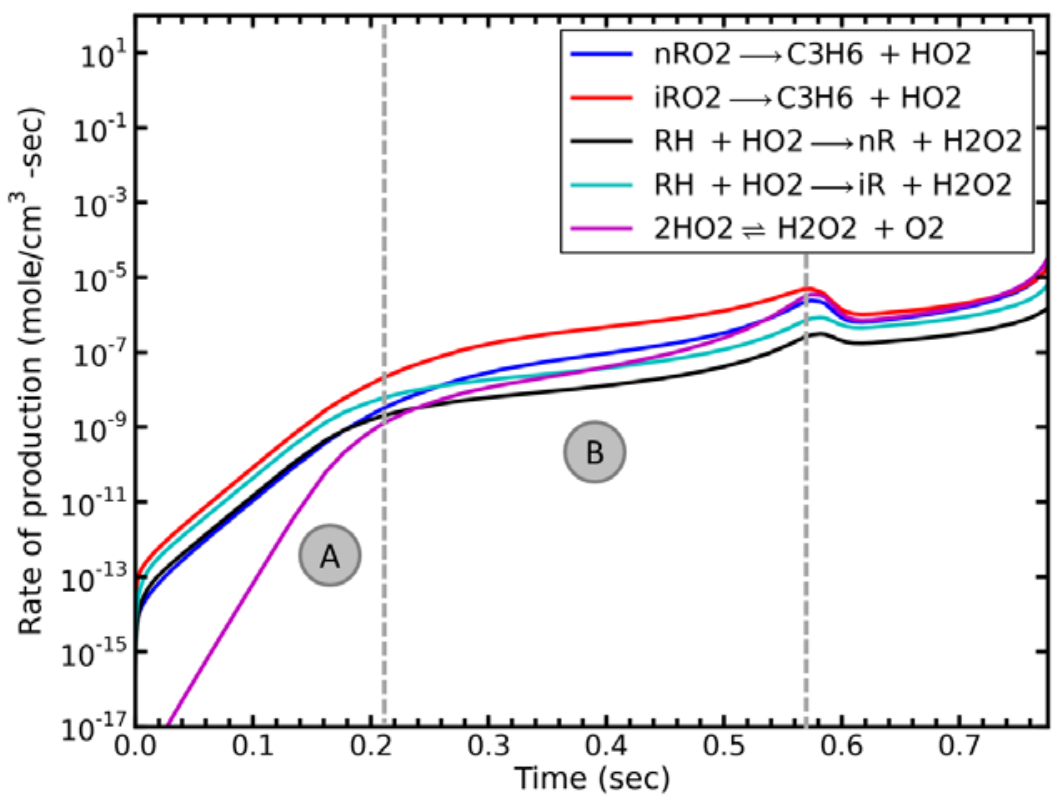

Figure 6: Magnitudes of the rates of important reactions producing or consuming $\mathrm{HO}_{2}$, for stoichiometric mixture of propane and air initially at $P_{0}=10$ bar and $T_{0}=650 \mathrm{~K}$. The transition from stage- $1 \mathrm{~A}$ to stage- $1 \mathrm{~B}$ occurs when $\mathrm{HO}_{2}$ recombination becomes comparable to other reactions. 
Stage-1B ends at time $\tau_{\text {stage-1, }}$, which is called the first-stage ignition delay of the fuel. The first-stage ignition delay may be experimentally observed if there is a detectable change in the temperature (or pressure) of the system followed by a second induction time prior to the main ignition event. $\tau_{\text {stage- } 1}$ is generally defined as the time when there is the first point of inflection in $T(\mathrm{t})$. The last important time scale (Figure 4 ) is the overall ignition delay of the fuel, $\tau_{\text {overall }} \cdot \tau_{\text {overall }}$ is observed experimentally when there is a sudden, dramatic change in the thermodynamic state of the system. Although the ignition event is relatively unambiguous, several different diagnostic techniques are used to measure $\tau_{\text {overall }}$ in practice, and these methods do not always agree precisely [62, 63]. Here we have defined the overall ignition delay as the time required for the first derivative of the temperature to reach its global maximum.

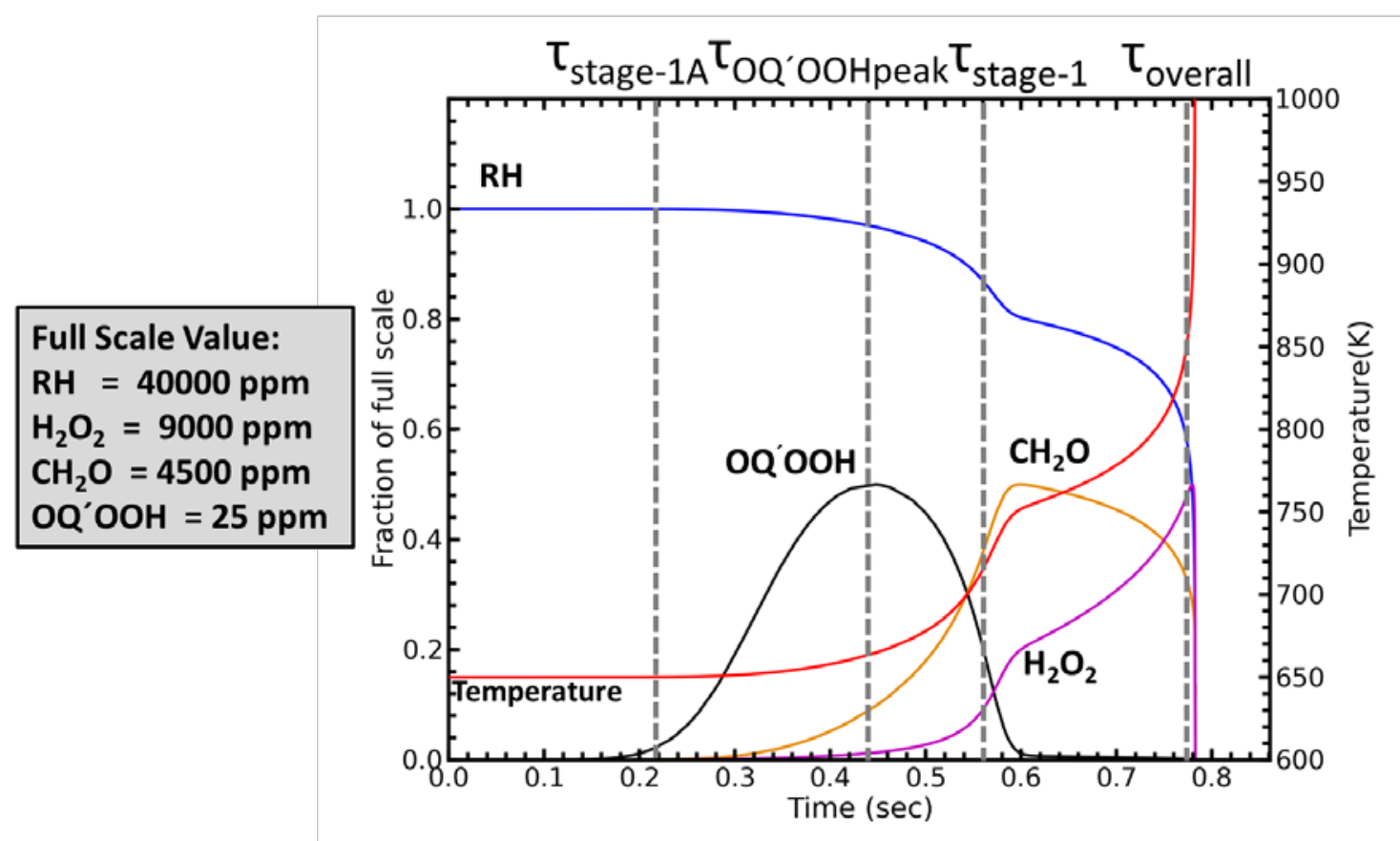

Figure 7: Evolution of key species during isochoric adiabatic reaction of stoichometric mixture of propane:air at $P_{0}=10$ bar and $T_{0}=650 \mathrm{~K}$. It should be noted that OQ'OOH peaks shortly before $\tau_{\text {stage-1. }}$. The full scale values of $\mathrm{H}_{2} \mathrm{O}_{2}, \mathrm{CH}_{2} \mathrm{O}$ and $\mathrm{OQ} \mathrm{OOH}$ were chosen to be of twice the maximum value reached in the simulation. 
Figure 7 summarizes the evolution of four key closed-shell species at the conditions of Figure 4. The oxidation process begins with an exponential rise in the concentration of ketohydroperoxide $\left(\mathrm{OQ}^{\prime} \mathrm{OOH}\right)$. As the temperature gradually increases, the concentration of OQ'OOH reaches a maximum ( $\left.\tau_{\mathrm{OQ}^{\prime} \mathrm{OOHpeak}}\right)$. It can be seen from Figure 7 that this maximum occurs shortly before the first-stage ignition delay $\tau_{\text {stage-1 }}$. Both the first-stage ignition delay and overall ignition delay can also be identified from the concentration profiles of the intermediates. For example, the $\mathrm{H}_{2} \mathrm{O}_{2}$ concentration profile shows a clear kink around $\tau_{\text {stage-1 }}$ while its concentration drops toward zero at $\tau_{\text {overall. }}$

The peak in the OQ'OOH concentration (Figure 7) can be attributed to decrease in both $\alpha$ and $\beta$ components of the gain. First, the reaction cycle illustrated in Figure 3 is net exothermic and this leads to a rise in the temperature of the system. As the temperature increases, the rate coefficient for $\mathrm{nRO}_{2} \rightarrow$ alkene $+\mathrm{HO}_{2}$ increases and the equilibrium constants for $\mathrm{nR}+\mathrm{O}_{2} \rightleftharpoons$ $\mathrm{nRO} \mathrm{O}_{2}$ and $\mathrm{QOOH}+\mathrm{O}_{2} \rightleftharpoons \mathrm{O}_{2} \mathrm{QOOH}$ shift back towards the reactants, thereby decreasing the ratio $\beta$ (given by (2)). So every time an $\mathrm{OQ}^{\prime} \mathrm{OOH}$ decomposes a smaller fraction of the $\mathrm{OH}$ radicals created will return back to the cycle to form new $\mathrm{OQ}^{\prime} \mathrm{OOH}$. The second contributing factor to the peak in $\mathrm{OQ}^{\prime} \mathrm{OOH}$ is the loss of $\mathrm{nRO}_{2}$ and $\mathrm{OH}$ radicals to the growing secondary products. Prior to $\tau_{\text {stage-1A }}$ (stage-1A), the concentration of products is sufficiently low that secondary reactions such as $\mathrm{OH}+$ products and $\mathrm{nRO}_{2}+$ products are negligible. Under these conditions there are more $\mathrm{OH}$ radicals being produced than consumed (i.e. $\mathrm{OH}$ gain factor $f_{\mathrm{OH}}>1$ ), thereby propagating the chain branching cycle, e.g. the sequence of black and blue lines in Figure 3. However eventually, the product concentrations are no longer negligible, and any reaction of $\mathrm{OH}$ or $\mathrm{nRO}_{2}$ with these products diverts the active radicals away from the chain branching pathway, 
thereby reducing the gain of the feedback system. The most important products in this context are $\mathrm{CH}_{2} \mathrm{O}$ and $\mathrm{H}_{2} \mathrm{O}_{2}$ for diverting $\mathrm{OH}$ and $\mathrm{CH}_{2} \mathrm{O}$ and $\mathrm{HO}_{2}$ for diverting $\mathrm{nRO}_{2}$, these pathways are illustrated by the dotted lines in Figure 3.

By $\tau_{\mathrm{OQ} \mathrm{Q}^{\prime} \mathrm{OHpeak}}$ the gain $f_{\mathrm{OH}}$ has decreased close to unity, hence additional losses will result in the cycle no longer being able to sustain itself. Beyond $\mathrm{t}>\tau_{\mathrm{OQ}^{\prime} \mathrm{OOH} p e a k}$ the $\mathrm{OQ}^{\prime} \mathrm{OOH}$ concentration that has built-up during the initial stages of the oxidation decreases, primarily decomposing via pathways that create two $\mathrm{OH}$ radicals (see Figure 3). The release of these radicals in the system causes a sudden jump in the temperature (and pressure), signaling the firststage ignition, $\tau_{\text {stage- } 1}$. At the same time the $\mathrm{CH}_{2} \mathrm{O}$ concentration, which is a side product of the OQ'OOH decomposition, is also seen to spike (see Figure 7 ). For this sequence, $\tau_{\mathrm{OQ}^{\prime} \mathrm{OOHpeak}}$ is a fairly reliable approximation for $\tau_{\text {stage-1}}$. This correlation is illustrated in Figure 8, where the solid line is the overall ignition delay, the dashed line is the first-stage ignition delay (as determined by the inflection point in the temperature), and the dashed-dotted line is the time of the peak $\mathrm{OQ}^{\prime} \mathrm{OOH}$. Note that the peak in OQ'OOH is an excellent predictor of the first-stage ignition delay, even well into the NTC regime, at which point the first-stage ignition delay is no longer a reliable predictor for the overall ignition delay anyway. 


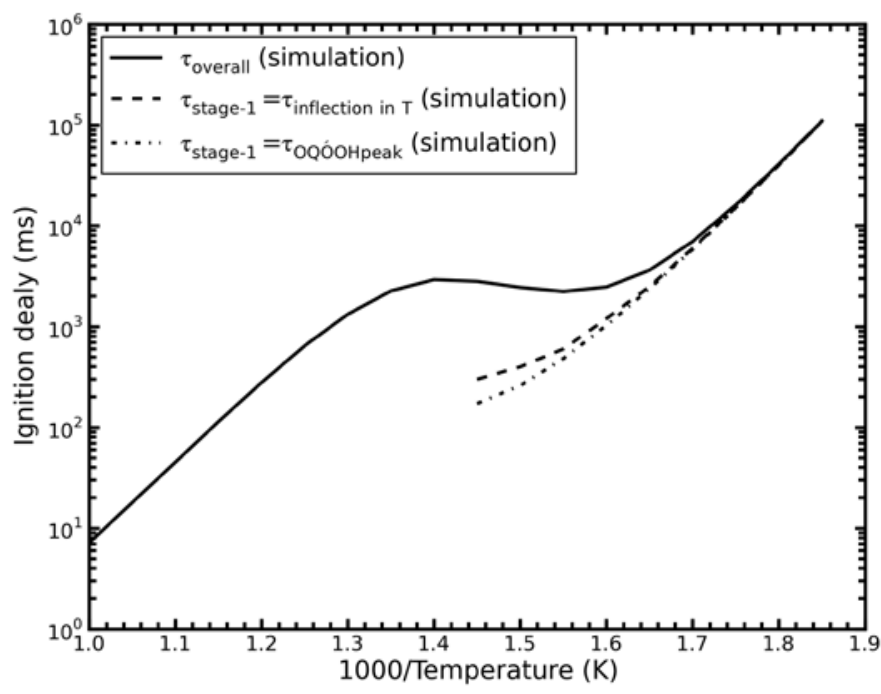

Figure 8: Arrhenius plot for adiabatic isochoric stoichometric mixture of propane in air initially at $P_{0}=10$ bar comparing $\tau_{\mathrm{OQ}^{\prime}{ }^{\prime} \text { OOHpeak }}$ to $\tau_{\text {stage-1 }}$ (determined by inflection in temperature). The $\tau_{\mathrm{OQ}^{\prime} \mathrm{OOH}_{\mathrm{OHa}}}$ is a good estimate of $\tau_{\text {stage-1. }}$.

Before we can derive analytical expressions that describe the low temperature combustion of propane, it is important to know whether or not quasi-steady state assumptions can be made for the system presented in Figure 7. Therefore, the net rate of reaction for the main oxidation reactions of $\mathrm{nR}\left(\mathrm{nC}_{3} \mathrm{H}_{7}\right)$ are shown in Figure 9. The net rate of reaction is defined as the flux for the forward reaction minus the reverse flux. Figure 9 illustrates that most rates of production quickly converge to the corresponding rates of destruction. First, at $t \approx 5 \times 10^{-5} \mathrm{~s}$, the net rates for $\mathrm{nRO}_{2} \rightarrow$ QOOH (dashed blue) and $\mathrm{O}_{2}+\mathrm{QOOH} \rightarrow \mathrm{O}_{2} \mathrm{QOOH}$ (solid blue) converge. This indicates that the net accumulation of QOOH is very small compared to its throughput and $\mathrm{QOOH}$ is in quasi-steady state beyond this time. Next, at $t \approx 5 \times 10^{-3} \mathrm{~s}$, the net rates for $\mathrm{O}_{2}+$ $\mathrm{QOOH} \rightarrow \mathrm{O}_{2} \mathrm{QOOH}$ (solid blue) converges with that for $\mathrm{O}_{2} \mathrm{QOOH} \rightarrow \mathrm{OQ} \mathrm{OOH}^{\circ} \mathrm{OH}$ (dashed green) signaling $\mathrm{O}_{2} \mathrm{QOOH}$ comes in quasi steady state. The net rate for OQ'OOH $\rightarrow \mathrm{OQ}^{\prime} \mathrm{O}+$ $\mathrm{OH}$ and $\mathrm{OQ}^{\prime} \mathrm{O} \rightarrow \mathrm{CH}_{2} \mathrm{CHO}+\mathrm{CH}_{2} \mathrm{O}$ converge $\mathrm{t} \approx 2 \times 10^{-3} \mathrm{~s}$, this reaction is not shown in the plot. 
Other reactions not shown in the plot are the net rate of formation $\left(\mathrm{RH}+\mathrm{O}_{2} / \mathrm{OH} / \mathrm{HO}_{2} \rightarrow \mathrm{nR}+\right.$ $\mathrm{HO}_{2} / \mathrm{H}_{2} \mathrm{O} / \mathrm{H}_{2} \mathrm{O}_{2}$ ) and consumption of $\mathrm{nR}$ which converge within microseconds, indicating nR to be the first species to reach quasi-steady state. . Figure 9 shows that $\mathrm{nRO}_{2}$ is close to quasi steady state while $\mathrm{OQ}^{\prime} \mathrm{OOH}$ is not in quasi steady state during first-stage of ignition.
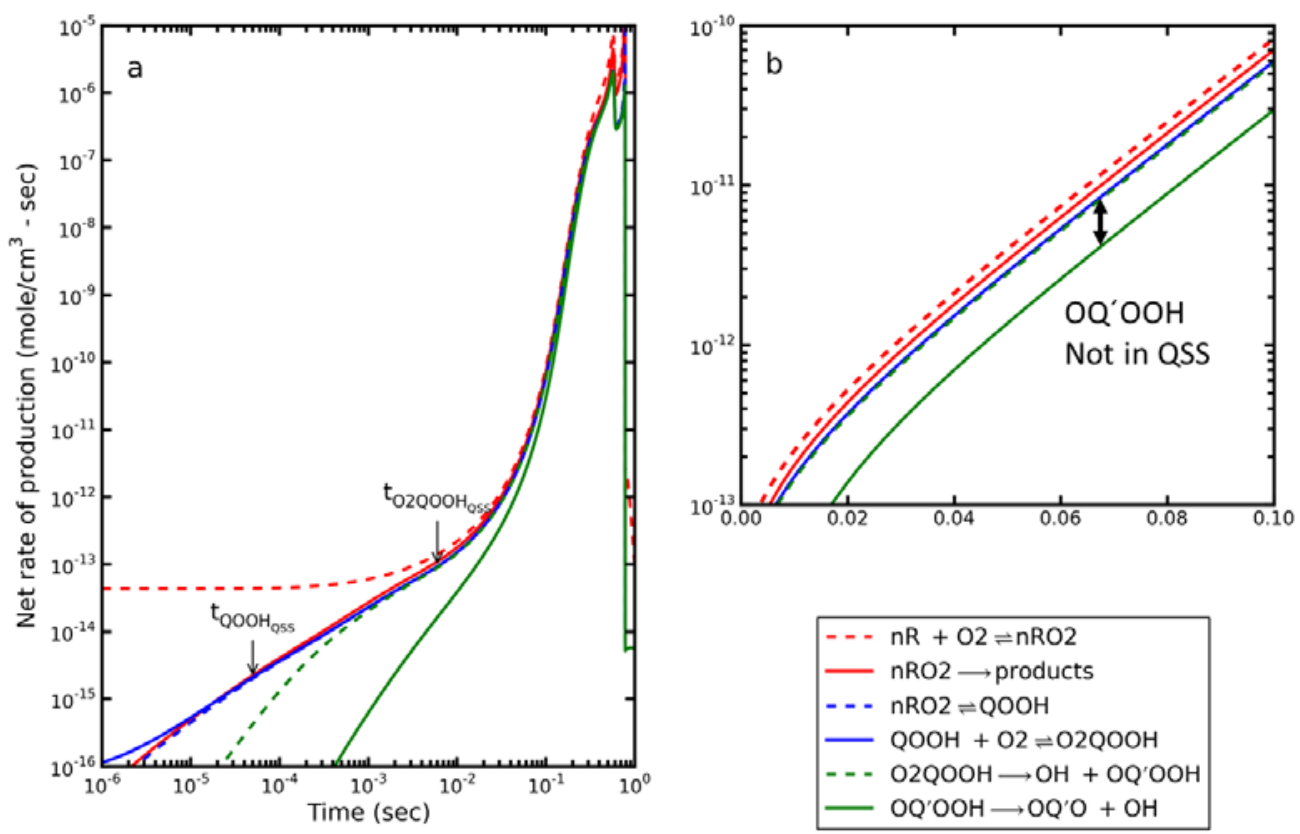

Figure 9: a) Net rate of production for reactions involved in $n$-propyl (nR) peroxy cycle, for adiabatic isochoric simulations $\left(P_{0}=10 \mathrm{bar}, T=650 \mathrm{~K}\right)$ of stoichiometric mixture of propane and air using the full propane model. The arrows indicate the time when the species come into quasi-steady state, most species are in quasi-steady state after $\mathrm{t} \sim 5$ ms. b) Inset of plot $5 \mathrm{a}$ ) - the rate of $\mathrm{O}_{2} \mathrm{QOOH} \rightarrow \mathrm{OQ} \mathrm{OQOH}^{\prime}+\mathrm{OH}$ and $\mathrm{OQ}^{\prime} \mathrm{OOH} \rightarrow \mathrm{OQ}^{\prime} \mathrm{O}+\mathrm{OH}$ are significantly different indicating $\mathrm{OQ}^{\prime} \mathrm{OOH}$ is not in quasi-steady state. For reference $\tau_{\text {stage-1A, }} \tau_{\mathrm{OQ} \mathrm{Q}^{\prime} \mathrm{OOH} \text { and }} \tau_{\text {stage- } 1}$ are $\sim 0.2, \sim 0.44$ and $\sim 0.56$ s respectively.

\section{Reduced model formulation for low temperature ignition}

The objective of this paper is not to provide a new propane mechanism; rather, it is to elucidate analytically what reactions in the larger mechanism are responsible for the lowtemperature, first-stage ignition delay. Based upon the preceding analysis, we begin with a simple reduced model that consists of only the most important reactions prior to first-stage 
ignition (the predicted ignition delay for the reduced and full model are within a factor of 2 , see supplemental material for the comparison). This reduced model includes reactions for: fuel $+\mathrm{O}_{2}$ initiation, fuel + radical, $\mathrm{O}_{2}+\mathrm{R}, \mathrm{O}_{2}+\mathrm{QOOH}$, OQ'OOH decomposition, and other important sources and sinks of $\mathrm{OH}$ from secondary chemistry of key species, including hydrogen abstraction from $\mathrm{HO}_{2}, \mathrm{H}_{2} \mathrm{O}_{2}$ and $\mathrm{CH}_{2} \mathrm{O}$. The $\mathrm{H}_{2} \mathrm{O}_{2}$ generation loop and the secondary chain branching loop (involving the alkyloxy radical), which were found to be important in previous studies [64, 65], also are included. During the prelude to ignition some reactions will rapidly equilibrate, and the corresponding reverse rate coefficients are included. For other reactions, the reverse reaction is negligible, and only the forward rate coefficient is required. The complete list of reactions in the reduced model is provided in Table 1.

Table 1: Simplified reaction mechanism for low-temperature propane ignition

\begin{tabular}{llll}
\hline Label & Reaction & Rate coefficient & Reference \\
\hline $\mathrm{R} 1$ & $\mathrm{RH}+\mathrm{O}_{2} \rightarrow \mathrm{nR}+\mathrm{HO}_{2}$ & $\mathrm{k}_{1}$ & {$[46]$} \\
$\mathrm{R} 2$ & $\mathrm{RH}+\mathrm{O}_{2} \rightarrow \mathrm{iR}+\mathrm{HO}_{2}$ & $\mathrm{k}_{2}$ & {$[46]$} \\
$\mathrm{R} 3$ & $\mathrm{RH}+\mathrm{OH} \rightarrow \mathrm{nR}+\mathrm{H}_{2} \mathrm{O}$ & $\mathrm{k}_{3}$ & {$[46]$} \\
$\mathrm{R} 4$ & $\mathrm{RH}+\mathrm{OH} \rightarrow \mathrm{iR}+\mathrm{H}_{2} \mathrm{O}$ & $\mathrm{k}_{4}$ & {$[46]$} \\
$\mathrm{R} 5$ & $\mathrm{RH}+\mathrm{HO}_{2} \rightarrow \mathrm{nR}+\mathrm{H}_{2} \mathrm{O}_{2}$ & $\mathrm{k}_{5}$ & {$[66]$} \\
$\mathrm{R} 6$ & $\mathrm{RH}+\mathrm{HO}_{2} \rightarrow \mathrm{iR}+\mathrm{H}_{2} \mathrm{O}_{2}$ & $\mathrm{k}_{6}, \mathrm{k}_{-7}$ & {$[66]$} \\
$\mathrm{R} 7$ & $\mathrm{nR}+\mathrm{O}_{2} \rightleftharpoons \mathrm{nRO}_{2}$ & $\mathrm{k}_{8}, \mathrm{k}_{-8}$ & {$[30]$} \\
$\mathrm{R} 8$ & $\mathrm{iR}+\mathrm{O}_{2} \rightleftharpoons \mathrm{iRO}_{2}$ & $\mathrm{k}_{9}, \mathrm{k}_{-9}$ & {$[30]$} \\
$\mathrm{R} 9$ & $\mathrm{nR}+\mathrm{O}_{2} \rightleftharpoons \mathrm{QOOH}$ & $\mathrm{k}_{10}$ & {$[30]$} \\
$\mathrm{R} 10$ & $\mathrm{nR}+\mathrm{O}_{2} \rightarrow \mathrm{C}_{3} \mathrm{H}_{6}+\mathrm{HO}_{2}$ & $\mathrm{k}_{11}$ & {$[30]$} \\
$\mathrm{R} 11$ & $\mathrm{iR}+\mathrm{O}_{2} \rightarrow \mathrm{C}_{3} \mathrm{H}_{6}+\mathrm{HO}_{2}$ & {$[30]$}
\end{tabular}




\begin{tabular}{llll}
$\mathrm{R} 12$ & $\mathrm{nRO}_{2} \rightarrow \mathrm{C}_{3} \mathrm{H}_{6}+\mathrm{HO}_{2}$ & $\mathrm{k}_{12}$ & {$[30]$} \\
$\mathrm{R} 13$ & $\mathrm{iRO}_{2} \rightarrow \mathrm{C}_{3} \mathrm{H}_{6}+\mathrm{HO}_{2}$ & $\mathrm{k}_{13}$ & {$[30]$} \\
$\mathrm{R} 14$ & $\mathrm{nRO}_{2} \rightleftharpoons \mathrm{QOOH}$ & $\mathrm{k}_{14}, \mathrm{k}_{-14}$ & {$[30]$} \\
$\mathrm{R} 15$ & $\mathrm{QOOH}+\mathrm{O}_{2} \rightleftharpoons \mathrm{O}_{2} \mathrm{QOOH}$ & $\mathrm{k}_{15}, \mathrm{k}_{-15}$ & {$[30]$} \\
$\mathrm{R} 16$ & $\mathrm{O}_{2} \mathrm{QOOH} \rightarrow \mathrm{OQ}^{\prime} \mathrm{OOH}+\mathrm{OH}$ & {$[30]$} \\
$\mathrm{R} 17$ & $\mathrm{OQ}^{\prime} \mathrm{OOH} \rightarrow \mathrm{OQ} \mathrm{O}+\mathrm{OH}$ & $\mathrm{k}_{17}$ & {$[30]$} \\
$\mathrm{R} 18$ & $\mathrm{OQ}^{\prime} \mathrm{O} \rightarrow \mathrm{CH} \mathrm{CHO}_{2} \mathrm{CH}_{2} \mathrm{O}$ & $\mathrm{k}_{18}$ & {$[30]$} \\
$\mathrm{R} 19$ & $\mathrm{CH}_{2} \mathrm{CHO}+\mathrm{O}_{2} \rightarrow \mathrm{CH} \mathrm{H}_{2}+\mathrm{CO}+\mathrm{OH}$ & $\mathrm{k}_{19}$ & {$[67]$} \\
$\mathrm{R} 20$ & $\mathrm{CH}_{2} \mathrm{O}+\mathrm{OH} \rightarrow \mathrm{HCO}+\mathrm{H}_{2} \mathrm{O}$ & $\mathrm{k}_{20}$ & {$[68]$} \\
$\mathrm{R} 21$ & $\mathrm{CH}_{2} \mathrm{O}+\mathrm{O}_{2} \rightarrow \mathrm{HCO}+\mathrm{HO}_{2}$ & $\mathrm{k}_{21}$ & {$[69]$} \\
$\mathrm{R} 22$ & $\mathrm{HCO}_{2} \mathrm{O}_{2} \rightarrow \mathrm{CO}+\mathrm{HO}_{2}$ & $\mathrm{k}_{22}$ & {$[70]$} \\
$\mathrm{R} 23$ & $\mathrm{H}_{2} \mathrm{O}_{2}+\mathrm{OH}^{2} \rightarrow \mathrm{H}_{2} \mathrm{O}+\mathrm{HO}_{2}$ & $\mathrm{k}_{23}$ & {$[71]$} \\
$\mathrm{R} 24$ & $\mathrm{HO}_{2}+\mathrm{HO}_{2} \rightarrow \mathrm{H}_{2} \mathrm{O}_{2}+\mathrm{O}_{2}$ & $\mathrm{k}_{24}$ & {$[71]$} \\
$\mathrm{R} 25$ & $\mathrm{H}_{2} \mathrm{O}_{2} \rightarrow 2 \mathrm{OH}$ & $\mathrm{k}_{25}$ & {$[71]$} \\
$\mathrm{R} 26$ & $\mathrm{nRO}_{2}+\mathrm{CH}_{2} \mathrm{O} \rightarrow \mathrm{nROOH}^{2} \mathrm{HCO}$ & $\mathrm{k}_{26}$ & {$[46]$} \\
$\mathrm{R} 27$ & $\mathrm{nRO}_{2}+\mathrm{HO}_{2} \rightarrow \mathrm{nROOH}+\mathrm{O}_{2}$ & $\mathrm{k}_{27}$ & {$[46]$} \\
\hline & & &
\end{tabular}

The mechanism listed in Table 1 represents a system of non-linear ordinary differential equations that consists of 20 species and 27 reactions (plus equations for the thermodynamic state variables). The original full model and reduced model are provided in the Supplemental Materials. 


\subsection{Analytic solution for stage-1A}

The extent to which the growth in radical concentration is exponential depends upon the comparative rates of production for radicals versus their loss to other channels. If OQ'OOH decomposition to produce $\mathrm{OH}$ radicals exceeds $\mathrm{OH}$ losses (e.g. R4, R20 and R23), then there will be explosive growth.

During stage- $1 \mathrm{~A}$ the concentration of products is negligible, and the fuel and $\mathrm{O}_{2}$ concentration remain essentially constant. These two assumptions effectively linearize the system of equations. For a system of linear ordinary differential equations, the solution is a sum of exponentials, and after an initial incubation period the eigenmode with the largest positive exponent $(\lambda)$ will dominate all the other modes. This incubation period is expected to be on the order of the larger of the two quantities: 1) the induction period where the initiation reactions contribute non-negligibly to the production of radicals and 2) 1/( $\left.\lambda-\lambda_{1}\right)$ where $\lambda_{1}$ is the second largest eigenvalue. We expect that to a good approximation, after the incubation period, all species (except for fuel, $\mathrm{O}_{2}, \mathrm{~N}_{2}$ ) will grow approximately exponentially with a single growth rate defined by the positive eigenvalue, e.g.

$$
\begin{aligned}
& {[\mathrm{OH}] \approx C_{\mathrm{OH}} \exp (\lambda t)} \\
& {\left[\mathrm{OQ}^{\prime} \mathrm{OOH}\right] \approx C_{\mathrm{OQ}^{\prime} \mathrm{OOH}} \exp (\lambda t)} \\
& {\left[\mathrm{HO}_{2}\right] \approx C_{\mathrm{HO} 2} \exp (\lambda t)}
\end{aligned}
$$

The ratios of the pre-exponential factors, $C_{X}$, and the exponent $\lambda$ can be evaluated numerically by diagonalizing the rate coefficient matrix (for details see Supplemental Materials). These parameters depend upon the initial concentrations, $[\mathrm{RH}]_{0}$ and $\left[\mathrm{O}_{2}\right]_{0}$, and upon the rate coefficients evaluated at the initial conditions, $T_{0}$ and $P_{0}$. To simplify the analysis, we note that 
after the initial induction period, several of the species will be in a quasi-steady state, including $\mathrm{nR}$, iR, QOOH, and $\mathrm{O}_{2} \mathrm{QOOH}, \mathrm{OQ}^{\prime} \mathrm{O}, \mathrm{OH}$, and $\mathrm{CH}_{2} \mathrm{CHO}$. It is also assumed that the vast majority of $\mathrm{QOOH}$ is formed via isomerization from $\mathrm{nRO}_{2}$, while the chemically activated production of $\mathrm{QOOH}$ from $\mathrm{nR}+\mathrm{O}_{2}$ is negligible [30]. This leads to the following equations (see Supplemental Material for how these equations were obtained):

$$
\begin{gathered}
{[\mathrm{nR}]=\frac{\left(k_{1}\left[\mathrm{O}_{2}\right]+k_{3}[\mathrm{OH}]+k_{5}\left[\mathrm{HO}_{2}\right]\right)[\mathrm{RH}]+k_{-7}\left[\mathrm{nRO}_{2}\right]+k_{-9}[\mathrm{QOOH}]}{\left(k_{7}+k_{9}+k_{10}\right)\left[\mathrm{O}_{2}\right]}} \\
{[\mathrm{iR}]=\frac{\left(k_{2}\left[\mathrm{O}_{2}\right]+k_{4}[\mathrm{OH}]+k_{6}\left[\mathrm{HO}_{2}\right]\right)[\mathrm{RH}]+k_{-8}\left[\mathrm{iRO}_{2}\right]}{\left(k_{8}+k_{11}\right)\left[\mathrm{O}_{2}\right]}} \\
{[\mathrm{QOOH}]=\frac{k_{9}[\mathrm{nR}]\left[\mathrm{O}_{2}\right]+k_{14}\left[\mathrm{nRO}_{2}\right]+k_{-15}\left[\mathrm{O}_{2} \mathrm{QOOH}\right]}{k_{-9}+k_{-14}+k_{15}\left[\mathrm{O}_{2}\right]}} \\
{\left[\mathrm{O}_{2} \mathrm{QOOH}\right]=\frac{k_{15}}{k_{-15}+k_{16}}\left[\mathrm{O}_{2}\right][\mathrm{QOOH}]} \\
{[\mathrm{OH}]=\frac{k_{16}\left[\mathrm{O}_{2} \mathrm{QOOH}\right]+k_{17}[\mathrm{OQ} \mathrm{OOH}]+k_{19}\left[\mathrm{CH}_{2} \mathrm{CHO}_{17}\left[\mathrm{OQ}_{2}\right]+2 \mathrm{OOH}_{25}\left[\mathrm{H}_{2} \mathrm{O}_{2}\right]\right.}{k_{18}}} \\
\left(k_{3}+k_{4}\right)[\mathrm{RH}]+k_{20}\left[\mathrm{CH}_{2} \mathrm{O}\right]+k_{23}\left[\mathrm{H}_{2} \mathrm{O}_{2}\right] \\
{\left[\mathrm{CH}_{2} \mathrm{CHO}\right]=\frac{k_{18}\left[\mathrm{OQQ}^{\prime} \mathrm{O}\right]}{k_{19}\left[\mathrm{O}_{2}\right]}}
\end{gathered}
$$

Three dimensionless parameters are introduced that will prove helpful in evaluating the differential equations:

$$
\alpha=\frac{k_{3}}{k_{3}+k_{4}}
$$




$$
\begin{gathered}
\beta=\frac{\theta k_{14}}{\theta k_{14}+k_{12}} \\
\theta=\frac{k_{16}\left[\mathrm{O}_{2} \mathrm{QOOH}\right]}{k_{14}\left[\mathrm{nRO}_{2}\right]}=\frac{\frac{k_{15} k_{16}}{k_{-15}+k_{16}}\left[\mathrm{O}_{2}\right]}{k_{-14}+\frac{k_{15} k_{16}}{k_{-15}+k_{16}}\left[\mathrm{O}_{2}\right]}
\end{gathered}
$$

In equation (11) above, $\alpha$ is defined as the fraction of $\mathrm{OH}$ radicals consumed that form $\mathrm{nR}$ $\left(\mathrm{nC}_{3} \mathrm{H}_{7}\right)$ under the assumption that during stage- $1 \mathrm{~A}$ the $\mathrm{OH}$ radicals will predominantly react by abstracting hydrogen from the parent fuel. However, $\alpha$ can be more generally interpreted as the fraction of $\mathrm{OH}$ radicals that reacts to form radicals that have the potential for chain branching. $\beta$ is the fraction of $\mathrm{nRO}_{2}$ radicals that react to form $\mathrm{OQ}^{\prime} \mathrm{OOH}$ via the sequence $\mathrm{R} 14, \mathrm{R} 15$ and $\mathrm{R} 16$ relative to the loss of $\mathrm{nRO}_{2}$ due to concerted $\mathrm{HO}_{2}$ elimination. $\theta$ in equation (13) is defined as the fraction of QOOH formed which goes on to form $\mathrm{OQ}^{\prime} \mathrm{OOH}$ (ratio of flux through $\mathrm{O}_{2} \mathrm{QOOH} \rightarrow$ $\mathrm{OQ}^{\prime} \mathrm{OOH}+\mathrm{OH}$ over the flux for $\left.\mathrm{nRO}_{2} \rightarrow \mathrm{QOOH}\right) . \theta$ can be interpreted as a correction factor for cases where $\mathrm{nRO}_{2} \rightarrow \mathrm{QOOH}$ is not the rate limiting step. It is constrained to be between 0 and 1 and it decreases with increasing temperature and decreasing pressure as illustrated in Figure 10. At low temperatures and high oxygen partial pressures, $\theta$ is close to 1 indicating that the reaction $\mathrm{nRO}_{2} \rightarrow \mathrm{QOOH}$ is the rate limiting step. As the temperature increases, $\theta$ starts to decrease primarily because of strong temperature dependence of $\mathrm{k}_{-15}\left(\mathrm{O}_{2} \mathrm{QOOH} \rightarrow \mathrm{QOOH}+\mathrm{O}_{2}\right)$ which begins to significantly compete with $\mathrm{O}_{2} \mathrm{QOOH} \rightarrow \mathrm{OQ}^{\prime} \mathrm{OOH}+\mathrm{OH}$. This shift in the $\mathrm{O}_{2} \mathrm{QOOH} \rightleftharpoons \mathrm{QOOH}+\mathrm{O}_{2}$ equilibrium can also be achieved by lowering the pressure at fixed stoichiometry: at $600 \mathrm{~K}$ in air $\theta$ drops from 1 at 100 bar to 0.3 at 1 bar. 


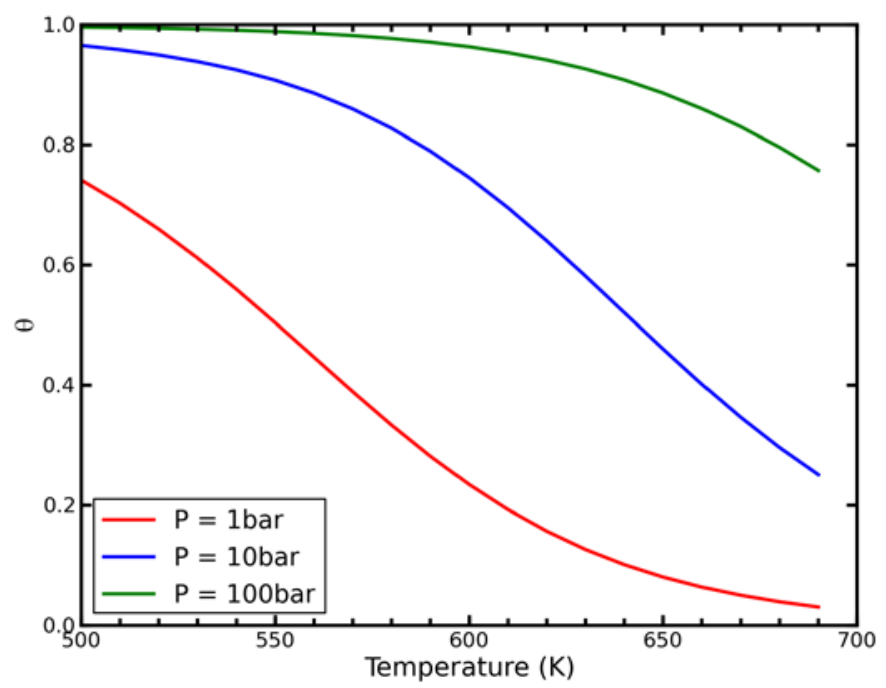

Figure 10: Effect of temperature on $\theta$ (equation (13)) at three different pressures for oxygen mole fraction of 0.2 . As the temperature increases, the fraction of $\mathrm{nRO}_{2}$ that participates in the chain branching sequence approaches zero. The fraction of $\mathrm{nRO}_{2}$ that participates in the chain branching sequence is higher at higher pressures.

Using equations (4)-(13), it is possible to decouple the differential equations for $\mathrm{nRO}_{2}$, $\mathrm{iRO}_{2}$, OQ'OOH, and $\mathrm{HO}_{2}$ from the remaining species. This leads to the following set of equations:

$$
\left[\begin{array}{c}
\frac{d\left[\mathrm{nRO}_{2}\right]}{d t} \\
\frac{d\left[\mathrm{iRO}_{2}\right]}{d t} \\
\frac{d\left[\mathrm{HO}_{2}\right]}{d t} \\
\frac{d[\mathrm{OQ} \mathrm{OOH}]}{d t}
\end{array}\right]=\left[\begin{array}{cccc}
\left.-(1-\alpha)+\frac{(1-\beta)}{\beta}\right) \theta k_{14} & 0 & k_{5}[\mathrm{RH}]_{0} & 2 \alpha k_{17} \\
(1-\alpha) \theta k_{14} & -k_{13} & k_{6}[\mathrm{RH}]_{0} & 2(1-\alpha) k_{17} \\
\frac{(1-\beta) \theta k_{14}}{\beta} & k_{13} & -\left(k_{5}+k_{6}\right)[\mathrm{RH}]_{0} & 0 \\
\theta k_{14} & 0 & 0 & -k_{17}
\end{array}\right]\left[\begin{array}{c}
{\left[\mathrm{nRO}_{2}\right]} \\
{\left[\mathrm{iRO} \mathrm{F}_{2}\right]} \\
{\left[\mathrm{HO}_{2}\right]} \\
{[\mathrm{OQQ} \mathrm{OOH}]}
\end{array}\right]+\left[\begin{array}{c}
k_{1}[\mathrm{RH}]_{0}\left[\mathrm{O}_{2}\right]_{0} \\
k_{2}[\mathrm{RH}]_{0}\left[\mathrm{O}_{2}\right]_{0} \\
\left(k_{1}+k_{2}\right)[\mathrm{RH}]_{0}\left[\mathrm{O}_{2}\right]_{0} \\
0
\end{array}\right]
$$

This system of equations can be written as

$$
\frac{d \underline{C}}{d t}=\underline{\underline{M}} \underline{C}+\underline{R}
$$

which has an exact solution given by (see Supplemental Material for complete details)

$$
\underline{C}=\underline{\underline{V}} \exp (\underline{\underline{\Lambda}}) \underline{\underline{V}}^{-1} \underline{C}_{0}+\underline{\underline{V}}(\exp (\underline{\underline{\Lambda} t})-\underline{I}) \underline{\underline{\Lambda}}^{-1} \underline{\underline{V}}^{-1} \underline{R}
$$


where $\underline{\underline{V}}$ and $\underline{\underline{\Lambda}}$ are the eigenvector and eigenvalue matrices of $\underline{\underline{M}}$ (i.e $\underline{\underline{M}}=\underline{\underline{V}} \underline{\underline{\Lambda}} \underline{\underline{V^{-1}}}$ ). From this set of four linear ordinary differential equations, we obtain four eigenvalues. For $P_{0}=10$ bar and $T_{0}=650 \mathrm{~K}$, the two real eigenvalues are $\lambda_{1 \mathrm{~A}}=55.4 \mathrm{~s}^{-1}$ and $\lambda_{2 \mathrm{~A}}=-39.4 \mathrm{~s}^{-1}$; the remaining eigenvalues $\lambda_{3 \mathrm{~A}}$ and $\lambda_{4 \mathrm{~A}}$ are complex with a negative real component $(-542 \pm 42 \mathrm{j}) \mathrm{s}^{-1}$ (Note that, while the values above are obtained through a numerical solution of equations (14) - (16), an analytical solution is possible under an additional simplifying approximation as shown in the Supplemental Material, but this introduces significant error). The positive real eigenvalue can be interpreted as the rise rate (inverse of the time constant) during stage-1A. It is perhaps worth noting that the smallest time constant of decay for the other eigenmodes is $\sim 1 / 94.8 \mathrm{~s}-1$ or 0.011 $\mathrm{s}$; and the induction time during which initiation reactions contribute non-negligibly to production of radicals is on the order of $\sim 0.01 \mathrm{~s}$. Thus, after a brief incubation time much shorter than the relevant ignition time scales, the concentration of the various species in this stage can hence be written as:

$$
[\mathrm{X}] \approx C_{\mathrm{X}, \mathrm{A}} \exp \left(\lambda_{\mathrm{IA}} t\right)
$$

This exponential growth should continue until one of the following events occurs and introduces nonlinearities to the system:

1. One of the species builds up to such a high concentration that its second-order reactions between itself and other minor species (i.e. not $\mathrm{C}_{3} \mathrm{H}_{8}$ and $\mathrm{O}_{2}$ ) become significant.

2. Concentrations of the fuel or $\mathrm{O}_{2}$ are no longer sufficiently close to their initial concentrations.

3. The net heat release alters the temperature (and pressure) enough to affect the kinetics through rate constants and/or equilibrium constants. Effects due to temperature are 
expected to be dominant over effects due to pressure rise. Note that while the linear approximation holds, we expect the temperature to follow $T=T_{0}+C_{T} \exp \left(\lambda_{1 A} t\right)$.

For all the cases studied, stage- $1 \mathrm{~A}$ ends when the concentration of $\mathrm{HO}_{2}$ increases to the point where the self-recombination reaction, $\mathrm{HO}_{2}+\mathrm{HO}_{2} \rightarrow \mathrm{H}_{2} \mathrm{O}_{2}+\mathrm{O}_{2}$ dominates the $\mathrm{HO}_{2}$ disappearance. This time can be estimated by the following approximation:

$$
\frac{d\left[\mathrm{HO}_{2}\right]}{d t} \approx \lambda_{1 \mathrm{~A}}\left[\mathrm{HO}_{2}\right]-2 k_{24}\left[\mathrm{HO}_{2}\right]^{2}=0
$$

Substituting for $\mathrm{HO}_{2}$

$$
\frac{d\left[\mathrm{HO}_{2}\right]}{d t} \approx \lambda_{1 \mathrm{~A}} C_{\mathrm{HO}_{2}, \mathrm{~A}} \exp \left(\lambda_{1 \mathrm{~A}} \tau_{\text {stage- }-\mathrm{A}}\right)-2 k_{24}\left(C_{\mathrm{HO}_{2}, \mathrm{~A}} \exp \left(\lambda_{1 \mathrm{~A}} \tau_{\text {stage- } 1 \mathrm{~A}}\right)\right)^{2}=0
$$

Solving equation (19) for $\tau_{\text {stage-1A }}$ yields

$$
\tau_{\text {stage }-1 \mathrm{~A}} \approx \frac{1}{\lambda_{1 \mathrm{~A}}} \ln \left(\frac{\lambda_{1 \mathrm{~A}}}{2 k_{24} C_{\mathrm{HO}_{2}, \mathrm{~A}}}\right)
$$

The pre-exponential factor for $\mathrm{HO}_{2}\left(\mathrm{C}_{\mathrm{HO} 2, \mathrm{~A}}\right)$, can be determined using the eigenvector, eigenvalues, vector $R$ and the initial conditions of the system, the exact equation is provided in the Supplemental Materials (S 53).

\subsection{Analytic solution for stage-1B}

The transition from stage-1A to stage-1B occurs when the self-reaction $\mathrm{HO}_{2}+\mathrm{HO}_{2} \rightarrow \mathrm{O}_{2}+$ $\mathrm{H}_{2} \mathrm{O}_{2}$ becomes the major $\mathrm{HO}_{2}$ consumption channel and slows the growth rate of $\mathrm{HO}_{2}$. In this stage, hydrogen abstractions by $\mathrm{HO}_{2}$ from the parent fuel are much less important than those by $\mathrm{OH}$ and it can be assumed that $\mathrm{HO}_{2}$ no longer contributes significantly to the production of propyl radicals. This observation implies that the differential equation for $\mathrm{HO}_{2}$ can be decoupled 
from those for $\mathrm{nRO}_{2}$ and $\mathrm{OQ}^{\prime} \mathrm{OOH}$, and yields the following set of differential equations for stage-1B:

$$
\begin{aligned}
& {\left[\begin{array}{c}
\frac{d\left[\mathrm{nRO}_{2}\right]}{d t} \\
\left.\frac{d\left[\mathrm{OQ}^{\prime} \mathrm{OOH}\right]}{d t}\right]
\end{array}\right]=\left[\begin{array}{cc}
-\left((1-\alpha)+\frac{(1-\beta)}{\beta}\right) \theta k_{14} & 2 \alpha k_{17} \\
\theta k_{14} & -k_{17}
\end{array}\right]\left[\begin{array}{c}
{\left[\mathrm{nRO}_{2}\right]} \\
{\left[\mathrm{OQ}^{\prime} \mathrm{OOH}\right]}
\end{array}\right]} \\
& {\left[\begin{array}{c}
{\left[\mathrm{nRO}_{2}\right]} \\
{\left[\mathrm{OQ}^{\prime} \mathrm{OOH}\right]}
\end{array}\right]_{t=\tau_{\text {stage- } 1 \mathrm{~A}}}=\left[\begin{array}{c}
{\left[\mathrm{nRO}_{2}\right]_{\text {stage }-1 A}} \\
{\left[\mathrm{OQ}^{\prime} \mathrm{OOH}\right]_{\text {stage }-1 A}}
\end{array}\right]}
\end{aligned}
$$

The eigenvalues for this system are:

$$
\begin{aligned}
& \lambda_{1 B}=\frac{k_{17}}{2}\left(-\left(1+\frac{(1-\alpha \beta) \theta k_{14}}{\beta k_{17}}\right)+\sqrt{4 \frac{(3 \alpha \beta-1) \theta k_{14}}{\beta k_{17}}+\left(1+\frac{(1-\alpha \beta) \theta k_{14}}{\beta k_{17}}\right)^{2}}\right) \\
& \lambda_{2 B}=\frac{k_{17}}{2}\left(-\left(1+\frac{(1-\alpha \beta) \theta k_{14}}{\beta k_{17}}\right)-\sqrt{4 \frac{(3 \alpha \beta-1) \theta k_{14}}{\beta k_{17}}+\left(1+\frac{(1-\alpha \beta) \theta k_{14}}{\beta k_{17}}\right)^{2}}\right)
\end{aligned}
$$

The second eigenvalue is negative under all conditions (with a value of $-505.2 \mathrm{~s}^{-1}$ for $P_{0}=$ 10 bar and $T_{0}=650 \mathrm{~K}$ ) such that its time constant for decay is small compared to the relevant ignition time scales. For $P_{0}=10$ bar and $T_{0}=650 \mathrm{~K}$, the positive eigenvalue is $\lambda_{1 B}=25.3 \mathrm{~s}^{-1}$. Using this linearized model the $\mathrm{OH}$ concentration during stage- $1 \mathrm{~B}\left(\mathrm{t}>\tau_{\text {stage- } 1 \mathrm{~A}}\right)$ is given by:

$$
[\mathrm{OH}]=C_{\mathrm{OH}, \mathrm{B}} \exp \left(\lambda_{1 \mathrm{~B}} t\right)
$$

Where the pre-exponential factor is given as

$$
C_{\mathrm{OH}, \mathrm{B}}=C_{\mathrm{OH}, \mathrm{A}} \exp \left(\left(\lambda_{1 \mathrm{~A}}-\lambda_{1 \mathrm{~B}}\right) \tau_{\text {stage }-1 \mathrm{~A}}\right)
$$

Using the above equations we can plot the predicted rise of $\mathrm{OH}$ radicals for stage-1B in propane ignition. Figure 11 provides a comparison between the predicted and simulated $\mathrm{OH}$ mole fraction during stage-1A and stage-1B for an adiabatic, isochoric system at $P_{0}=10$ bar and $T_{0}=650 \mathrm{~K}$ 
using the full propane oxidation model. It can be seen that both the rise rate in stage- $1 \mathrm{~A}$ and the initial rise rate of stage-1B are reproduced well. At later times in stage-1B the rise rate decreases due to loss of $\mathrm{OH}$ and $\mathrm{nRO}_{2}$ radicals to secondary reactions. End of stage-1B will occur when the rise rate has decreased to zero therefore the initial rise rate in stage- $1 \mathrm{~B}\left(\lambda_{1 \mathrm{~B}}\right)$ represents an upper bound and the expressions based on this rise rate give a lower bound on the predicted first-stage ignition delay.

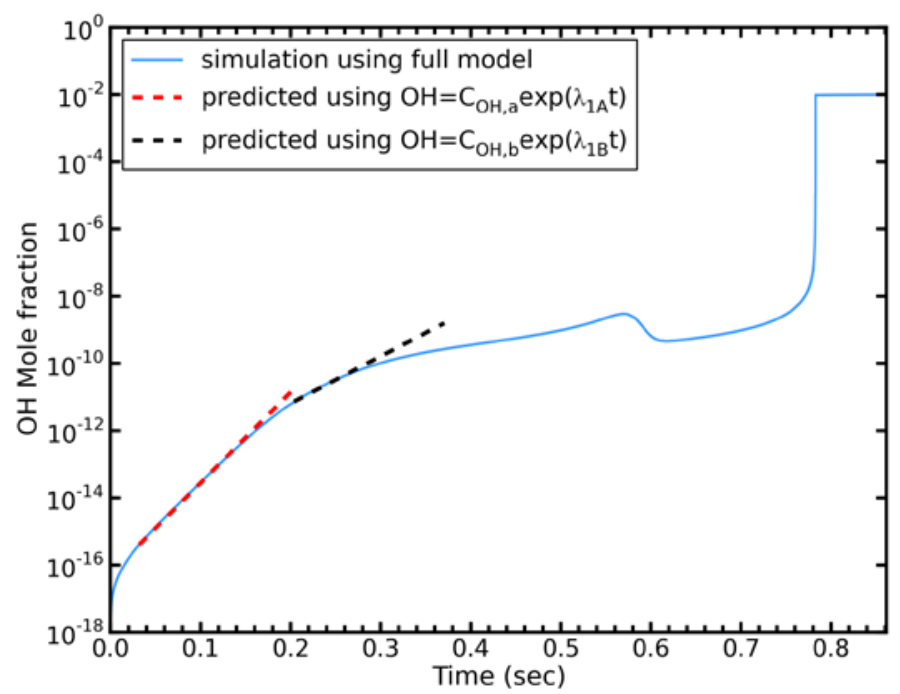

Figure 11: Comparison of the predicted and the simulated $\mathrm{OH}$ mole fraction profiles, for adiabatic isochoric simulations at $P=10$ bar, $T=650 \mathrm{~K}$ and stoichiometric mixture of propane: air using the full model. The red line corresponds to the stage-1A prediction while the black line corresponds to the stage-1B prediction. The predictions are made using the equation $[\mathrm{OH}]=C_{\mathrm{OH}, \mathrm{X}} \exp \left(\lambda_{1 \mathrm{X}} t\right)$ where $\lambda_{1 \mathrm{~A}}=55.4 \mathrm{~s}^{-1}$ and $\lambda_{1 \mathrm{~B}}=25.3 \mathrm{~s}^{-1}$.

\subsubsection{Predicting first-stage ignition}

Similar to stage-1A, stage-1B will end when secondary reactions become important and interfere with the chain mechanism presented in Figure 3 or when the temperature rises enough to significantly alter the kinetics. The end of this stage may be experimentally observed if there is a large enough change in temperature (or pressure) of the system. The kink in the temperature profile is correlated with the depletion of $\mathrm{OQ}^{\prime} \mathrm{OOH}$, which had built-up in the initial stages of the 
ignition. For straight-chain alkanes as shown in Figure 8 (for propane) and also by Musculus et al. [72] (for heptane), there is only a small delay between the peak in $\mathrm{OQ}^{\prime} \mathrm{OOH}$ and the point of inflection in $\mathrm{T}(\mathrm{t})$. A reasonable approximation is, hence to equate the first-stage ignition delay with the peak in OQ'OOH.

The OQ'OOH concentration will peak when the rise rate has decreased to zero:

$$
\lambda_{\mathrm{IB}}(\underline{C}, T)=0
$$

where $\lambda_{1 \mathrm{~B}}$ here is both a function of the temperature and the composition of the system, the former due to rate coefficients and equilibrium constants and latter due to secondary reactions. The rise rate $\lambda_{1 \mathrm{~B}}$ (equation (22)) will be zero when the following condition is satisfied:

$$
f_{\mathrm{OH}}=3 \alpha \beta=1
$$

In other words, $\mathrm{OQ}^{\prime} \mathrm{OOH}$ peaks when the three $\mathrm{OH}$ radicals that are generated by the decomposition of $\mathrm{O}_{2} \mathrm{QOOH}$, are insufficient to overcome losses in order to maintain the radical chain mechanism. Both $\alpha$ and $\beta$ depend on the temperature, i.e. through the rate coefficients, and also on the composition of the mixture. As the concentrations of the secondary products grow, additional loss channels (primarily due to hydrogen abstractions from $\mathrm{CH}_{2} \mathrm{O}$ and $\mathrm{H}_{2} \mathrm{O}_{2}$ ) will influence the $\mathrm{OH}$ balance of the chain mechanism. In that case $\alpha$ and $\beta$ can be represented as:

$$
\begin{aligned}
& \alpha=\frac{k_{3}}{k_{3}+k_{4}+k_{20} \frac{\left[\mathrm{CH}_{2} \mathrm{O}\right]}{[\mathrm{RH}]}+k_{23} \frac{\left[\mathrm{H}_{2} \mathrm{O}_{2}\right]}{[\mathrm{RH}]}} \\
& \beta=\frac{\theta k_{14}}{\theta k_{14}+k_{12}+k_{26}\left[\mathrm{CH}_{2} \mathrm{O}\right]+k_{27}\left[\mathrm{HO}_{2}\right]}
\end{aligned}
$$

The evolution of $\alpha$ and $\beta$ during the various stages of the ignition for the adiabatic case at $650 \mathrm{~K}$ and 10 bar using the full model is shown in Figure 12. It can be seen that $\alpha$ starts from a 
value of around 0.5 and hardly decreases while the value of $\beta$ drops from an initial value of 0.85 to 0.66 at the end of stage- $1 \mathrm{~B}$. As the relative decrease in $\beta$ is much larger than that in $\alpha$, the variation in $\beta$ will have a larger influence on the $\mathrm{OH}$ balance of the chain mechanism. The $\mathrm{OH}$ loss due to hydrogen abstraction from the secondary products is partially compensated by the additional production of $\mathrm{OH}$ radicals from the decomposition of hydroperoxides ( $\mathrm{ROO}+\mathrm{HO}_{2} \rightarrow$ $\mathrm{ROOH}+\mathrm{O}_{2} \rightarrow \mathrm{RO}+\mathrm{OH}+\mathrm{O}_{2}$ ). The inclusion of this cycle makes the system very complex and for sake of simplicity here we assume that $\alpha \approx 0.5$ throughout the simulation under all conditions, yielding equation (30) for the condition of peak OQ'OOH. In the following sections it is demonstrated how equation (30) can be used to predict first-stage ignition delay under adiabatic conditions.

$$
\frac{\theta k_{14}}{\theta k_{14}+k_{12}+k_{26}\left[\mathrm{CH}_{2} \mathrm{O}\right]+k_{27}\left[\mathrm{HO}_{2}\right]}=\frac{2}{3}
$$

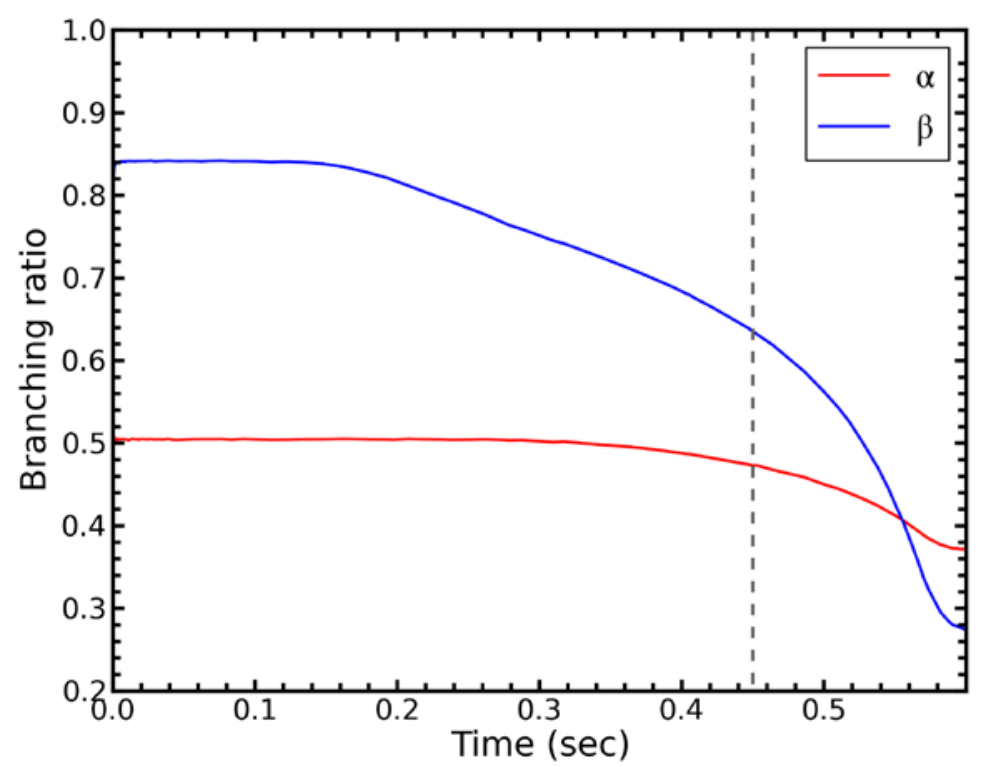

Figure 12: Simulated $\mathrm{OH}$ loss terms $\alpha$ and $\beta$ as function of time for stoichiometric mixture of propane at $T_{0}=650 \mathrm{~K}$ and $P_{0}=10$ bar under adiabatic conditions. The dashed grey line indicates the time when OQ'OOH peaks in the simulation. 


\subsubsection{First-stage ignition delay under adiabatic conditions}

Under adiabatic conditions, the time at which OQ'OOH peaks is determined by both the temperature increase of the system and the loss of $\mathrm{nRO}_{2}\left(\right.$ active $\left.\mathrm{RO}_{2}\right)$ radicals to the growing secondary chemistry. At higher temperatures $\mathrm{nRO}_{2}$ radicals are more likely to react by the higher barrier $\mathrm{HO}_{2}$ elimination channel which yields $\mathrm{HO}_{2}$ and propene reducing $\beta$ and thereby reducing the gain term $f_{\mathrm{OH}}$.

The temperature rise can be modeled by assuming overall reactions for the chain mechanism presented in Figure 3. As $\mathrm{OH}$ is the main fuel abstractor in stage-1B, this can be achieved by introducing two global reactions:

$$
\begin{gathered}
\mathrm{C}_{3} \mathrm{H}_{8}+\mathrm{OH}+\mathrm{O}_{2} \rightarrow \mathrm{C}_{3} \mathrm{H}_{6}+\mathrm{H}_{2} \mathrm{O}+\mathrm{HO}_{2} \\
\mathrm{C}_{3} \mathrm{H}_{8}+\mathrm{OH}+3 \mathrm{O}_{2} \rightarrow \mathrm{CO}+2 \mathrm{CH}_{2} \mathrm{O}+\mathrm{H}_{2} \mathrm{O}+3 \mathrm{OH}
\end{gathered}
$$

R1 corresponds to the sum of the hydrogen abstraction from the secondary carbon atom in propane and the decomposition of $\mathrm{nRO}_{2}$ into $\mathrm{C}_{3} \mathrm{H}_{6}$ and $\mathrm{HO}_{2}$. $\mathrm{R} 2$ is the overall reaction for the chain mechanism presented in Figure 3 and starts with the hydrogen abstraction by $\mathrm{OH}$ from the primary carbon atom. Reaction enthalpies (at $298 \mathrm{~K}$ ) for R1 and R2 amount to $-153.5 \mathrm{~kJ} \mathrm{~mol}^{-1}$ and $-399 \mathrm{~kJ} \mathrm{~mol}^{-1}$, respectively [73]. As the rate coefficients for hydrogen abstractions by $\mathrm{OH}$ from the primary and secondary site in propane are almost identical, the effective heat released per mole of propane consumed amounts to approximately $\sim 275 \mathrm{~kJ} \mathrm{~mol}^{-1}$ (Most of the heat is released later in stage-1 since this is an exponential process).

In stage-1B, the fuel conversion $X$ and temperature are correlated:

$$
d T=-\frac{\Delta H_{\text {eff }}}{C_{V} C_{\text {tot }}} d[\mathrm{RH}]=\frac{\Delta H_{\text {eff }} X_{0, \mathrm{RH}}}{c_{V}} d X
$$


with $\Delta H_{\text {eff }}$ the effective reaction enthalpy, $c_{\mathrm{v}}$ the average molar specific heat capacity of the system and $x_{0, \mathrm{RH}}$ the initial fuel mole fraction. Integrating the above equation will give

$$
T-T_{0}=\frac{\Delta H_{\mathrm{eff}} X_{0, \mathrm{RH}}}{c_{V}} X
$$

where $T_{0}$ is the initial temperature of the system. Assuming that formaldehyde and $\mathrm{OQ}^{\prime} \mathrm{OOH}$ have the stage-1B exponential behavior and $\mathrm{HO}_{2}$ is in quasi-steady state (see Supplemental Material), yields:

$$
\begin{gathered}
{\left[\mathrm{CH}_{2} \mathrm{O}\right]=C_{\mathrm{CH}_{2} \mathrm{O}, \mathrm{B}} \exp \left(\lambda_{1 \mathrm{~B}} t\right)=\frac{C_{\mathrm{CH}_{2} \mathrm{O}, \mathrm{B}}\left[\mathrm{OQ}^{\prime} \mathrm{OOH}\right]}{C_{\mathrm{OQ}} \mathrm{OOOH}, \mathrm{B}}} \\
{\left[\mathrm{HO}_{2}\right]=\sqrt{\frac{k_{17}}{k_{24}}\left[\mathrm{OQ}^{\prime} \mathrm{OOH}\right]}}
\end{gathered}
$$

Since both the ketohydroperoxide and the fuel conversion are assumed to be exponentially increasing at the same rate, equation (33) and (34) can also be expressed in terms of fuel conversion

$$
\begin{gathered}
{\left[\mathrm{CH}_{2} \mathrm{O}\right]=C_{\mathrm{CH}_{2} \mathrm{O}, \mathrm{B}} \exp \left(\lambda_{\mathrm{IB}} t\right)=\frac{C_{\mathrm{CH}_{2} \mathrm{O}, \mathrm{B}} X}{X_{0, \mathrm{~B}}}} \\
{\left[\mathrm{HO}_{2}\right]=\sqrt{\frac{k_{17}}{k_{24}} \frac{C_{\mathrm{OQ}^{\prime} \mathrm{OOH}, \mathrm{B}}}{X_{0, \mathrm{~B}}} X}}
\end{gathered}
$$

where the fuel conversion is given by $\mathrm{X}=\mathrm{X}_{0, \mathrm{~B}} \exp \left(\lambda_{1 \mathrm{~B}} t\right)$. The pre-exponential factor $\mathrm{X}_{0, \mathrm{~B}}$ is given by

$$
X_{0, B}=X_{0, \mathrm{~A}} \exp \left(\left(\lambda_{1 \mathrm{~A}}-\lambda_{1 B}\right) \tau_{\text {stage }-1 \mathrm{~A}}\right)
$$


Where $\mathrm{X}_{0, \mathrm{~A}}$ is obtained from full model simulations, for $T_{0}=650 \mathrm{~K}$ and $P_{0}=10$ bar $\mathrm{X}_{0, \mathrm{~A}}$ was 3E-7. The value of $\mathrm{X}_{0, \mathrm{~A}}$ will vary by an order of magnitude, depending on conditions. Sensitivity analysis shows that the exact value has little impact on the predictions; hence we keep it fixed for all the conditions studied. The pre-exponential factor for $\mathrm{CH}_{2} \mathrm{O}$ and $\mathrm{OQ}^{\prime} \mathrm{OOH}, C_{\mathrm{X}, \mathrm{B}}$ is given by

$$
C_{X, B}=C_{X, A} \exp \left(\left(\lambda_{1 A}-\lambda_{1 B}\right) \tau_{\text {stage }-1 A}\right)
$$

As stated in the previous section the criterion to determine the end of stage- 1 is given by (30). Substituting for $\left[\mathrm{CH}_{2} \mathrm{O}\right]$ and $\left[\mathrm{HO}_{2}\right]$ using equation (35) and (36) in (30), we reduce it to a function of conversion and temperature.

$$
\frac{\theta k_{14}}{\theta k_{14}+k_{12}+k_{26} \frac{C_{\mathrm{CH}_{2} \mathrm{O}, \mathrm{B}} X}{X_{0, B}}+k_{27} \sqrt{\frac{k_{17} \frac{C_{\mathrm{OQ}^{\prime} \mathrm{OOH}, \mathrm{B}}}{k_{24}} X}{X_{0, B}}}}=\frac{2}{3}
$$

If we substitute for conversion with (32), we reduce the above equation to be only a

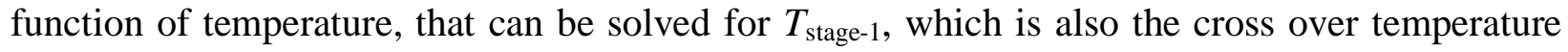
described by Peters et al. [10] (or alternatively fuel conversion at end of stage-1 $X_{\text {stage-1). }}$.

\subsubsection{Critical temperature for the autocatalytic QOOH cycle}

It is interesting to note that if the secondary chemistry is ignored (set $\mathrm{k}_{26}\left[\mathrm{CH}_{2} \mathrm{O}\right]$ and $\mathrm{k}_{27}\left[\mathrm{HO}_{2}\right]=0$ ), equation (30) simplifies to an equation giving a specific temperature $T_{\text {stage-1,max, }}$, at which the system becomes subcritical:

$$
\frac{\theta\left(T_{\text {stage }-1, \max ,} \mathrm{P}_{0,}\left[\mathrm{O}_{2}\right]_{0}\right) k_{14}\left(T_{\text {stage }-1, \max ,} \mathrm{P}_{0}\right)}{\theta\left(T_{\text {stage }-1, \max ,} \mathrm{P}_{0,}\left[\mathrm{O}_{2}\right]_{0}\right) k_{14}\left(T_{\text {stage }-1, \max ,} \mathrm{P}_{0}\right)+k_{12}\left(T_{\text {stage }-1, \max ,} \mathrm{P}_{0}\right)}=\frac{2}{3}
$$

In that case, $T_{\text {stage-1,max }}$ is independent of the initial temperature $T_{0}$ of the system. At this temperature, the loss of radicals from the autocatalytic cycle due to concerted $\mathrm{HO}_{2}$ elimination 
alone becomes large enough to decrease the value of $\beta$ to $0.66 . T_{\text {stage-1,max }}$ also represents the maximum possible temperature to which the system can rise before OQ'OOH peaks. For propane in air at $P=10 \mathrm{bar}, T_{\text {stage-1, } \max }=690 \mathrm{~K}$. Above the critical temperature the autocatalytic cycle does not operate; positive feedback leading to ignition must come from other cycles (e.g. $\mathrm{H}_{2} \mathrm{O}_{2}$ ). Using equations (32) and (37) the time required for the temperature to reach $T_{\text {stage-1,max }}$ will be given by

$$
\tau_{\text {OQ'OOHpeak }} \approx \frac{1}{\lambda_{1 \mathrm{~B}}\left(T_{0}\right)} \ln \left(\frac{T_{\text {stage-1,max }}-T_{0}}{\frac{\Delta H_{\mathrm{eff}} X_{0, \mathrm{RH}}}{c_{V}} X_{A}}\right)+\tau_{\text {stage-1A }}
$$

where $\lambda_{1 \mathrm{~B}}$ is the rise rate at the start of stage-1B as given by (22).

Figure 13 provides a comparison of the $\tau_{\mathrm{OQ} \text { 'OOHpeak }}$ obtained from the full model simulations and predicted using (41) for adiabatic isochoric conditions. The time delay for peak OQ'OOH as predicted by (41) is longer than that computed by the full model simulations; however they are within 30\% over the temperature range investigated. Equation (41) provides a practical way to estimate first-stage ignition delays for $T_{0}<T_{\text {stage-1,max }} \approx 690 \mathrm{~K}$ for mixtures of propane: air at $P_{0}=10$ bar) and to understand how they depend on initial temperature, stoichiometry and mixture heat capacity. The dependence on rate coefficients and thermochemistry is manifested in $\tau_{\text {stage-1A }}, \lambda_{\mathrm{IB}}, \Delta H_{\text {eff }}$ and $T_{\text {stage-1,max. The first-stage ignition }}$ delay as estimated by equation (41) is an analytical expression depending on 10 rate coefficients, while the full model is a stiff system of differential equations involving 630 rate coefficients. 


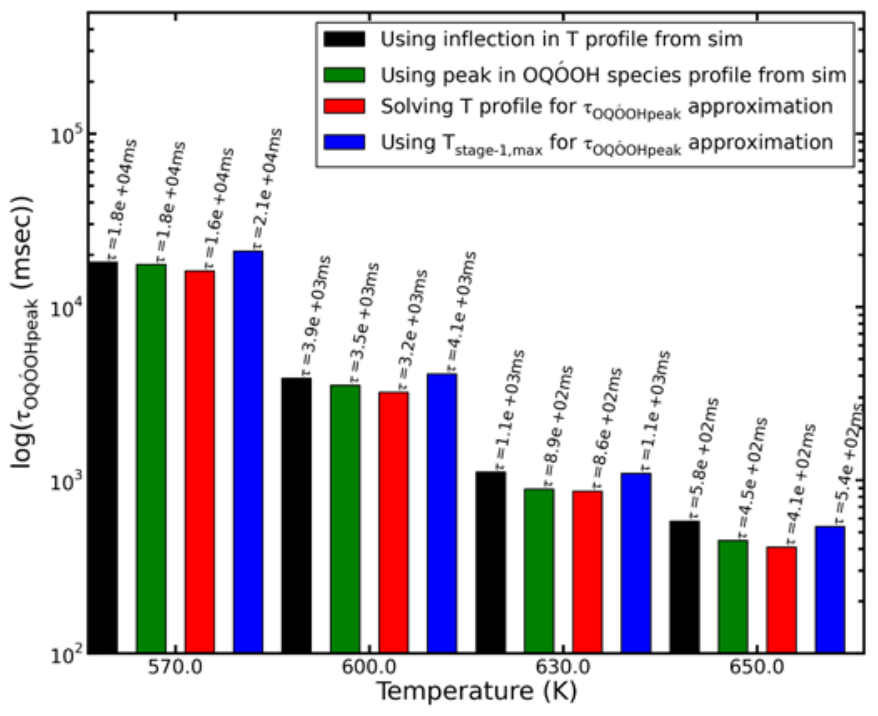

Figure 13: Comparison of the first-stage ignition delays ( $\left.\tau_{\mathrm{OQ}^{\prime} \mathrm{OOHpeak}}\right)$ obtained from 1$)$ the time of the inflection point in the temperature profile from full model simulation, 2) the time of the OQ'OOH peak in the full model simulation 3) the time for $f_{\mathrm{OH}}=1$ predicted from the solution to equations (31)-(36) and 4) the time for $f_{\mathrm{OH}}=1$ predicted by equation (41) for adiabatic, isochoric simulations of stoichiometric mixtures of propane and air, $P_{0}=10$ bar.

It is important to note that the above discussion is only valid for fuel/air mixtures (or mixtures close to fuel/air mixtures) and would not yield satisfactory results under very dilute or rich conditions. For sufficiently dilute mixtures the temperature rise would never drive the system to end of stage- 1 and the system remains close to isothermal. Under these conditions the secondary reactions play a dominant role in the end of stage-1. We provide only a brief analysis of these cases in the Supplementary Materials; future work will address these cases in greater detail.

\section{Predicting first-stage ignition delay for longer chain alkane fuels}

The framework developed for interpreting propane ignition can be extended to larger nalkane fuels. For longer straight chain fuels (e.g. butane, pentane etc.), all sites on the carbon chain can participate in the peroxy chemistry cycle $\left(\mathrm{R}+2 \mathrm{O}_{2} \rightarrow\right.$ intermediates $\left.\rightarrow \mathrm{OQ}^{\prime} \mathrm{OOH}\right)$ to 
produce $\mathrm{OH}$ radicals. This change in reactivity is due to the availability of at least two hydrogen atoms on the $\gamma$-C for every alkyl radical site, which can participate in the facile six-membered isomerization transition states that permit the peroxy chemistry cycle to occur. Figure 14 provides a schematic of a generalized fuel molecule undergoing peroxy chemistry. As the length of the carbon chain increases, one reaches a limit where effectively every site on the fuel can be treated as an equivalent site; a single-site assumption can be used to estimate the first-stage ignition delay. For straight-chain and branched fuels $\beta$-scission of the alkyl radical can occur to form alkenes and smaller radicals. However for $\mathrm{T}<800 \mathrm{~K}$ this was seen as an insignificant loss channel for $\mathrm{P}>10$ bar.

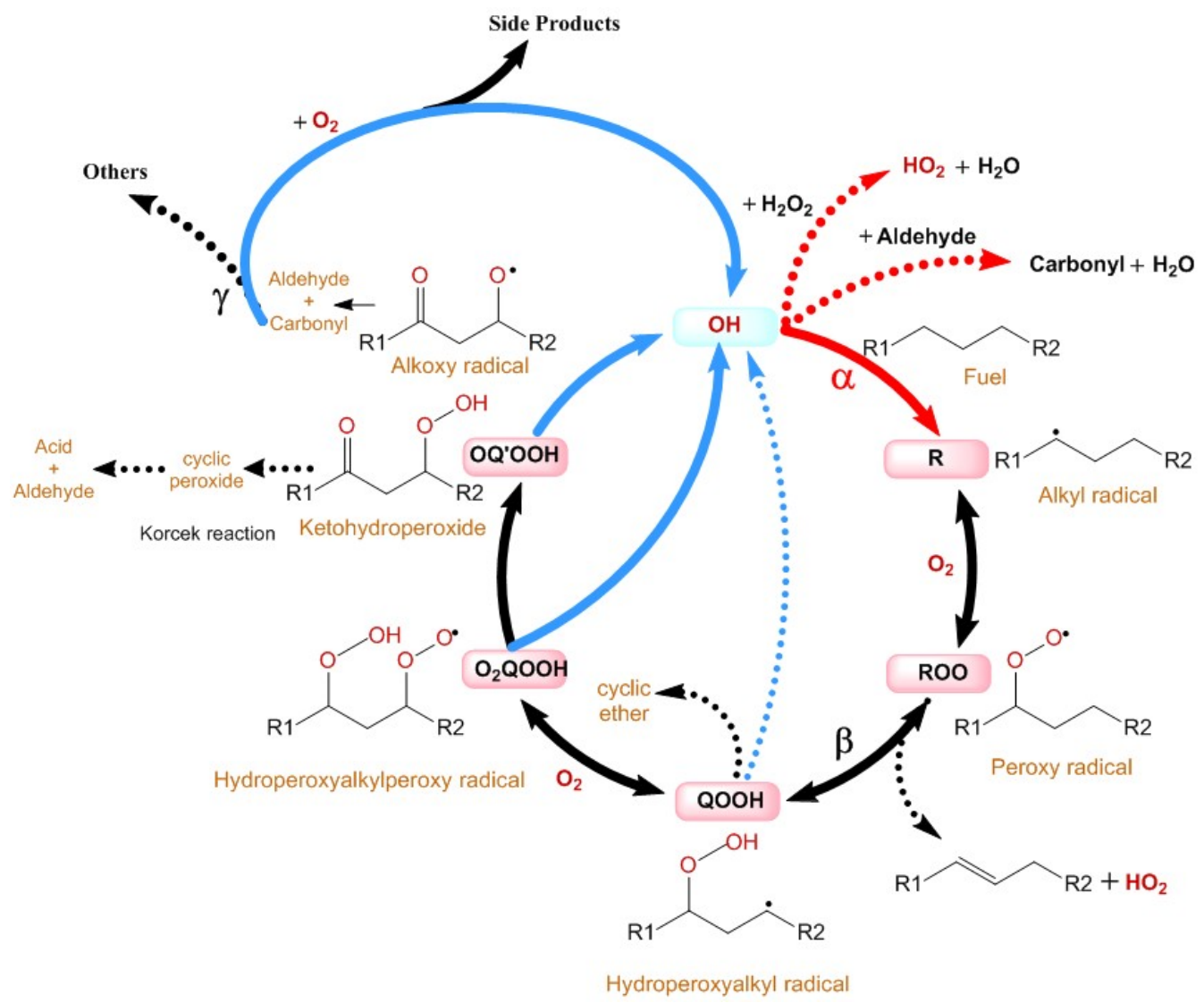

Figure 14: Schematic of an long $n$-alkane fuel undergoing low temperature peroxy chemistry. As the carbon chain increases every site can be treated as an equivalent site. The blue arrows are $\mathrm{OH}$ formation reactions while the red arrows show loss of $\mathrm{OH}$ radicals. The dotted arrows are reactions that compete with low temperature branching reactions and 
delay the first stage ignition of the fuel.

For long chain fuels the $\mathrm{OH}$ radicals can abstract hydrogen from the fuel and also secondary products with carbonyl groups (that tend not to contribute to chain branching, these secondary products are labeled as "aldehyde" in the equations below). In this case, since all hydrogen abstractions by $\mathrm{OH}$ from the fuel lead into potential chain branching sequences for all alkyl radical sites, the generalized fraction of $\mathrm{OH}$ consumption reactions that can lead to chain branching, $\alpha$ can be represented as:

$$
\alpha=\frac{\text { fuel }+\mathrm{OH} \rightarrow \sum_{i} \mathrm{R}_{\mathrm{i}}+\mathrm{H}_{2} \mathrm{O}}{\text { total consumption rate of } \mathrm{OH}}=\frac{\sum_{i} k_{\mathrm{RH}+\mathrm{OH} \rightarrow \mathrm{R}_{i}+\mathrm{H}_{2} \mathrm{O}}[\mathrm{RH}]}{\sum_{i} k_{\mathrm{RH}+\mathrm{OH} \rightarrow \mathrm{R}_{i}+\mathrm{H}_{2} \mathrm{O}}[\mathrm{RH}]+\sum_{i} k_{\text {aldehyde } \mathrm{OH} \rightarrow \mathrm{P}_{i}}[\text { aldehyde }]+k_{\mathrm{H}_{2} \mathrm{O}_{2}+\mathrm{OH} \rightarrow \mathrm{HO}_{2}+\mathrm{H}_{2} \mathrm{O}}\left[\mathrm{H}_{2} \mathrm{O}_{2}\right]}
$$

In long straight chain alkanes all $n$ sites are assumed equivalent, which reduces $\alpha$ to:

$$
\alpha=\frac{k_{\mathrm{RH}+\mathrm{OH} \rightarrow \mathrm{R}+\mathrm{H}_{2} \mathrm{O}}[\mathrm{RH}]}{k_{\mathrm{RH}+\mathrm{OH} \rightarrow \mathrm{R}+\mathrm{H}_{2} \mathrm{O}}[\mathrm{RH}]+\sum_{i} \frac{k_{\text {addehyde } \mathrm{OH} \rightarrow \mathrm{P}_{i}}}{n}[\text { aldehyde }]+\frac{k_{\mathrm{H}_{2} \mathrm{O}_{2}+\mathrm{OH} \rightarrow \mathrm{HO}_{2}+\mathrm{H}_{2} \mathrm{O}}}{n}\left[\mathrm{H}_{2} \mathrm{O}_{2}\right]}
$$

$\beta$ for long chain alkanes is given by:

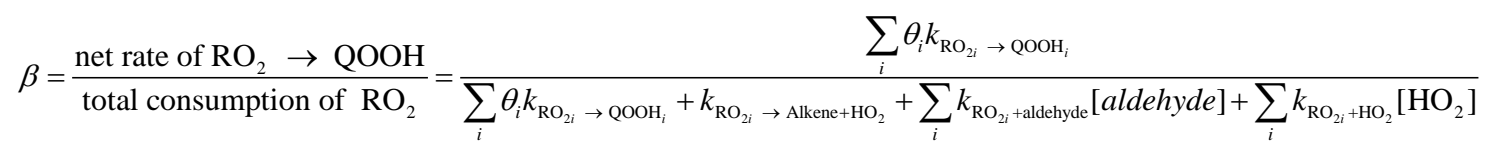

We simplify the above expression by assuming all $n$ sites to be equivalent to the secondary $\mathrm{RO}_{2}$ radical going to secondary $\gamma$-QOOH radical, which reduces $\beta$ to:

$$
\beta=\frac{\theta k_{\mathrm{RO}_{2} \rightarrow \mathrm{QOOH}}}{\theta k_{\mathrm{RO}_{2} \rightarrow \mathrm{QOOH}}+k_{\mathrm{RO}_{2} \rightarrow \text { alkene+HO }}+\sum_{i} \frac{k_{\mathrm{RO}_{2 i}+\text { aldehyde }}}{n}[\text { aldehyde }]+\sum_{i} \frac{k_{\mathrm{RO}_{2 i}+\mathrm{HO}_{2}}}{n}\left[\mathrm{HO}_{2}\right]}
$$

where the expression for $\theta$ is given by equation (46). 


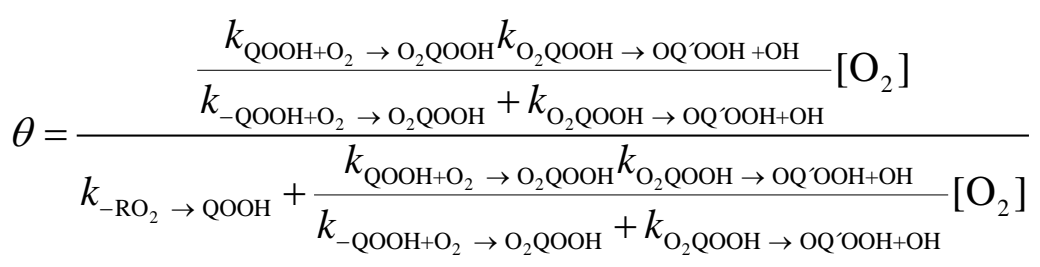

For long straight chain alkanes the carbonyl radical formed by decomposition of OQ'O radical can either react with an additional $\mathrm{O}_{2}$ to give $\mathrm{OH}$ radical or decompose to give radical + stable product. However, we found that current detailed mechanisms have no systematic treatment for this species. To account for this we define an additional ratio

$$
\gamma=\frac{\text { rate of Carbonyl }+\mathrm{O}_{2} \rightarrow \mathrm{OH}+\text { Side Product }}{\text { total consumption rate of Carbonyl }}
$$

The value of $\gamma$ is uncertain and ranges from 0 to 1 . The gain in $\mathrm{OH}$ for the cycle shown in Figure 14 can be defined as follows

$$
f_{\mathrm{OH}}=(2+\gamma) \alpha \beta
$$

The concentration of $\mathrm{HO}_{2}$ to $\mathrm{OH}$ for long straight chain alkanes is often so low that $\mathrm{HO}_{2}$ does not contribute significantly to fuel consumption. The two sub-stages are therefore not observed distinctly $\left(\lambda_{1 A} \approx \lambda_{1 B}\right)$ in long chain alkanes. The generalized differential equation over a single site for the first stage ignition can then be written as:

$$
\left[\begin{array}{c}
\frac{d\left[\mathrm{RO}_{2}\right]}{d t} \\
\frac{d\left[\mathrm{OQ}^{\prime} \mathrm{OOH}\right]}{d t}
\end{array}\right]=\left[\begin{array}{cc}
-\left((1-\alpha)+\frac{(1-\beta)}{\beta}\right) \theta k_{14} & (1+\gamma) \alpha k_{17} \\
\theta k_{14} & -k_{17}
\end{array}\right]\left[\begin{array}{c}
{\left[\mathrm{RO}_{2}\right]} \\
{\left[\mathrm{OQ}^{\prime} \mathrm{OOH}\right]}
\end{array}\right]
$$

In the above equation, $\theta, \mathrm{k}_{14}$ and $\mathrm{k}_{17}$ correspond to the parameters for the secondary $\mathrm{RO}_{2}$ radical. The positive eigenvalue for the above system of equation is given by: 


$$
\lambda_{1 B}=\frac{k_{17}}{2}\left(-\left(1+\frac{(1-\alpha \beta) \theta k_{14}}{\beta k_{17}}\right)+\sqrt{4 \frac{((2+\gamma) \alpha \beta-1) \theta k_{14}}{\beta k_{17}}+\left(1+\frac{(1-\alpha \beta) \theta k_{14}}{\beta k_{17}}\right)^{2}}\right)
$$

It is worth noting that in contrast to propane where approximately $50 \%$ of the $\mathrm{OH}$ radicals are lost to the $i$-propyl channel, for large $n$-alkanes the loss of $\mathrm{OH}$ radicals is effectively only due to secondary chemistry (i.e reactions with aldehydes, alkenes, cyclic ethers). Thus, within the single site assumption in the initial stages of the ignition where intermediates and secondary products have relatively small concentrations, the value of $\alpha$ will be close to unity.

The time for first stage ignition delay is given approximately by the following expression:

$$
\tau_{\text {OQ'OOHpeak }} \approx \frac{1}{\lambda_{1 \mathrm{~B}}\left(T_{0}\right)} \ln \left(\frac{T_{\text {stage-1,max }}-T_{0}}{\frac{\Delta H_{\mathrm{eff}} X_{0, \mathrm{RH}}}{C_{V}} X_{0, B}}\right)
$$

where $\lambda_{1 \mathrm{~B}}$ is given by equation (50), with $\beta$ and $\theta$ needed to evaluate $\lambda_{1 \mathrm{~B}}$ are given by the expressions (12) and (13) respectively. Table 2 gives the rate coefficients for the respective alkanes needed to evaluate $\lambda_{1 \mathrm{~B}}$. The value for $\alpha$ is assumed to be 1 for long alkanes. The critical temperature $T_{\text {stage-1,max }}$ for long chain alkanes is obtained by solving:

$$
\frac{\theta\left(T_{\text {stage- } 1, \text { max }}, \mathrm{P}_{0,}\left[\mathrm{O}_{2}\right]_{0}\right) k_{14}\left(T_{\text {stage }-1, \text { max },} \mathrm{P}_{0}\right)}{\theta\left(T_{\text {stage }-1, \max ,} \mathrm{P}_{0,}\left[\mathrm{O}_{2}\right]_{0}\right) k_{14}\left(T_{\text {stage }-1, \max ,} \mathrm{P}_{0}\right)+k_{12}\left(T_{\text {stage }-1, \max ,} \mathrm{P}_{0}\right)}=\frac{1}{(2+\gamma)}
$$

Table 3 gives the calculated critical temperatures for $\gamma=0$ and $\gamma=1$ for various alkanes. We note that $\mathrm{T}_{\text {stage-1,max }}$ is conceptually and mathematically similar to the cross-over temperature discussed by Peters et al. [10] for the case of heptane, but because Peters et al.’s heptane model 
did not include the reactions $\mathrm{RO}_{2} \rightarrow$ alkene $+\mathrm{HO}_{2}$, now known to be very important, it is hard to compare our results with the results in [10]. Beeckmann et al. [13] recently developed analytical expression for low temperature ignition delay for dimethyl-ether mixtures. However a direct comparison cannot be made since the controlling mechanism in ether is significantly different than alkanes; the chain branching is controlled by either the QOOH radical undergoing $\beta$ scission or second $\mathrm{O}_{2}$ addition. Since the fate of OQ'O is uncertain in the current chemical mechanisms, we assume the value of $\gamma=1$ for the rest of the section. More research is needed to identify the proper value of $\gamma$ for various alkanes. The fuel conversion at the end of the incubation period $\left(X_{0, \mathrm{~B}}\right)$ which appears in equation (51), was kept fixed for all alkanes at the value obtained for full model simulations of propane $~ 3 E-7$. Sensitivity analysis showed that this term does not have a large effect on the predicted ignition.

The rate coefficients in Table 2 come from published chemical kinetic mechanisms for each n-alkane. This table highlights significant discrepancies between these literature mechanisms. For example the $\mathrm{OQ}^{\prime} \mathrm{OOH} \rightarrow \mathrm{OQ}^{\prime} \mathrm{O}+\mathrm{OH}$ rate is faster for heptane than for pentane, butane and propane. Also the $\mathrm{RO}_{2} \rightarrow$ alkene $+\mathrm{HO}_{2}$ rate has a very non-Arrhenius behavior probably because it comes from a pressure dependent calculation, but the form should be different for different size molecules. Figure 15 provides a comparison of the overall ignition delay for the full model simulations of propane, $n$-butane (Healy et al. [59]), $n$-pentane (Mehl et al. [3]) and $n$-heptane (Mehl et al. [3]) with that predicted for the first stage ignition delay using (51). The predicted ignition delay ( $\mathrm{T}<700 \mathrm{~K})$ is within a factor of $2-3$ of the full model simulation for most fuels. The value of $\alpha$ will not be unity as the secondary products grow in as the reaction proceeds. Notably, even decreasing the value of $\alpha$ to 0.9 (10\% loss of $\mathrm{OH}$ radicals to 
secondary chemistry, which was the typical loss seen from full model simulations) or alternatively $\gamma$ to 0.7 markedly improves the agreement between the predicted and simulated ignition delays as shown by the dashed-dotted lines in Figure 15. The good agreement suggests that the approximations (e.g. lumping of all the different type of carbon sites in the molecule to a single site) used to calculate $\tau_{\mathrm{OQ} \text { OOHpeak }}$ are reasonably accurate.

Table 2: Arrhenius rate coefficient parameters for reactions required to calculate the first stage ignition delay using equation (51). The parameters come from the 10 atm PLOG fits for $n$-propyl pathway from Goldsmith et al. [30], from the detailed model of Healey et al. [59] for propane $+\mathrm{OH}$ and butane and the detailed model by Mehl et al. [3] for pentane and heptane.

\begin{tabular}{|c|c|c|c|c|}
\hline Reaction & Fuel & $\begin{array}{l}\text { A } \\
\left(\mathrm{cm}^{3} / \mathrm{mol}-\mathrm{s}\right) \\
\text { or s }^{-1}\end{array}$ & $\mathbf{n}$ & $\begin{array}{l}\mathrm{E}_{\mathbf{a}} \\
(\mathbf{k c a l} / \mathrm{mol})\end{array}$ \\
\hline \multirow[t]{4}{*}{$\mathrm{RH}+\mathrm{OH} \rightarrow \mathrm{R}+\mathrm{H}_{2} \mathrm{O}$} & Heptane & $4.9 \mathrm{E}+06$ & 2.0 & -0.59 \\
\hline & Pentane & $9.3 \mathrm{E}+07$ & 1.61 & -0.035 \\
\hline & Butane & $9.3 \mathrm{E}+07$ & 1.61 & -0.035 \\
\hline & Propane & $1.0 \mathrm{E}+10$ & 0.97 & 1.59 \\
\hline \multirow[t]{4}{*}{$\mathrm{RO}_{2} \rightleftharpoons \mathrm{QOOH}^{\mathrm{a}}$} & Heptane & $2.5 \mathrm{E}+10$ & 0.0 & 20.5 \\
\hline & Pentane & $2.5 \mathrm{E}+10$ & 0.0 & 20.8 \\
\hline & Butane & $3.8 \mathrm{E}+10$ & 0.0 & 24.4 \\
\hline & Propane & 1.01 & 3.38 & 18.9 \\
\hline $\mathrm{RO}_{2} \rightarrow$ alkene $+\mathrm{HO}_{2}$ & Heptane & $20.0 \mathrm{E}+42$ & -9.4 & 42.5 \\
\hline
\end{tabular}




\begin{tabular}{|c|c|c|c|c|}
\hline & Pentane & $20.0 \mathrm{E}+42$ & -9.4 & 42.5 \\
\hline & Butane & $20.0 \mathrm{E}+42$ & -9.4 & 42.5 \\
\hline & Propane & $2.6 \mathrm{E}+16$ & -1.2 & 32.8 \\
\hline \multirow[t]{4}{*}{$\mathrm{QOOH}+\mathrm{O}_{2} \rightleftharpoons \mathrm{O}_{2} \mathrm{QOOH}^{\mathrm{a}}$} & Heptane & $7.5 \mathrm{E}+12$ & 0.0 & 0.0 \\
\hline & Pentane & $7.5 \mathrm{E}+12$ & 0.0 & 0.0 \\
\hline & Butane & $4.5 \mathrm{E}+12$ & 0.0 & 0.0 \\
\hline & Propane & $2.2 \mathrm{E}+27$ & -4.8 & 4.0 \\
\hline \multirow[t]{4}{*}{$\mathrm{O}_{2} \mathrm{QOOH} \rightarrow \mathrm{OQ}^{\prime} \mathrm{OOH}+\mathrm{OH}$} & Heptane & $1.2 \mathrm{E}+10$ & 0.0 & 17.5 \\
\hline & Pentane & $1.2 \mathrm{E}+10$ & 0.0 & 17.5 \\
\hline & Butane & $2 \mathrm{E}+11$ & 0.0 & 26.4 \\
\hline & Propane & $4.5 \mathrm{E}+11$ & -0.5 & 18.4 \\
\hline \multirow[t]{4}{*}{$\mathrm{OQ}^{\prime} \mathrm{OOH} \rightarrow \mathrm{OQ}^{\prime} \mathrm{O}+\mathrm{OH}$} & Heptane & $1.0 \mathrm{E}+16$ & 0.0 & 39.0 \\
\hline & Pentane & $1.5 \mathrm{E}+16$ & 0.0 & 42.0 \\
\hline & Butane & $1.5 \mathrm{E}+16$ & 0.0 & 41.6 \\
\hline & Propane & $5.2 E+43$ & -8.7 & 51.5 \\
\hline
\end{tabular}

*Note: (a) The reverse rate coefficients were obtained from the respective thermodynamic parameters of the species and are provided in a separate file. 


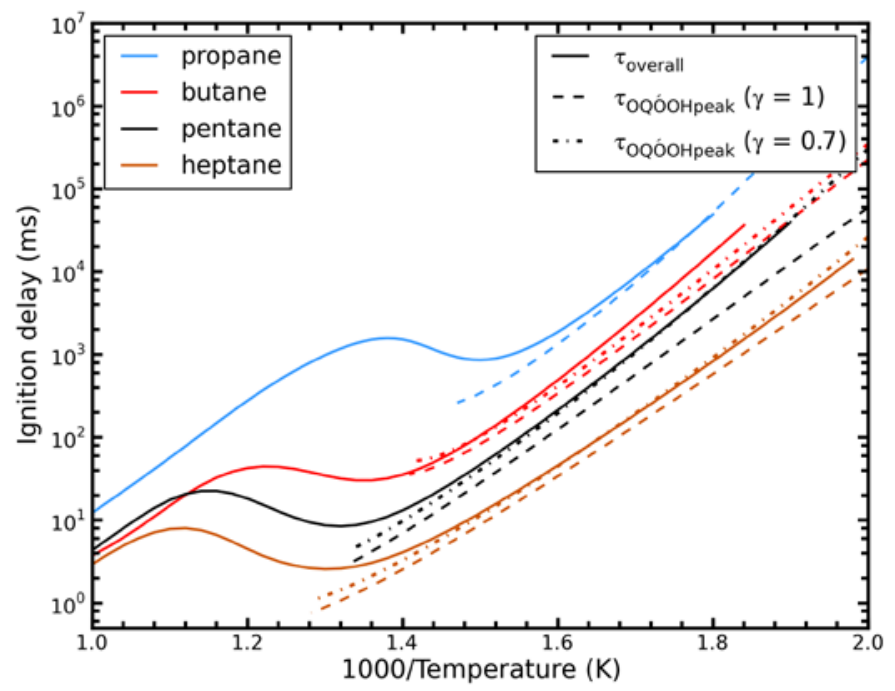

Figure 15: Comparison of the numerically simulated full-model adiabatic isochoric overall ignition delays with the first stage ignition delay predicted by Eqs. (50)-(52), for different n-alkanes with initial conditions $P_{0}=10$ bar and $\Phi=1$ in air. The parameters are tabulated in Table 2 and

Table 3. The value of $\gamma$ is uncertain for fuels larger than propane, here we plot results using $\gamma=1$ and $\gamma=0.7$.

\subsubsection{Implications for chemistry of first-stage ignition}

In this section we analyze how different chemical kinetic parameters and mixture composition affect first stage ignition delay. Since the time for first stage ignition is inversely proportional to the rise rate, parameters that affect the eigenvalue necessarily affect the firststage ignition delay. The rise rate $\left(\lambda_{1 B}\right)$ for long straight chain alkanes is given by equation (50), and for $\gamma=1$ this equation reduces to equation (22). As discussed previously, $\lambda_{1 B}$ is a function of $\alpha$ the fraction of $\mathrm{OH}$ radicals that participates in the chain-branching process by producing viable alkyl radicals, and $\beta$, which is the fraction of $\mathrm{RO}_{2}$ radicals that can go on to participate in the peroxy cycle. The third parameter, $\theta$, is the ratio of flux through $\mathrm{O}_{2} \mathrm{QOOH} \rightarrow \mathrm{OQ} \mathrm{OOH}^{\prime} \mathrm{OH}$ over the flux for $\mathrm{RO}_{2} \rightarrow \mathrm{QOOH}$. The rise rate is independent of the fuel concentration ([RH]), however the fuel concentration will affect the initial condition of the system via the $\mathrm{RH}+\mathrm{O}_{2}$ reaction which forms the initial radical pool. Changing the fuel concentration at constant $\mathrm{C}_{\mathrm{v}}$ also 
proportionally affects the temperature rise. However as seen from equation (51) the first stage ignition delay has only a logarithmic dependence on fuel mole fraction $x_{0, \mathrm{RH}}$. Hence, increasing the fuel concentration modestly decreases the first stage ignition delay. The oxygen dependence of the first stage ignition delay is via $\mathrm{RH}+\mathrm{O}_{2}$, similar to the fuel dependence discussed above, but more significantly via $\theta$. As discussed in Section 5.1, $\theta$ for propane tends to 1 for $\mathrm{T}<600 \mathrm{~K}$ and $\mathrm{P}>10$ bar so the rise rate will become independent of the oxygen concentration. Under these conditions the reaction $\mathrm{nRO}_{2} \rightarrow \mathrm{QOOH}$ is the rate limiting step. However for $\mathrm{T}>650 \mathrm{~K}$ and low pressures, $\theta$ is no longer 1 and the rise rate is a function of $\theta^{0.5}$. As the temperature is increased or pressure is decreased (i.e. oxygen concentration is decreased) a larger fraction of $\mathrm{O}_{2} \mathrm{QOOH}$ will dissociate back to $\mathrm{O}_{2}$ and QOOH. An increase in temperature also increases the reverse rate of $\mathrm{RO}_{2} \rightarrow \mathrm{QOOH}$ and consequently the reaction $\mathrm{O}_{2} \mathrm{QOOH} \rightarrow \mathrm{OQ}^{\prime} \mathrm{OOH}+\mathrm{OH}$ becomes rate limiting. The parameter $\theta$ can be approximated by:

$$
\theta \approx \frac{k_{16} K_{15} x_{O 2} P / R T}{k_{-14}+k_{16} K_{15} x_{O 2} P / R T}
$$

where $x_{O 2}$ is the mole fraction of oxygen. The parameter $\theta$ also affects the $T_{\text {stagel,max }}$ through $\beta$. As the pressure is increased a smaller fraction of $\mathrm{RO}_{2}$ radicals are lost via $\mathrm{RO}_{2} \rightarrow$ alkene $+\mathrm{HO}_{2}$ causing the critical temperature $\left(T_{\text {stage1, max }}\right)$ to increase.

Table 3 gives $T_{\text {stagel,max }}$ as function of pressure for various straight chain alkanes. Both of these effects lead to first stage ignition delay having a modest dependence on the oxygen concentration at higher temperatures (the Supplemental Material provides predictions for propane first stage ignition delay under varying equivalence ratios and pressures). The above analysis is specific to 
fuel/air mixtures (or mixtures that are close to fuel/air mixtures) and should not be used for very dilute or rich mixtures.

Table 3: Critical temperature $\left(T_{\text {stage-1,max }}\right)$ calculated for stoichometric mixture of fuel in air. The range in $T_{\text {stage-1,max }}$ corresponds to $\gamma$ values of 0 and 1 respectively. For propane the fate of $\mathrm{OQ}^{\prime} \mathrm{O}$ is well understood and $\gamma=1$.

$$
T_{\text {stage-1,max }}(\mathrm{K})
$$

\begin{tabular}{lccc} 
Fuel & $P_{0}=1$ bar & $P_{0}=10$ bar & $P_{0}=50$ bar \\
\hline Propane & 650 & 690 & 760 \\
Butane & $680-710$ & $710-750$ & $740-810$ \\
Pentane & $760-800$ & $860-930$ & $930-1030$ \\
Heptane & $790-830$ & $890-950$ & $970-1070$ \\
\hline
\end{tabular}

\subsubsection{Overall activation energy of first-stage ignition for long chain alkanes}

It has often been observed that the low-temperature portion of a measured ignition delay for long-chain fuels can be well represented by an Arrhenius expression. Using the expression derived above (51), we can determine the overall activation energy. For long straight-chain alkanes, as a first approximation, during pre-ignition we can assume $\alpha \approx 1$ (this was verified using full model simulations for $n$-alkanes). For $T<600 \mathrm{~K}$ and $P>10$ bar it is reasonable to further approximate $\beta \approx 1$ (alkene $+\mathrm{HO}_{2}$ is negligible) and $\theta \approx 1$ (the back reaction of $\mathrm{RO}_{2} \rightleftharpoons$ $\mathrm{QOOH}$ is insignificant compared to the rate at which $\mathrm{QOOH}$ reacts away to $\mathrm{O}_{2} \mathrm{QOOH}$ ). The ignition time given by equation (52) scales as follows (See Supplemental Material for details):

$$
\tau_{\text {OQ'OOHpeak }} \propto \frac{1}{\sqrt{2 k_{14} k_{17}}}
$$


Such that the ignition delay can be expressed as an Arrhenius expression

$$
\ln \left(\tau_{\text {OQ'OOHpeak }}\right)=-\left(\ln A_{\text {eff }}-\frac{E_{\text {eff }}}{T}\right)
$$

where

$$
E_{\text {eff }} \approx \frac{1}{2}\left(E_{14}+E_{17}\right)
$$

The above equation has an important implication that the overall activation energy $E_{\text {eff }}$ for the first stage ignition delay $\tau_{\mathrm{OQ}^{\prime} \mathrm{OOHpeak}}$ is dependent not only on the activation energy of the isomerization between $\mathrm{RO}_{2}$ (secondary carbon) and QOOH (radical on the secondary carbon), as stated by Zhao and Law [12], but also on the activation energy of the ketohydroperoxide decomposition. Zhao and Law [12], obtained their correlation by simply comparing their fitted $E_{\text {eff }}$ with the activation energy of different reactions in their mechanism. Since the decomposition of ketohydroperoxide controls the release of $\mathrm{OH}$ radicals it is reasonable to expect this term to affect the activation energy of the ignition. Table 4 provides the overall activation energy $E_{\text {eff }}$ for the first stage ignition delay $\tau_{\mathrm{OQ} \text { OOHpeak }}$ for different fuels in the temperature range of $550-650$ K as obtained via Arrhenius expressions fitted to full model simulations, equation (56) and $E_{\text {eff }}=$ $E_{a, R O 2=Q O O H}$. Clearly equation (56) provides a better prediction of the overall activation energy than does $E_{\text {eff }}=E_{a, R O 2=Q O O H}$.

Table 4: Overall activation energy $(\mathrm{kcal} / \mathrm{mol})$ for first stage ignition delay for different n-alkanes for stoichometric mixture of fuel and air at $P_{0}=10$ bar.

\begin{tabular}{llll}
\hline Fuel & $\begin{array}{l}\text { Activation } \\
\text { Energy }\end{array}$ & $\begin{array}{l}\text { Activation } \\
\text { Energy }\end{array}$ & $\mathrm{E}_{\mathrm{a}(\mathrm{RO} 2 \rightleftharpoons \mathrm{QOOH})}$ \\
& $($ Full model $)$ & Eq (56) & \\
\hline Butane & 35.0 & 32.6 & 24.4
\end{tabular}


Pentane

Heptane
33.9

28.6
31.0

29.3
20.8

20.5

*Note: The overall activation energy from the full model is obtained by linear least square fit of the simulated full model first stage ignition delay to the temperature $\left(\ln \left(\tau_{\mathrm{OQ} \text { 'оOHpak }}\right)=\mathrm{A}+\mathrm{E} / \mathrm{RT}\right)$. The temperature range was limited to $\mathrm{T}<650 \mathrm{~K}$.

\section{Concluding remarks}

Using a detailed propane model we analyze the controlling chemistry for the first-stage ignition of propane. The analysis demonstrates that low-temperature auto-ignition of straightchain alkanes is a multi-stage process. The experimentally observed first-stage ignition can be divided into two stages. In stage- $1 \mathrm{~A}$, both $\mathrm{OH}$ and $\mathrm{HO}_{2}$ radicals abstract hydrogen atoms from the fuel, and the resulting alkyl radicals initiate a peroxy radical cycle, which leads to chain branching via the thermal decomposition of ketohydroperoxides. This process causes the $\mathrm{OH}$ and $\mathrm{HO}_{2}$ concentrations to rise exponentially and continues until the concentration of $\mathrm{HO}_{2}$ is sufficiently large that the recombination reaction, $\mathrm{HO}_{2}+\mathrm{HO}_{2} \rightarrow \mathrm{H}_{2} \mathrm{O}_{2}+\mathrm{O}_{2}$, becomes competitive with the rate of $\mathrm{HO}_{2}$ formation. Once this occurs, which marks the beginning of stage- $1 \mathrm{~B}$, the $[\mathrm{OH}] /\left[\mathrm{HO}_{2}\right]$ ratio rises sharply and the vast majority of fuel consumption occurs through $\mathrm{OH}$. Fuels that do not produce a significant amount of $\mathrm{HO}_{2}$ (e.g. long straight-chain alkanes) will not show this "multistage" phenomenon so distinctly, but instead stage-1A and stage-1B will be observed as a single stage driven by $\mathrm{OH}$ radicals.

Several phenomena occur as the first-stage ends. First, oxidation products such as aldehydes, alkenes and $\mathrm{H}_{2} \mathrm{O}_{2}$ accumulate, diverting some of the $\mathrm{OH}$ radicals from chain branching pathways. An increasing fraction of the $\mathrm{nRO}_{2}$ radicals also get consumed by the growing secondary chemistry $\left(\mathrm{CH}_{2} \mathrm{O}\right.$ and $\left.\mathrm{HO}_{2}\right)$. Most importantly the increase in temperature of the system speeds up the loss due to the concerted elimination of $\mathrm{RO}_{2}$ to alkene $+\mathrm{HO}_{2}$. This 
diversion of the $\mathrm{OH}$ and $\mathrm{nRO}_{2}$ radicals reduces the gain of the autocatalytic cycle to $<1$. The combination of these effects causes the ketohydroperoxide concentration to first rise exponentially, then peak and drop rapidly, leading to the point of inflection in the temperature profile that has often been used to mark the end of first-stage ignition. The peak in ketohydroperoxide concentration, which occurs when gain $\approx 1$, is used here as a convenient chemical marker for the end of first-stage ignition.

The analysis also clarifies which species are in quasi steady-state. From these approximations, analytical expressions for first-stage ignition delay were derived: equations (22), (40) and (41) for propane, and equations (50) - (52) for longer $n$-alkanes. The accuracy of these analytical expressions emphasizes that first-stage ignition delay depends on the rate coefficients of only about a dozen reactions, not on the hundreds or thousands of other reactions in the mechanism. Furthermore, from the dependence of $\tau_{\mathrm{OQ}}{ }^{\prime} \mathrm{OOHpeak}$ on important rate coefficients and mixture composition, the following observations can be made:

1. The first-stage ignition delay is nearly independent of the fuel and oxygen concentration for low temperatures $(T<650 \mathrm{~K})$ and high pressure $(P>50 \mathrm{bar})$.

2. The first-stage ignition delay however will have a weak $\left[\mathrm{O}_{2}\right]$ dependence for lower pressures and higher temperatures $(T>650 \mathrm{~K})$.

3. The overall activation energy of first-stage ignition delay is dependent on the activation energy of isomerization of $\mathrm{RO}_{2}$ to $\mathrm{QOOH}$ and the activation energy of the decomposition of the ketohydroperoxide. For large alkanes at high oxygen partial pressures and low temperatures $<650 \mathrm{~K}$, the global activation energy for the ignition delay time can be estimated through the following equation: 


$$
E_{\text {eff }} \approx \frac{1}{2}\left(E_{\mathrm{ROO}=\mathrm{QOOH}}+E_{\mathrm{OQ}^{\prime} \mathrm{OOHdecmp}}\right)
$$

4. The first-stage ignition delay is determined by the competition between pathways that go on to chain branch versus those that go onto chain terminate. The major branch points are

a. Fuel $+\mathrm{OH}$ selectivity towards fuel radicals with different reactivity e.g. $n$ propyl vs iso-propyl radicals. We denote this branching ratio by $\alpha$. For propane only $n$-propyl radicals contribute to chain branching and $\alpha \sim 0.5$. For longer $n$ alkanes all alkyl radicals can contribute to radical generation and we use a value of $\alpha \sim 1$.

b. Peroxy radical $\left(\mathrm{RO}_{2}\right)$ that are lost by decomposition to alkene $+\mathrm{HO}_{2}$ and by reaction with oxidation products (e.g. $\mathrm{HO}_{2}, \mathrm{H}_{2} \mathrm{O}_{2}$, carbonyl compounds). This decomposition is often the major loss term and it increases with increasing temperature leading to longer ignition delays. We denote this branching ratio by $\beta$. The value of $\beta$ is a strong function of temperature for all alkanes.

c. What fraction of the carbonyl (acyl-oxyl) radicals formed by ketohydroperoxide decomposition go on to form $\mathrm{OH}$ or otherwise initiate new autocatalytic cycles. We denote this branching ratio by $\gamma$. For propane, which forms 2-formyl ethoxy radicals, there is a consensus that $\gamma \sim 1$, but for longer $n$-alkanes the value of $\gamma$ is unclear, different literature models give different values [3, 46]. 
5. Above a critical fuel specific temperature $\left(T_{\text {stage-1, } \max }\right)$ the QOOH cycle is ineffective at creating additional radicals (gain - $f_{\mathrm{OH}}=(2+\gamma) \alpha \beta \approx 1$ ).

The results obtained from the present simple model for the first-stage of propane ignition were extended to longer straight chain fuels under the approximation of a single effective (average) site. This simplifying assumption gives reasonable agreement of the predicted $\tau_{\text {stage- } 1}$ with the numerical solutions of large reaction mechanisms.

\section{Acknowledgements}

This work is supported by the Division of Chemical Sciences, Geosciences, and Biosciences, the

Office of Basic Energy Science (BES) of the U.S. Department of Energy. The portion at MIT was supported through the Energy Frontier Research Center for Combustion Science through Grant DE-SC0001198, while the portion at ANL was supported under contract DEAC0206CH11357 through both the Energy Frontier Research Center for Combustion Science (SJK) and through the Argonne-Sandia Consortium on High-Pressure Combustion Chemistry; FWP\# 59044 (CFG and MPB). CFG and MPB also gratefully acknowledge support from the Argonne Director's Fellowship.

\section{Appendix A. Supplementary Material}

Supplementary content associated with this article can be found, in the online version, at http://XXXX. This includes the full propane model in CHEMKIN format, validation of that full model versus experiments [74], derivations of several of the equations, and comparisons between the full-model simulations and the simple analytic formulas for several cases. 


\section{Supplementary Material}

\subsection{Validation of the Full Propane Model}

The full propane model used in this work gives reasonable predictions against low temperature ignition delay data obtained using rapid compression machine as seen from Fig below

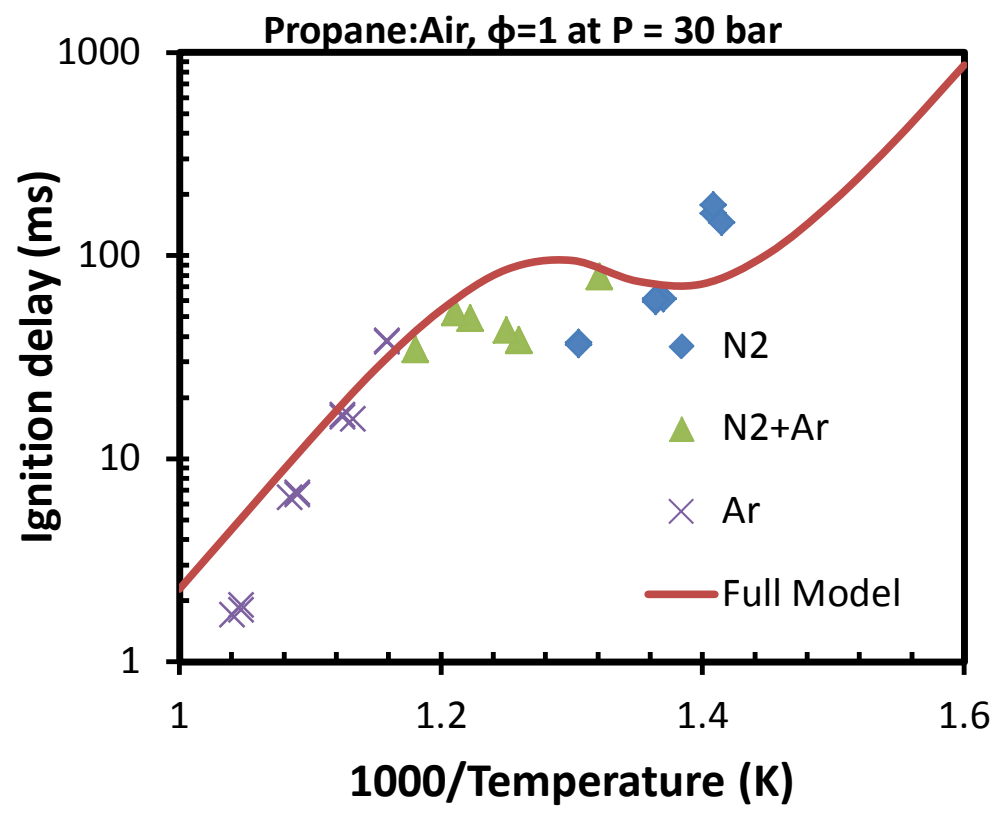




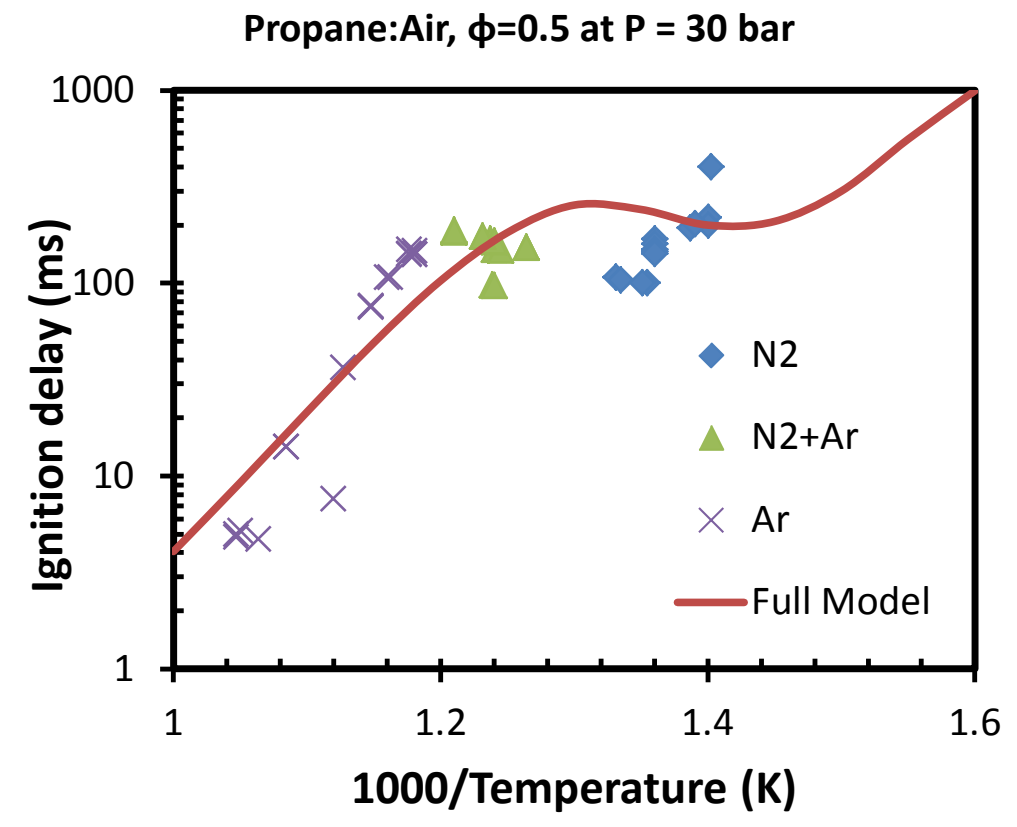

Figure 16: Comparison of experimental measured overall (filled symbols) and simulated (line) ignition delays in a rapid compression machine (RCM) for propane [74] at $P_{0}=30$ bar, $\varphi=1$ and $\varphi=0.5$. The simulations are performed using the constant volume assumption and do not account for the heat loss.

The reduced model provided in Table 1 provides reasonable predictions of the first-stage ignition delay for propane as illustrated in Figure 17. 


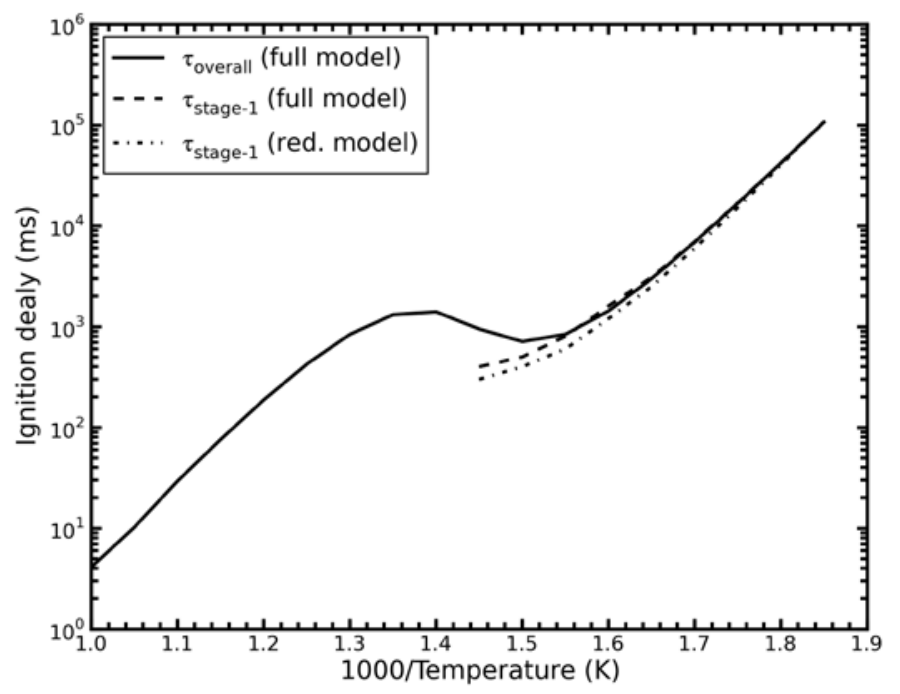

Figure 17: Comparison of the predicted first-stage ignition delay for constant volume adiabatic simulations using the full and reduced propane model, for $P_{0}=10 \mathrm{bar}$, stoichometric mixture of propane in air. The $\tau_{\text {stage- } 1}$ was obtained using the first inflection in the temperature profile. 


\subsubsection{Derivation for explosive eigenvalue using reduced model for stage-1A}

The following set of ODE's can be constructed from the reduced model

$$
\begin{aligned}
& \frac{\mathrm{d}[\mathrm{nR}]}{\mathrm{dt}}=\mathrm{k}_{1}[\mathrm{RH}]\left[\mathrm{O}_{2}\right]+\mathrm{k}_{3}[\mathrm{RH}][\mathrm{OH}]+\mathrm{k}_{5}[\mathrm{RH}]\left[\mathrm{HO}_{2}\right]-\mathrm{k}_{7}[\mathrm{nR}]\left[\mathrm{O}_{2}\right]+\mathrm{k}_{-7}\left[\mathrm{nRO}_{2}\right]-\mathrm{k}_{9}[\mathrm{nR}]\left[\mathrm{O}_{2}\right]+\mathrm{k}_{-9}[\mathrm{QOOH}]-\mathrm{k}_{10}[\mathrm{nR}]\left[\mathrm{O}_{2}\right] \\
& \frac{\mathrm{d}[\mathrm{iR}]}{\mathrm{dt}}=k_{2}[\mathrm{RH}]\left[\mathrm{O}_{2}\right]+k_{4}[\mathrm{RH}][\mathrm{OH}]+k_{6}[\mathrm{RH}]\left[\mathrm{HO}_{2}\right]-k_{8}[\mathrm{iR}]\left[\mathrm{O}_{2}\right]+k_{-8}\left[\mathrm{iRO}_{2}\right]-k_{11}[\mathrm{iR}]\left[\mathrm{O}_{2}\right] \\
& \frac{d\left[\mathrm{nRO}_{2}\right]}{d t}=k_{7}[\mathrm{nR}]\left[\mathrm{O}_{2}\right]-k_{-7}\left[\mathrm{nRO}_{2}\right]-k_{12}\left[\mathrm{nRO}_{2}\right]-k_{14}\left[\mathrm{nRO}_{2}\right]+k_{-14}[\mathrm{QOOH}] \\
& \frac{d\left[\mathrm{iRO}_{2}\right]}{d t}=k_{8}[\mathrm{iR}]\left[\mathrm{O}_{2}\right]-k_{-8}\left[\mathrm{iRO}_{2}\right]-k_{13}\left[\mathrm{iRO}_{2}\right] \\
& \frac{d[\mathrm{QOOH}]}{d t}=k_{9}[\mathrm{nR}]\left[\mathrm{O}_{2}\right]-k_{-9}\left[\mathrm{nRO}_{2}\right]+k_{14}\left[\mathrm{nRO}_{2}\right]-k_{-9}[\mathrm{OQOOH}]-k_{-14}[\mathrm{QOOH}] \\
& -k_{15}[\mathrm{QOOH}]\left[\mathrm{O}_{2}\right]+k_{-15}\left[\mathrm{O}_{2} \mathrm{QOOH}\right] \\
& \frac{d\left[\mathrm{O}_{2} \mathrm{QOOH}\right]}{d t}=k_{15}[\mathrm{QOOH}]\left[\mathrm{O}_{2}\right]-k_{-15}\left[\mathrm{O}_{2} \mathrm{QOOH}\right]-k_{16}\left[\mathrm{O}_{2} \mathrm{QOOH}\right] \\
& \frac{d\left[\mathrm{OQ}^{\prime} \mathrm{OOH}\right]}{d t}=k_{16}\left[\mathrm{O}_{2} \mathrm{QOOH}\right]-k_{17}\left[\mathrm{OQ}^{\prime} \mathrm{OOH}\right] \\
& \frac{d\left[\mathrm{OQ}^{\prime} \mathrm{O}\right]}{d t}=k_{17}[\mathrm{OQ} \mathrm{OOH}]-k_{18}\left[\mathrm{OQ}^{\prime} \mathrm{O}\right]
\end{aligned}
$$




$$
\begin{aligned}
& \frac{d\left[\mathrm{CH}_{2} \mathrm{CHO}\right]}{d t}=k_{18}\left[\mathrm{OQ}^{\prime} \mathrm{O}\right]-k_{19}\left[\mathrm{CH}_{2} \mathrm{CHO}\right]\left[\mathrm{O}_{2}\right] \\
& \frac{d[\mathrm{OH}]}{d t}=-k_{1}[\mathrm{RH}][\mathrm{OH}]-k_{2}[\mathrm{RH}][\mathrm{OH}]+k_{16}\left[\mathrm{O}_{2} \mathrm{QOOH}\right]+k_{17}[\mathrm{OQ} \mathrm{OOH}]+k_{19}\left[\mathrm{CH}_{2} \mathrm{CHO}_{[}\left[\mathrm{O}_{2}\right]\right. \\
& +2 k_{25}\left[\mathrm{H}_{2} \mathrm{O}_{2}\right] \\
& \frac{d\left[\mathrm{HO}_{2}\right]}{d t}=k_{1}[\mathrm{RH}]\left[\mathrm{O}_{2}\right]+k_{2}[\mathrm{RH}]\left[\mathrm{O}_{2}\right]-k_{5}[\mathrm{RH}]\left[\mathrm{HO}_{2}\right]-k_{6}[\mathrm{RH}]\left[\mathrm{HO}_{2}\right]+k_{10}[\mathrm{nR}]\left[\mathrm{O}_{2}\right]+k_{11}[\mathrm{iR}]\left[\mathrm{O}_{2}\right] \\
& +k_{12}\left[\mathrm{nRO}_{2}\right]+k_{13}\left[\mathrm{iRO}_{2}\right]+k_{21}[\mathrm{CH} 2 \mathrm{O}]\left[\mathrm{O}_{2}\right]+k_{22}[\mathrm{HCO}]\left[\mathrm{O}_{2}\right]+k_{23}\left[\mathrm{H}_{2} \mathrm{O}_{2}\right][\mathrm{OH}]-2 k_{24}\left[\mathrm{HO}_{2}\right]^{2} \\
& \frac{d\left[\mathrm{CH}_{2} \mathrm{O}\right]}{d t}=k_{18}[\mathrm{OQ} \mathrm{O}]+k_{19}\left[\mathrm{CH}_{2} \mathrm{CHO}\right]\left[\mathrm{O}_{2}\right]-k_{20}\left[\mathrm{CH}_{2} \mathrm{O}\right][\mathrm{OH}]-k_{21}\left[\mathrm{CH}_{2} \mathrm{O}\right]\left[\mathrm{O}_{2}\right]
\end{aligned}
$$

After the induction period, several radical species will be in QSS including nR, iR, $\mathrm{OH}, \mathrm{QOOH}$, $\mathrm{O}_{2} \mathrm{QOOH}, \mathrm{OQ}^{\prime} \mathrm{O}$ and $\mathrm{CH}_{2} \mathrm{CHO}$

$$
\begin{gathered}
{[\mathrm{nR}]=\frac{\left(k_{1}\left[\mathrm{O}_{2}\right]+k_{3}[\mathrm{OH}]+k_{5}\left[\mathrm{HO}_{2}\right]\right)[\mathrm{RH}]+k_{-7}\left[\mathrm{nRO}_{2}\right]+k_{-9}[\mathrm{QOOH}]}{\left(k_{7}+k_{9}+k_{10}\right)\left[\mathrm{O}_{2}\right]}} \\
{[\mathrm{iR}]=\frac{\left(k_{2}\left[\mathrm{O}_{2}\right]+k_{4}[\mathrm{OH}]+k_{6}\left[\mathrm{HO}_{2}\right]\right)[\mathrm{RH}]+k_{-8}\left[\mathrm{iRO}_{2}\right]}{\left(k_{8}+k_{11}\right)\left[\mathrm{O}_{2}\right]}} \\
{[\mathrm{QOOH}]=\frac{k_{9}[\mathrm{nR}][\mathrm{O} 2]+k_{14}\left[\mathrm{nRO}_{2}\right]+k_{-15}\left[\mathrm{O}_{2} \mathrm{QOOH}\right]}{k_{-9}+k_{-14}+k_{15}\left[\mathrm{O}_{2}\right]}} \\
{\left[\mathrm{O}_{2} \mathrm{QOOH}\right]=\frac{k_{15}}{k_{-15}+k_{16}}\left[\mathrm{O}_{2}\right][\mathrm{QOOH}]} \\
{\left[\mathrm{OQ}^{\prime} \mathrm{O}\right]=\frac{k_{17}\left[\mathrm{OQ}^{\prime} \mathrm{OOH}\right]}{k_{18}}}
\end{gathered}
$$




$$
\begin{gathered}
{[\mathrm{OH}]=\frac{k_{16}\left[\mathrm{O}_{2} \mathrm{QOOH}\right]+k_{17}\left[\mathrm{OQ}^{\prime} \mathrm{OOH}\right]+k_{19}\left[\mathrm{CH}_{2} \mathrm{CHO}\right]\left[\mathrm{O}_{2}\right]+2 k_{25}\left[\mathrm{H}_{2} \mathrm{O}_{2}\right]}{\left(k_{3}+k_{4}\right)[\mathrm{RH}]+k_{20}\left[\mathrm{CH}_{2} \mathrm{O}\right]+k_{23}\left[\mathrm{H}_{2} \mathrm{O}_{2}\right]}} \\
{\left[\mathrm{CH}_{2} \mathrm{CHO}\right]=\frac{k_{18}\left[\mathrm{OQ}^{\prime} \mathrm{O}\right]}{k_{19}\left[\mathrm{O}_{2}\right]}}
\end{gathered}
$$

We make the following simplifications:

1. For pressures greater than one atmosphere, the vast majority of QOOH is formed via isomerization from $\mathrm{RO}_{2}$, such that the chemically activated production of QOOH from $\mathrm{R}$ $+\mathrm{O}_{2}$ is sufficiently small that its contribution can be considered negligible.

2. Similarly the contributions of reaction 10 and 11 are also negligible, as confirmed by flux analysis with the complete model.

3. For temperatures less than $800 \mathrm{~K}$ (those considered here) the decomposition of $\mathrm{H}_{2} \mathrm{O}_{2}$ to $\mathrm{OH}$ is not significant during stage- 1 and can be neglected.

Applying these simplifications to (S 13)-(S 19):

$$
\begin{gathered}
{[\mathrm{nR}]=\frac{\left(k_{1}\left[\mathrm{O}_{2}\right]+k_{3}[\mathrm{OH}]+k_{5}\left[\mathrm{HO}_{2}\right]\right)[\mathrm{RH}]+k_{-7}\left[\mathrm{nRO}_{2}\right]}{k_{7}\left[\mathrm{O}_{2}\right]}} \\
{[\mathrm{iR}]=\frac{\left(k_{2}\left[\mathrm{O}_{2}\right]+k_{4}[\mathrm{OH}]+k_{6}\left[\mathrm{HO}_{2}\right]\right)[\mathrm{RH}]+k_{-8}\left[\mathrm{iRO}_{2}\right]}{\left(k_{8}+k_{11}\right)\left[\mathrm{O}_{2}\right]}} \\
{[\mathrm{QOOH}]=\frac{k_{14}\left[\mathrm{nRO}_{2}\right]+k_{-15}\left[\mathrm{O}_{2} \mathrm{QOOH}\right]}{k_{-14}+k_{15}\left[\mathrm{O}_{2}\right]}} \\
{\left[\mathrm{O}_{2} \mathrm{QOOH}\right]=\frac{k_{15}}{k_{-15}+k_{16}}\left[\mathrm{O}_{2}\right][\mathrm{QOOH}]}
\end{gathered}
$$




$$
\begin{gathered}
{\left[\mathrm{OQ}^{\prime} \mathrm{O}\right]=\frac{k_{17}\left[\mathrm{OQ}^{\prime} \mathrm{OOH}\right]}{k_{18}}} \\
{[\mathrm{OH}]=\frac{k_{16}\left[\mathrm{O}_{2} \mathrm{QOOH}\right]+k_{17}\left[\mathrm{OQ}^{\prime} \mathrm{OOH}\right]+k_{19}\left[\mathrm{CH}_{2} \mathrm{CHO}\right]\left[\mathrm{O}_{2}\right]}{\left(k_{3}+k_{4}\right)[\mathrm{RH}]+k_{20}\left[\mathrm{CH}_{2} \mathrm{O}\right]+k_{23}\left[\mathrm{H}_{2} \mathrm{O}_{2}\right]}} \\
{\left[\mathrm{CH}_{2} \mathrm{CHO}\right]=\frac{k_{18}\left[\mathrm{OQ}^{\prime} \mathrm{O}\right]}{k_{19}\left[\mathrm{O}_{2}\right]}}
\end{gathered}
$$

Substituting for $\mathrm{O}_{2} \mathrm{QOOH}$ (S 23) in (S 22) and solving gives

$$
\left[\mathrm{O}_{2} \mathrm{QOOH}\right]=\frac{k_{14} \frac{k_{15}}{k_{-15}+k_{16}}\left[\mathrm{O}_{2}\right]}{k_{-14}+\frac{k_{15} k_{16}}{k_{-15}+k_{16}}\left[O_{2}\right]}\left[\mathrm{nRO}_{2}\right]
$$

Substituting for QOOH (S 22) in (S 23) and solving gives:

$$
[\mathrm{QOOH}]=\frac{k_{14}}{k_{-14}+\frac{k_{15} k_{16}}{k_{-15}+k_{16}}\left[O_{2}\right]}\left[\mathrm{nRO}_{2}\right]
$$

Substituting for $\mathrm{CH}_{2} \mathrm{CHO}$ (S 24) and (S 26) in the expression (S 25) for OH:

$$
[\mathrm{OH}]=\frac{k_{16}\left[\mathrm{O}_{2} \mathrm{QOOH}\right]+2 k_{17}\left[\mathrm{OQ}^{\prime} \mathrm{OOH}\right]}{\left(k_{3}+k_{4}\right)[\mathrm{RH}]+k_{20}\left[\mathrm{CH}_{2} \mathrm{O}\right]+k_{23}\left[\mathrm{H}_{2} \mathrm{O}_{2}\right]}
$$

Initially during stage-1 the concentrations of intermediates and products is sufficiently small that their contributions to $\mathrm{OH}$ consumption can be neglected. However this assumption breaks down as the fuel is consumed, which leads to the production of secondary products.

$$
[\mathrm{OH}]=\frac{k_{16}\left[\mathrm{O}_{2} \mathrm{QOOH}\right]+2 k_{17}\left[\mathrm{OQ}^{\prime} \mathrm{OOH}\right]}{\left(k_{3}+k_{4}\right)[\mathrm{RH}]}
$$

We can simplify the notation by introducing three non-dimensional parameters: 


$$
\begin{gathered}
\alpha=\frac{k_{3}}{k_{3}+k_{4}} \\
\beta=\frac{\theta k_{14}}{\theta k_{14}+k_{12}} \\
\theta=\frac{\frac{k_{15} k_{16}}{k_{-15}+k_{16}}\left[O_{2}\right]}{k_{-14}+\frac{k_{15} k_{16}}{k_{-15}+k_{16}}\left[O_{2}\right]}
\end{gathered}
$$

Using (S 27) in ODE for OQ'OOH (S 7):

$\frac{d\left[\mathrm{OQ}^{\prime} \mathrm{OOH}\right]}{d t}=k_{14} \theta\left[\mathrm{nRO}_{2}\right]-k_{17}\left[\mathrm{OQ}^{\prime} \mathrm{OOH}\right]$

Using (S 20), (S 28) and (S 30) in (S 3):

$\frac{d\left[\mathrm{nRO}_{2}\right]}{d t}=\alpha\left(k_{16}\left[\mathrm{O}_{2} \mathrm{QOOH}\right]+2 k_{17}\left[\mathrm{OQ}^{\prime} \mathrm{OOH}\right]\right)+\left(k_{1}\left[\mathrm{O}_{2}\right]+k_{5}\left[\mathrm{HO}_{2}\right]\right)[\mathrm{RH}]-k_{12}\left[\mathrm{nRO}_{2}\right]-k_{14} \theta\left[\mathrm{nRO}_{2}\right]$

Using (S 27) in (S 35) and simplifying:

$\frac{d\left[\mathrm{nRO}_{2}\right]}{d t}=2 \alpha k_{17}[\mathrm{OQ} \mathrm{OOH}]+\left(k_{1}\left[\mathrm{O}_{2}\right]+k_{5}\left[\mathrm{HO}_{2}\right]\right)[\mathrm{RH}]+\left((\alpha-1) k_{14} \theta-k_{12}\right)\left[\mathrm{nRO}_{2}\right]$

Using (S 14) and (S 30) in (S 4):

$\frac{d\left[\mathrm{iRO}_{2}\right]}{d t}=(1-\alpha)\left(k_{16}\left[\mathrm{O}_{2} \mathrm{QOOH}\right]+2 k_{17}\left[\mathrm{OQ}^{\prime} \mathrm{OOH}\right]\right)+\left(k_{2}\left[\mathrm{O}_{2}\right]+k_{6}\left[\mathrm{HO}_{2}\right]\right)[\mathrm{RH}]-k_{13}\left[\mathrm{iRO}_{2}\right]$

Using (S 27) in (S 37) and simplifying:

$\frac{d\left[\mathrm{iRO}_{2}\right]}{d t}=(1-\alpha)\left(\theta\left[n \mathrm{RO}_{2}\right]+2 k_{17}\left[\mathrm{OQ}^{\prime} \mathrm{OOH}\right]\right)+\left(k_{2}\left[\mathrm{O}_{2}\right]+k_{6}\left[\mathrm{HO}_{2}\right]\right)[\mathrm{RH}]-k_{13}\left[\mathrm{iRO}_{2}\right]$

The ODE for $\mathrm{HO}_{2}$ after ignoring contributions from R10 and R11 is given by: 
$\frac{d\left[\mathrm{HO}_{2}\right]}{d t}=k_{1}[\mathrm{RH}]\left[\mathrm{O}_{2}\right]+k_{2}[\mathrm{RH}]\left[\mathrm{O}_{2}\right]-k_{5}[\mathrm{RH}]\left[\mathrm{HO}_{2}\right]-k_{6}[\mathrm{RH}]\left[\mathrm{HO}_{2}\right]$
$+k_{12}\left[\mathrm{nRO}_{2}\right]+k_{13}\left[\mathrm{iRO}_{2}\right]+k_{21}\left[\mathrm{CH}_{2} \mathrm{O}\right]\left[\mathrm{O}_{2}\right]+k_{22}[\mathrm{HCO}]\left[\mathrm{O}_{2}\right]+k_{23}\left[\mathrm{H}_{2} \mathrm{O}_{2}\right][\mathrm{OH}]-2 k_{24}\left[\mathrm{HO}_{2}\right]^{2}$

At early times the concentration of secondary product $\left(\mathrm{CH}_{2} \mathrm{O}, \mathrm{H}_{2} \mathrm{O}_{2}\right)$ can be considered negligibly small. The $\mathrm{HO}_{2}$ concentration is also sufficiently small that the rate of its self- reaction can be neglected, which allows for simplification of (S 39) to:

$\frac{d\left[\mathrm{HO}_{2}\right]}{d t}=k_{1}[\mathrm{RH}]\left[\mathrm{O}_{2}\right]+k_{2}[\mathrm{RH}]\left[\mathrm{O}_{2}\right]-k_{5}[\mathrm{RH}]\left[\mathrm{HO}_{2}\right]-k_{6}[\mathrm{RH}]\left[\mathrm{HO}_{2}\right]+k_{12}\left[\mathrm{nRO}_{2}\right]+k_{13}\left[\mathrm{iRO}_{2}\right]$

We can also neglect the consumption terms for $\mathrm{CH}_{2} \mathrm{O}$ simplifying (S 12) to

$\frac{d\left[\mathrm{CH}_{2} \mathrm{O}\right]}{d t}=k_{18}\left[\mathrm{OQ}^{\prime} \mathrm{O}\right]+k_{19}\left[\mathrm{CH}_{2} \mathrm{CHO}\right]\left[\mathrm{O}_{2}\right]$

The above equation can be simplified using (S 24) and (S 26) to (S 42), which is valid during early times when the concentration of $\mathrm{CH}_{2} \mathrm{O}$ has not grown significantly

$\frac{d\left[\mathrm{CH}_{2} \mathrm{O}\right]}{d t} \approx 2 k_{17}\left[\mathrm{OQ}^{\prime} \mathrm{OOH}\right]$

During stage- 1 the concentration of the fuel and oxygen remains nearly constant such that

$[\mathrm{RH}]\left[\mathrm{O}_{2}\right] \approx[\mathrm{RH}]_{0}\left[\mathrm{O}_{2}\right]_{0}$

Since $\alpha, \beta$ and $\theta$ are approximately constants, equations (S 34), (S 36), (S 38) and (S 40) are linear ODE’s which can be solved using eigenvalue analysis 


$$
\left[\begin{array}{c}
\frac{d\left[\mathrm{nRO}_{2}\right]}{d t} \\
\frac{d\left[\mathrm{iRO}_{2}\right]}{d t} \\
\frac{d\left[\mathrm{HO}_{2}\right]}{d t} \\
\frac{d[\mathrm{OQ} \mathrm{OOH}]}{d t}
\end{array}\right]=\left[\begin{array}{cccc}
\left.-(1-\alpha)+\frac{(1-\beta)}{\beta}\right) \theta k_{14} & 0 & k_{5}[\mathrm{RH}]_{0} & 2 \alpha k_{17} \\
(1-\alpha) \theta k_{14} & -k_{13} & k_{6}[\mathrm{RH}]_{0} & 2(1-\alpha) k_{17} \\
\frac{(1-\beta) \theta k_{14}}{\beta} & k_{13} & -\left(k_{5}+k_{6}\right)[\mathrm{RH}]_{0} & 0 \\
\theta k_{14} & 0 & 0 & -k_{17}
\end{array}\right]\left[\begin{array}{c}
{\left[\mathrm{nRO}_{2}\right]} \\
{\left[\mathrm{iRO} \mathrm{R}_{2}\right]} \\
{\left[\mathrm{HO}_{2}\right]} \\
{[\mathrm{OQ} \mathrm{OOH}]}
\end{array}\right]+\left[\begin{array}{c}
k_{1}[\mathrm{RH}]_{0}\left[\mathrm{O}_{2}\right]_{0} \\
k_{2}[\mathrm{RH}]_{0}\left[\mathrm{O}_{2}\right]_{0} \\
\left(k_{1}+k_{2}\right)[\mathrm{RH}]_{0}\left[\mathrm{O}_{2}\right]_{0} \\
0
\end{array}\right]
$$

The system of linear ODE's can be written in terms of a concentration vector C, coefficient matrix $\mathrm{M}$ and source term $\mathrm{R}$.

$\frac{d \underline{C}}{d t}=\underline{\underline{M}} \underline{C}+\underline{R}$

For which $\mathrm{M}$ can decomposed into an eigenvector matrix, $\mathrm{V}$ and eigenvalue matrix, $\Lambda$ as

$$
\underline{\underline{M}}=\underline{\underline{V}} \underline{\underline{\Lambda}} \underline{\underline{V^{-1}}}
$$

$\frac{d \underline{C}}{d t}=\underline{\underline{V}} \underline{\underline{\Lambda}} \underline{\underline{V}}^{-1} \underline{C}+\underline{R}$

Transforming variables from the concentration vector to the eigenvectors, $\underline{Z}=\underline{\underline{V^{-1}}} \underline{\underline{C}}$ diagonalizes the equation

$$
\frac{d \underline{Z}}{d t}=\underline{\Lambda} \underline{Z}+\underline{E}
$$

where $\underline{E}=\underline{V}^{-1} \underline{R}$

Another change of variables to $\underline{\underline{\Lambda}} \underline{\underline{Y}}=\underline{\underline{\Lambda}} \underline{Z}+\underline{E}$ further simplifies the equation to

$$
\frac{d \underline{Y}}{d t}=\underline{\underline{\Lambda}} \underline{\underline{Y}}
$$

This has a general solution of the form

$$
\underline{Y}=\exp (\underline{\underline{\Lambda}}) \underline{Y_{0}}
$$


Substituting for $\mathrm{C}$ we get back

$\underline{C}=\underline{\underline{V}} \exp (\underline{\underline{\Lambda}}) \underline{Y_{0}}-\underline{\underline{V}} \underline{\underline{\Lambda}}^{-1} \underline{\underline{V}}^{-1} \underline{R}$

where the value of $\underline{Y_{0}}$ can be obtained from $\underline{R}$ and the true initial conditions $\underline{C_{0}}(t=0)$

$\underline{Y_{0}}=\underline{\underline{V^{-1}}} \underline{C_{0}}+\underline{\underline{\Lambda}}^{-1} \underline{\underline{V^{-1}}} \underline{R}$

Hence if the complete eigenvectors and the true initial conditions $\underline{C_{0}}(t=0)$ are used, then the numerical solutions to the above can be found exactly (without any further approximations).

Since only one of the eigenvalues $\left(\lambda_{1}\right)$ has a positive real number, after a brief induction period of time $C$ can be approximated as

$C_{i} \approx y_{0,1} V_{i, 1} \exp \left(\lambda_{1} t\right)$ where we assume $\operatorname{real}\left(\lambda_{1}\right)>0$

The initial conditions for $\mathrm{HO}_{2}, \mathrm{RO}_{2}$ and $\mathrm{OQ}^{\prime} \mathrm{OOH}$ in stage-1A is given by

$C_{i 0, A} \approx y_{0,1} V_{i, 1}$

Initial conditions for all other species will just be linear combinations of $\mathrm{HO}_{2}, \mathrm{RO}_{2}$ and OQ'OOH.

If desired we can take the ratio of concentrations to eliminate the initial condition

$\frac{C_{i+1}}{C_{i}} \approx \frac{V_{i+1,1}}{V_{i, 1}}$

Figure 18 compares the ratio of concentrations obtained from the eigenvectors (S 54) and the full model simulation. 


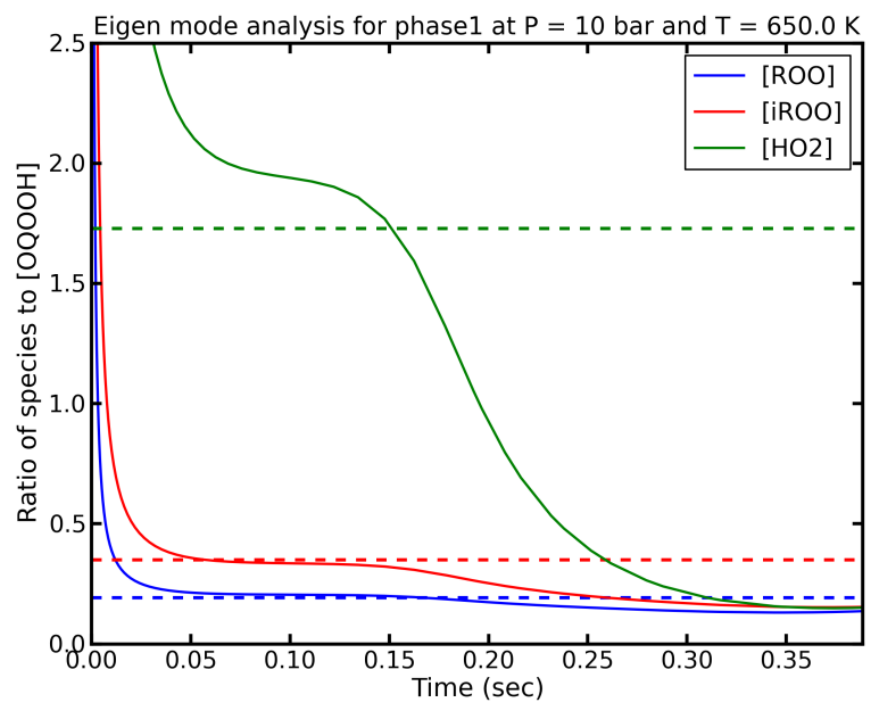

Figure 18: Predictions (dotted lines) for relative concentrations of species involved in first-stage ignition (stage-1A) by eigen mode analysis for simulations at $P_{0}=10$ bar and $T_{0}=650 \mathrm{~K}$ for a stoichiometric mixture of propane in air. The solid lines are obtained from full model simulations, the dotted lines are the ratio of the eigenvector elements $\mathrm{V}_{(\text {(species })} / \mathrm{V}_{(\mathrm{OQ}} \mathrm{OOOH}^{\prime}$ corresponding to the positive eigenvalue in stage-1A.

\subsubsection{Analytical solution for the explosive eigenvalue for stage-1A}

An analytical solution to the system of linear ODE's, equation (S 44), can be achieved if the quartic system is reduced to a cubic equation by making the following assumption for HO2

$$
\frac{d\left[\mathrm{HO}_{2}\right]}{d t}=2 k_{17}[\mathrm{OQOOH}]-\frac{d\left[\mathrm{nRO}_{2}\right]}{d t}-\frac{d\left[\mathrm{iRO}_{2}\right]}{d t} \approx 2 k_{17}\left[\mathrm{OQ}^{\prime} \mathrm{OOH}\right]
$$

The left hand side of the above expression comes from rearranging (S 40) using (S 37) and (S 38).

Figure 19 gives the comparison of the net $\mathrm{HO}_{2}$ flux and the flux estimated by the approximation made in (S 55). As seen from Figure 19 the approximation provides a satisfactory reproduction of the net $\mathrm{HO}_{2}$ flux until the $\mathrm{HO}_{2}$ self-reaction becomes a significant contributor to $\mathrm{HO}_{2}$ consumption near the end of stage-1A. 


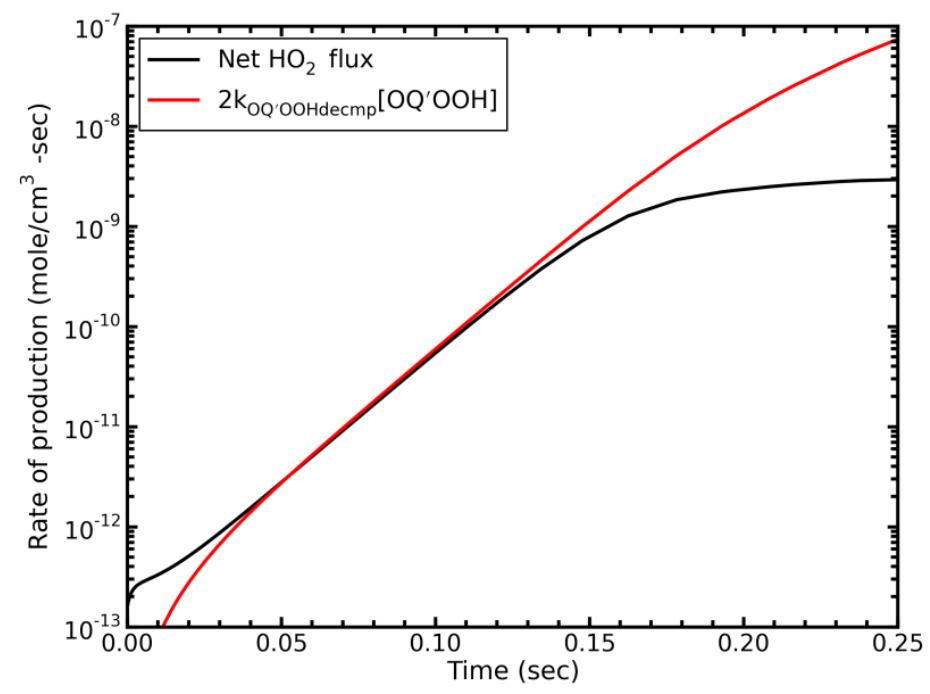

Figure 19: Comparison of the net $\mathrm{HO} 2$ flux (from the full model simulation) and the approximation $2 \mathrm{k}_{\mathrm{OQ}^{\prime} \mathrm{OOH}}$ decmp $\left[\mathrm{OQ}^{\prime} \mathrm{OOH}\right]$ for $P_{0}=10$ bar and $T_{0}=650 \mathrm{~K}$.

This approximation effectively decouples $\mathrm{iRO}_{2}$ from the system of differential equations (S 44), reducing it to a cubic system.

$$
\left[\begin{array}{c}
\frac{d\left[\mathrm{nRO}_{2}\right]}{d t} \\
\frac{d\left[\mathrm{HO}_{2}\right]}{d t} \\
\frac{d[\mathrm{OQ} \mathrm{OOH}]}{d t}
\end{array}\right]=\left[\begin{array}{ccc}
\left.-(1-\alpha)+\frac{(1-\beta)}{\beta}\right) \theta k_{14} & k_{5}[\mathrm{RH}]_{0} & 2 \alpha k_{17} \\
0 & 0 & 2 k_{17} \\
\theta k_{14} & 0 & -k_{17}
\end{array}\right]\left[\begin{array}{c}
{\left[\mathrm{nRO}_{2}\right]} \\
{\left[\mathrm{HO}_{2}\right]} \\
{[\mathrm{OQ} \mathrm{OOH}]}
\end{array}\right]+\left[\begin{array}{c}
k_{1}[\mathrm{RH}]_{0}\left[\mathrm{O}_{2}\right]_{0} \\
\left(k_{1}+k_{2}\right)[\mathrm{RH}]_{0}\left[\mathrm{O}_{2}\right]_{0} \\
0
\end{array}\right]
$$

The eigenvalues are roots of the following cubic characteristic equation

$$
\lambda^{3}+\left(\left((1-\alpha)+\left(\frac{1-\beta}{\beta}\right)\right) \theta k_{14}+k_{17}\right) \lambda^{2}+\left((1-3 \alpha)+\left(\frac{1-\beta}{\beta}\right)\right) \theta k_{14} k_{17} \lambda-2 \theta k_{14} k_{17} k_{5}[R H]=0
$$

The characteristic equation is a general cubic of the form $x^{3}+b x^{2}+c x+d=0$ and will have three roots. 


$$
\begin{aligned}
& \lambda_{1}=-\frac{b}{3}+\frac{\sqrt[3]{\left(-2 b^{3}+3 \sqrt{3} \sqrt{4 b^{3} d-b^{2} c^{2}-18 b c d+4 c^{3}+27 d^{2}}+9 b c-27 d\right)}}{3 \sqrt[3]{2}} \\
& -\frac{\sqrt[3]{2}\left(3 c-b^{2}\right)}{3 \sqrt[3]{\left(-2 b^{3}+3 \sqrt{3} \sqrt{4 b^{3} d-b^{2} c^{2}-18 b c d+4 c^{3}+27 d^{2}}+9 b c-27 d\right)}} \\
& +\frac{b}{3 \times 2^{\frac{2}{3}} \sqrt[3]{\left(-2 b^{3}+3 \sqrt{3} \sqrt{4 b^{3} d-b^{2} c^{2}-18 b c d+4 c^{3}+27 d^{2}}+9 b c-27 d\right)}} \\
& \lambda_{3}=-\frac{b}{3}-\frac{(1-i \sqrt{3}) \sqrt[3]{\left(-2 b^{3}+3 \sqrt{3} \sqrt{4 b^{3} d-b^{2} c^{2}-18 b c d+4 c^{3}+27 d^{2}}+9 b c-27 d\right)}}{6 \sqrt[3]{2}}-\frac{(1+i \sqrt{3}) \sqrt[3]{\left(-2 b^{3}+3 \sqrt{3} \sqrt{4 b^{3} d-b^{2} c^{2}-18 b c d+4 c^{3}+27 d^{2}}+9 b c-27 d\right)}}{6 \sqrt[3]{2}} \\
& +\frac{(1-i \sqrt{3})\left(3 c-b^{2}\right)}{3 \times 2^{\frac{2}{3}} \sqrt[3]{\left(-2 b^{3}+3 \sqrt{3} \sqrt{4 b^{3} d-b^{2} c^{2}-18 b c d+4 c^{3}+27 d^{2}}+9 b c-27 d\right)}}
\end{aligned}
$$

where

$$
\begin{aligned}
& b=\left((1-\alpha)+\left(\frac{1-\beta}{\beta}\right)\right) \theta k_{14}+k_{17} \\
& c=\left((1-3 \alpha)+\left(\frac{1-\beta}{\beta}\right)\right) \theta k_{14} k_{17} \\
& d=-2 \theta k_{14} k_{17} k_{5}[R H]
\end{aligned}
$$


Table 5: Comparison of the positive eigenvalue $\left(\lambda_{1 \mathrm{~A}}\right)$ obtained solving (S 44) numerically and the positive root of the cubic equation (S 57) for $P_{0}=10$ bar, stoichometric mixture of propane in air.

\begin{tabular}{lll}
\hline $\mathrm{T}_{0}(\mathrm{~K})$ & $\begin{array}{l}\lambda_{1 \mathrm{~A}} \\
\text { (Numerical) }\end{array}$ & $\begin{array}{l}\lambda_{1 \mathrm{~A}} \\
\text { (Cubic } \\
\text { approx.) }\end{array}$ \\
\hline 550 & 0.7 & 0.9 \\
600 & 8.5 & 9.8 \\
650 & 55.4 & 61.0 \\
\hline
\end{tabular}

\subsubsection{Simplification of the explosive eigenvalue for stage-1B}

The expression for the explosive eigenvalue for a general fuel (for $\gamma=1$ ) is given by:

$$
\begin{aligned}
& \lambda_{1 B}=\frac{k_{17}}{2}\left(-\left(1+\frac{(1-\alpha \beta) \theta k_{14}}{\beta k_{17}}\right)+\sqrt{4 \frac{(3 \alpha \beta-1) \theta k_{14}}{\beta k_{17}}+\left(1+\frac{(1-\alpha \beta) \theta k_{14}}{\beta k_{17}}\right)^{2}}\right) \\
& \lambda_{1 B}=\frac{k_{17}}{2}\left(1+\frac{(1-\alpha \beta) \theta k_{14}}{\beta k_{17}}\right)\left(-1+\sqrt{4 \frac{\frac{(3 \alpha \beta-1) \theta k_{14}}{\beta k_{17}}}{\left(1+\frac{(1-\alpha \beta) \theta k_{14}}{\beta k_{17}}\right)^{2}}}\right)
\end{aligned}
$$

The above expression can be further approximated as

$$
\begin{gathered}
\lambda_{1 B} \approx \frac{k_{17}}{2}\left(1+\frac{(1-\alpha \beta) \theta k_{14}}{\beta k_{17}}\right)\left(\sqrt{\left.4 \frac{\frac{(3 \alpha \beta-1) \theta k_{14}}{\beta k_{17}}}{\left(1+\frac{(1-\alpha \beta) \theta k_{14}}{\beta k_{17}}\right)^{2}}\right)}\right. \\
\lambda_{1 B} \approx\left(\sqrt{\frac{(3 \alpha \beta-1) \theta k_{14} k_{17}}{\beta}}\right)
\end{gathered}
$$


For high pressures and low temperature and high pressures ( $\mathrm{T}<600 \mathrm{~K}, \mathrm{P}>10 \mathrm{bar}) \theta \rightarrow 1$, which yields

$$
\lambda_{1 B} \approx\left(\sqrt{\frac{(3 \alpha \beta-1) k_{14} k_{17}}{\beta}}\right)
$$

For $\alpha=1$ and $\beta=1$ we get

$$
\lambda_{1 B} \approx \sqrt{2 k_{14} k_{17}}
$$

Note this approximation has significant error in the absolute value of $\lambda_{1 \mathrm{~B}}$ and not recommended to be used above the limited temperature and pressure range.

\subsubsection{Prediction for first-stage ignition delay for propane under varying equivalence ratios and pressure}

Figure 20 provides the comparison of first-stage ignition delay for propane under varying equivalence ratios in air for $P_{0}=10$ bar. The first-stage ignition delay does not change significantly with fuel concentration. 


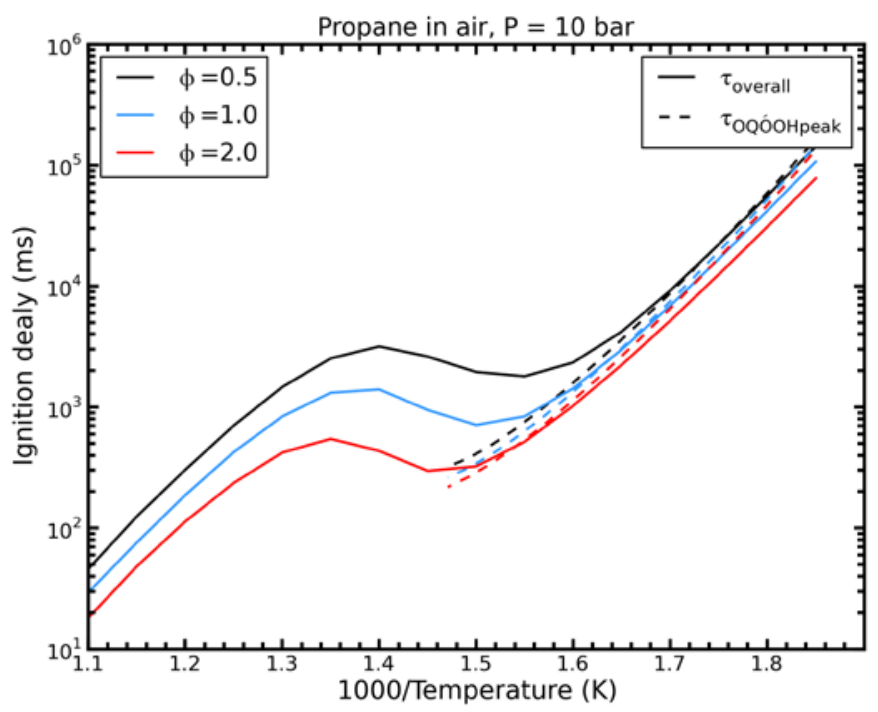

Figure 20: Comparison of the simulated adiabatic isochoric overall ignition delay with the predicted first-stage ignition delay for various equivalence ratios of propane in air. All simulations are for $P_{0}=10$ bar. The overall ignition delay (solid line) is obtained from the full model simulations, while the predicted first-stage ignition delay (dashed line) is obtained using equation (41).

Figure 21 provides the comparison of first-stage ignition delay for propane under varying pressure for $\varphi=1$. The first-stage ignition delay is a function of pressure (or oxygen concentration) as the temperature is increased ( $\mathrm{T}>650 \mathrm{~K})$. 


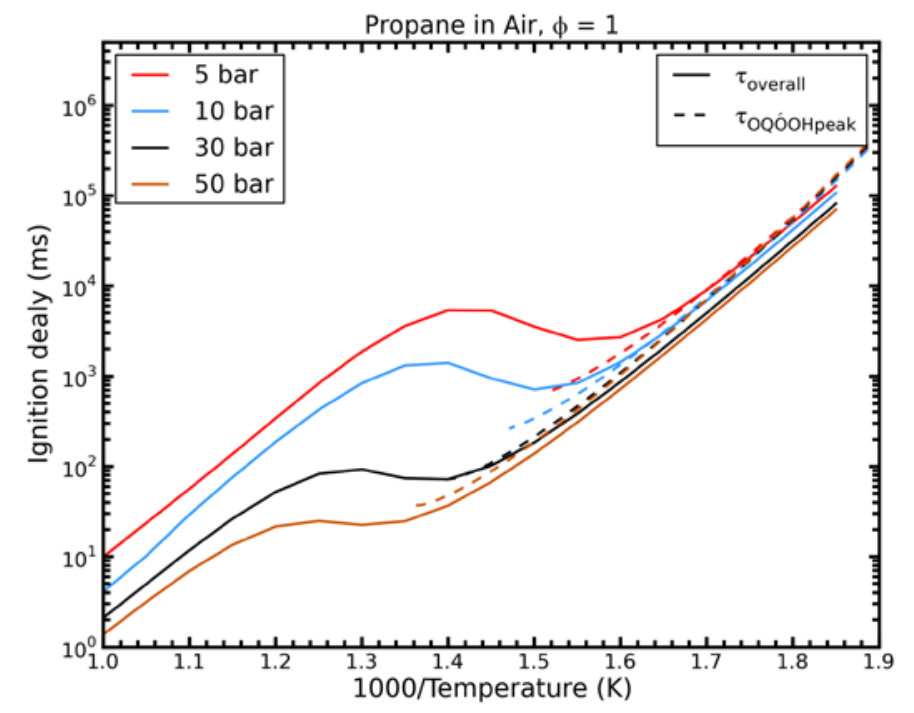

Figure 21: Comparison of the simulated adiabatic isochoric overall ignition delay with the predicted first-stage ignition delays for various pressures. All simulation are for stoichometric mixture of of propane in air. The overall ignition delay (solid line) is obtained from the full model simulations, while the predicted first-stage ignition delay (dashed line) is obtained using equation (41). 
Table 6: Comparison of important parameters used in predicting first-stage ignition delay for propane under varying $T_{0}$, $P_{0}$ and equivalence ratio.

\begin{tabular}{|c|c|c|c|c|}
\hline \multirow[b]{2}{*}{$\varphi=1$} & \multicolumn{2}{|c|}{$T_{0}=600 \mathrm{~K}$} & \multicolumn{2}{|c|}{$T_{0}=650 \mathrm{~K}$} \\
\hline & $P_{0}=10 \mathrm{bar}$ & $P_{0}=50 \mathrm{bar}$ & $P_{0}=10 \mathrm{bar}$ & $P_{0}=50 \mathrm{bar}$ \\
\hline$\alpha\left(\mathrm{T}_{0}\right)$ & 0.5 & 0.5 & 0.5 & 0.5 \\
\hline$\beta\left(\mathrm{T}_{0}\right)$ & 0.94 & 0.95 & 0.85 & 0.9 \\
\hline$\theta\left(\mathrm{T}_{0}\right)$ & 0.75 & 0.93 & 0.46 & 0.8 \\
\hline$\lambda_{1 A}\left(\mathrm{~T}_{0}\right)\left(\mathrm{s}^{-1}\right)$ & 8.5 & 13.1 & 55.4 & 102.9 \\
\hline$\lambda_{1 B}\left(\mathrm{~T}_{0}\right)\left(\mathrm{s}^{-1}\right)$ & 3.0 & 3.2 & 25.3 & 37.5 \\
\hline$\tau_{\text {stage-1A }}(\mathrm{s})$ & 1.2 & 0.7 & 0.2 & 0.1 \\
\hline$\tau_{\mathrm{OQ}^{\prime} \text { OOHpeak }}(\mathrm{s})$ & 3.2 & 1.8 & 0.4 & 0.2 \\
\hline \multirow[t]{2}{*}{$T_{\text {stage-1,max }}(\mathrm{K})$} & 690 & 760 & 690 & 760 \\
\hline & \multicolumn{2}{|c|}{$T_{0}=600 \mathrm{~K}$} & \multicolumn{2}{|c|}{$T_{0}=650 \mathrm{~K}$} \\
\hline$\varphi=0.5$ & $P_{0}=10 \mathrm{bar}$ & $P_{0}=50 \mathrm{bar}$ & $P_{0}=10 \mathrm{bar}$ & $P_{0}=50 \mathrm{bar}$ \\
\hline$\alpha\left(\mathrm{T}_{0}\right)$ & 0.5 & 0.5 & 0.5 & 0.5 \\
\hline$\beta\left(\mathrm{T}_{0}\right)$ & 0.94 & 0.95 & 0.85 & 0.9 \\
\hline$\theta\left(\mathrm{T}_{0}\right)$ & 0.75 & 0.93 & 0.46 & 0.8 \\
\hline$\lambda_{1 A}\left(\mathrm{~T}_{0}\right)\left(\mathrm{s}^{-1}\right)$ & 7.0 & 11.4 & 46.1 & 87.3 \\
\hline$\lambda_{1 B}\left(\mathrm{~T}_{0}\right)\left(\mathrm{s}^{-1}\right)$ & 3.0 & 3.2 & 25.5 & 37.6 \\
\hline$\tau_{\text {stage-1A }}(s)$ & 1.5 & 0.8 & 0.24 & 0.11 \\
\hline$\tau_{\mathrm{OQ}^{\prime} \mathrm{OOHpeak}}(\mathrm{s})$ & 4.0 & 2.1 & 0.51 & 0.25 \\
\hline$T_{\text {stage-1,max }}(\mathrm{K})$ & 690 & 760 & 690 & 760 \\
\hline
\end{tabular}




\subsubsection{First-stage ignition delay under isothermal conditions for propane}

Under isothermal conditions, the criticality of the system will be completely determined by the concentrations of $\mathrm{CH}_{2} \mathrm{O}$ and $\mathrm{HO}_{2}$. Substituting (33) and (34) in (30) and solving for the OQ'OOH concentration yields:

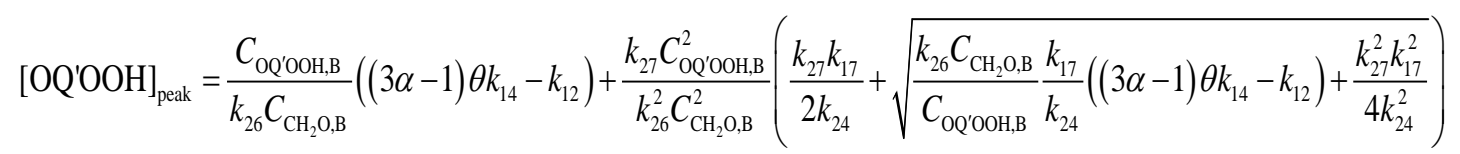

The first-stage ignition delay under isothermal conditions is then approximated by:

$$
\tau_{\mathrm{OQ} \text { OOHpeak }} \approx \frac{1}{\lambda_{\mathrm{IB}}\left(T_{0}\right)} \ln \left(\frac{\left[\mathrm{OQ}^{\prime} \mathrm{OOH}\right]_{\mathrm{peak}}}{\mathrm{C}_{\mathrm{OQ} \mathrm{OOH}_{\mathrm{B}}}}\right)+\tau_{\text {stage-1A }}
$$

where $\lambda_{1 \mathrm{~B}}\left(\mathrm{~T}_{0}\right)$ is the rise rate at start of stage-1B. Figure 22 gives a comparison between various estimates for $\tau_{\mathrm{OQ}^{\prime} \mathrm{OOHpeak}}$ obtained from 1) the time at which OQ'OOH peaks in the full model simulation, 2) the time at which the simulated $\mathrm{OH}$ multiplication factor is equal to 1 , where $f_{\mathrm{OH}}$ is defined as:

$$
f_{\mathrm{OH}}=3 \alpha\left(1+\frac{\sum \mathrm{k}_{\mathrm{ROOH} \rightarrow \mathrm{RO}+\mathrm{OH}}[\mathrm{ROOH}]}{3\left(\mathrm{k}_{\mathrm{O}_{2} \mathrm{QOOH} \rightarrow \mathrm{OQ} \mathrm{OOH}+\mathrm{OH}}\left[\mathrm{O}_{2} \mathrm{QOOH}\right]\right)}\right) \beta
$$

3) the time when the system becomes subcritical using the time predicted by equation (S 68). The predictions are within a factor of 2 for the entire low temperature regime and the accuracy increases as we approach the negative temperature coefficient (NTC) region. 


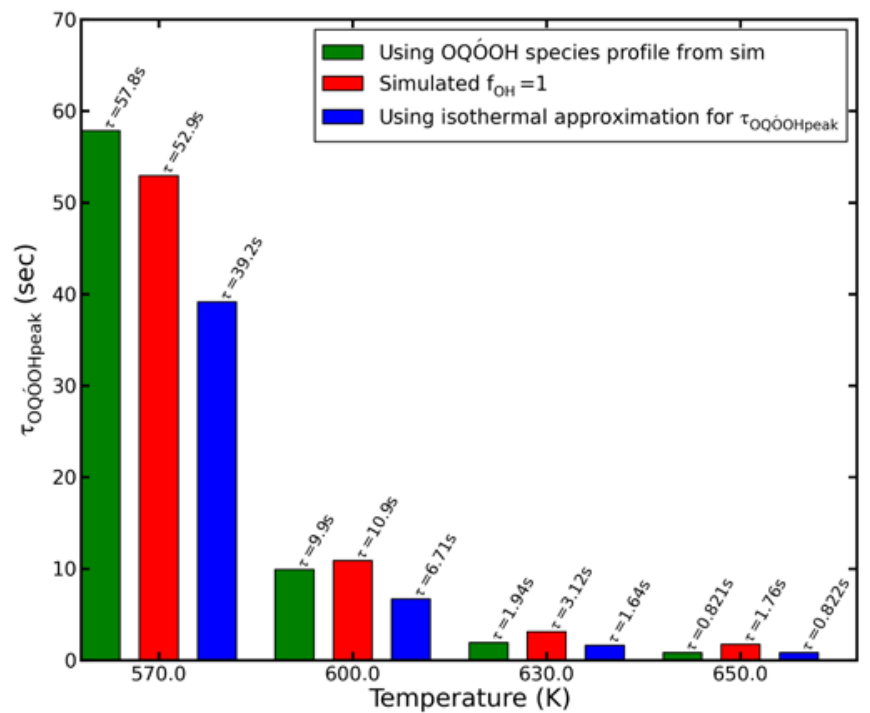

Figure 22: Comparison of the $\tau_{\mathrm{OQ}^{\prime} \mathrm{OOHpeak}}$ obtained from 1 ) the OQ'OOH peak computed numerically from the full model, 2) the time at which criterion set by equation (30) is met using reaction fluxes obtained from full-model simulations, 3) the time predicted by equation (S 68), all for an isothermal isochoric simulation of a stoichiometric mixture of propane and air. 


\section{References}

1. A. Yates, C. Viljoen, A. Swarts, SAE Technical Paper 2004-01-2017 (2004).

2. G. Kalaghatgi, Fuel/Engine Interactions, SAE International, 2013.

3. M. Mehl, W. J. Pitz, C. K. Westbrook, H. J. Curran, P Combust Inst 33 (2011) 193-200.

4. M. Yao, Z. Zheng, H. Liu, Progress in Energy and Combustion Science 35 (5) (2009) 398-437.

5. $\quad$ S. L. Kokjohn, R. D. Reitz, Int J Engine Res 14 (5) (2013) 452-468.

6. C. Gibson, P. Gray, J. F. Griffiths, S. M. Hasko, Symposium (International) on Combustion 20 (1) (1985) 101-109.

7. J. C. Keck, H. Hu, Symposium (International) on Combustion 21 (1) (1988) 521-529.

8. J. F. Griffiths, Progress in Energy and Combustion Science 21 (1) (1995) 25-107.

9. C. K. Westbrook, P Combust Inst 28 (2000) 1563-1577.

10. N. Peters, G. Paczko, R. Seiser, K. Seshadri, Combustion and Flame 128 (1-2) (2002) 38-59.

11. A. Kazakov, M. Chaos, Z. W. Zhao, F. L. Dryer, J Phys Chem A 110 (21) (2006) 70037009.

12. P. Zhao, C. K. Law, Combustion and Flame 160 (11) (2013) 2352-2358.

13. J. Beeckmann, L. Cai, A. Berens, N. Peters, H. Pitsch, P Combust Inst 35 (1) (2015) 275281.

14. H. J. Curran, P. Gaffuri, W. J. Pitz, C. K. Westbrook, Combustion and Flame 114 (1-2) (1998) 149-177.

15. C. S. Yoo, T. F. Lu, J. H. Chen, C. K. Law, Combustion and Flame 158 (9) (2011) 17271741.

16. G. E. Quelch, M. M. Gallo, H. F. Schaefer, J Am Chem Soc 114 (21) (1992) 8239-8247.

17. J. C. Rienstra-Kiracofe, W. D. Allen, H. F. Schaefer, J Phys Chem A 104 (44) (2000) 9823-9840.

18. I. S. Ignatyev, Y. M. Xie, W. D. Allen, H. F. Schaefer, J Chem Phys 107 (1) (1997) 141155.

19. I. R. Slagle, Q. Feng, D. Gutman, J Phys Chem-Us 88 (16) (1984) 3648-3653.

20. R. K. Jensen, S. Korcek, L. R. Mahoney, M. Zinbo, J Am Chem Soc 101 (25) (1979) 7574-7584. 
21. R. K. Jensen, S. Korcek, L. R. Mahoney, M. Zinbo, J Am Chem Soc 103 (7) (1981) 1742-1749.

22. R. K. Jensen, M. Zinbo, S. Korcek, J Chromatogr Sci 21 (9) (1983) 394-397.

23. R. K. Jensen, S. Korcek, M. Zinbo, M. D. Johnson, Int J Chem Kinet 22 (10) (1990) 1095-1107.

24. A. Jalan, I. M. Alecu, R. Meana-Paneda, J. Aguilera-Iparraguirre, K. R. Yang, S. S. Merchant, D. G. Truhlar, W. H. Green, J Am Chem Soc 135 (30) (2013) 11100-11114.

25. C. F. Goldsmith, M. P. Burke, Y. Georgievskii, S. J. Klippenstein, P Combust Inst 35 (1) (2015) 283-290.

26. D. R. Glowacki, J. Lockhart, M. A. Blitz, S. J. Klippenstein, M. J. Pilling, S. H. Robertson, P. W. Seakins, Science 337 (6098) (2012) 1066-1069.

27. M. P. Burke, C. F. Goldsmith, Y. Georgievskii, S. J. Klippenstein, P Combust Inst 35 (1) (2015) 205-213.

28. M. Cord, B. Sirjean, R. Fournet, A. Tomlin, M. Ruiz-Lopez, F. Battin-Leclerc, J Phys Chem A 116 (24) (2012) 6142-6158.

29. C. F. Goldsmith, G. R. Magoon, W. H. Green, J Phys Chem A 116 (36) (2012) 90339057.

30. C. F. Goldsmith, W. H. Green, S. J. Klippenstein, J Phys Chem A 116 (13) (2012) 33253346.

31. A. Miyoshi, J Phys Chem A 115 (15) (2011) 3301-3325.

32. A. Miyoshi, Int J Chem Kinet 44 (1) (2012) 59-74.

33. S. M. Villano, H. H. Carstensen, A. M. Dean, J Phys Chem A 117 (30) (2013) 64586473.

34. S. M. Villano, L. K. Huynh, H.-H. Carstensen, A. M. Dean, The Journal of Physical Chemistry A 115 (46) (2011) 13425-13442.

35. S. M. Villano, L. K. Huynh, H.-H. Carstensen, A. M. Dean, The Journal of Physical Chemistry A 116 (21) (2012) 5068-5089.

36. F. Zhang, T. S. Dibble, J Phys Chem A 115 (5) (2011) 655-663.

37. L. K. Huynh, H. H. Carstensen, A. M. Dean, J Phys Chem A 114 (24) (2010) 6594-6607.

38. J. W. Allen, C. F. Goldsmith, W. H. Green, Phys Chem Chem Phys 14 (3) (2012) 11311155.

39. Y. Georgievskii, J. A. Miller, M. P. Burke, S. J. Klippenstein, J Phys Chem A 117 (46) (2013) 12146-54.

40. $\quad$ S. J. Klippenstein, J. A. Miller, J Phys Chem A 106 (40) (2002) 9267-9277.

41. A. W. Jasper, K. M. Pelzer, J. A. Miller, E. Kamarchik, L. B. Harding, S. J. Klippenstein, Science 346 (6214) (2014) 1212-1215. 
42. S. M. Sarathy, C. K. Westbrook, M. Mehl, W. J. Pitz, C. Togbe, P. Dagaut, H. Wang, M. A. Oehlschlaeger, U. Niemann, K. Seshadri, P. S. Veloo, C. Ji, F. N. Egolfopoulos, T. Lu, Combustion and Flame 158 (12) (2011) 2338-2357.

43. M. Mehl, J. Y. Chen, W. J. Pitz, S. M. Sarathy, C. K. Westbrook, Energ Fuel 25 (11) (2011) 5215-5223.

44. S. M. Sarathy, G. Kukkadapu, M. Mehl, W. Wang, T. Javed, S. Park, M. A. Oehlschlaeger, A. Farooq, W. J. Pitz, C.-J. Sung, P Combust Inst 35 (1) (2015) 249-257.

45. M. F. Campbell, S. Wang, C. S. Goldenstein, R. M. Spearrin, A. M. Tulgestke, L. T. Zaczek, D. F. Davidson, R. K. Hanson, P Combust Inst 35 (1) (2015) 231-239.

46. D. Healy, H. J. Curran, J. M. Simmie, D. M. Kalitan, C. M. Zinner, A. B. Barrett, E. L. Petersen, G. Bourque, Combustion and Flame 155 (3) (2008) 441-448.

47. K. J. Hughes, J. F. Griffiths, M. Fairweather, A. S. Tomlin, Phys Chem Chem Phys 8 (27) (2006) 3197-3210.

48. C. F. Goldsmith, A. S. Tomlin, S. J. Klippenstein, P Combust Inst 34 (2013) 177-185.

49. D. M. A. Karwat, S. W. Wagnon, M. S. Wooldridge, C. K. Westbrook, Combustion and Flame 160 (12) (2013) 2693-2706.

50. G. Mittal, C. J. Sung, Combustion and Flame 156 (9) (2009) 1852-1855.

51. G. Mittal, M. Chaos, C. J. Sung, F. L. Dryer, Fuel Process Technol 89 (12) (2008) 12441254.

52. J. Zádor, C. A. Taatjes, R. X. Fernandes, Progress in Energy and Combustion Science 37 (4) (2011) 371-421.

53. J. Pfaendtner, L. J. Broadbelt, Ind Eng Chem Res 47 (9) (2008) 2897-2904.

54. J. D. DeSain, S. J. Klippenstein, J. A. Miller, C. A. Taatjes, J Phys Chem A 107 (22) (2003) 4415-4427.

55. J. Li, Z. Zhao, A. Kazakov, F. L. Dryer, Int J Chem Kinet 36 (10) (2004) 566-575.

56. S. Dooley, M. P. Burke, M. Chaos, Y. Stein, F. L. Dryer, V. P. Zhukov, O. Finch, J. M. Simmie, H. J. Curran, Int J Chem Kinet 42 (9) (2010) 527-549.

57. J. Li, Z. W. Zhao, A. Kazakov, M. Chaos, F. L. Dryer, J. J. Scire, Int J Chem Kinet 39 (3) (2007) 109-136.

58. Z. Zhao, M. Chaos, A. Kazakov, F. L. Dryer, Int J Chem Kinet 40 (1) (2008) 1-18.

59. D. Healy, N. S. Donato, C. J. Aul, E. L. Petersen, C. M. Zinner, G. Bourque, H. J. Curran, Combustion and Flame 157 (8) (2010) 1526-1539.

60. E. M. Fisher, W. J. Pitz, H. J. Curran, C. K. Westbrook, P Combust Inst 28 (2000) 15791586.

61. CHEMKIN-Pro ver 5, Reaction Design Inc, San Diego, CA, 2011.

62. D. F. Davidson, R. K. Hanson, Int J Chem Kinet 36 (9) (2004) 510-523. 
63. M. Chaos, F. L. Dryer, Int J Chem Kinet 42 (3) (2010) 143-150.

64. H. Ando, K. Kuwahara, Int J Engine Res 10 (6) (2009) 389-398.

65. F. Battin-Leclerc, F. Buda, M. Fairweather, P. A. Glaude, J. F. Griffiths, K. J. Hughes, R. Porter, A. S. Tomlin, Proceedings of the European Combustion Meeting (2005).

66. M. Scott, R. W. Walker, Combustion and Flame 129 (4) (2002) 365-377.

67. D. L. Baulch, C. T. Bowman, C. J. Cobos, R. A. Cox, T. Just, J. A. Kerr, M. J. Pilling, D. Stocker, J. Troe, W. Tsang, R. W. Walker, J. Warnatz, J Phys Chem Ref Data 34 (3) (2005) 7571397.

68. W. Tsang, J Phys Chem Ref Data 16 (3) (1987) 471-508.

69. Y. Hidaka, T. Taniguchi, H. Tanaka, T. Kamesawa, K. Inami, H. Kawano, Combustion and Flame 92 (4) (1993) 365-376.

70. $\quad$ R. S. Timonen, E. Ratajczak, D. Gutman, J Phys Chem-Us 92 (3) (1988) 651-655.

71. M. P. Burke, M. Chaos, Y. Ju, F. L. Dryer, S. J. Klippenstein, Int J Chem Kinet (2012).

72. $\quad$ M. P. B. Musculus, P. C. Miles, L. M. Pickett, Progress in Energy and Combustion Science 39 (2-3) (2013) 246-283.

73. NIST Chemistry webbook, Standard Reference Database 69. http://webbook.nist.gov/ (2013).

74. S. M. Gallagher, H. J. Curran, W. K. Metcalfe, D. Healy, J. M. Simmie, G. Bourque, Combustion and Flame 153 (1-2) (2008) 316-333. 


\section{Tables}

Table 1: Simplified reaction mechanism for low-temperature propane ignition.

\begin{tabular}{|c|c|c|c|}
\hline Label & Reaction & Rate coefficient & Reference \\
\hline $\mathrm{R} 1$ & $\mathrm{RH}+\mathrm{O}_{2} \rightarrow \mathrm{nR}+\mathrm{HO}_{2}$ & $\mathrm{k}_{1}$ & [46] \\
\hline $\mathrm{R} 2$ & $\mathrm{RH}+\mathrm{O}_{2} \rightarrow \mathrm{iR}+\mathrm{HO}_{2}$ & $\mathrm{k}_{2}$ & {$[46]$} \\
\hline R3 & $\mathrm{RH}+\mathrm{OH} \rightarrow \mathrm{nR}+\mathrm{H}_{2} \mathrm{O}$ & $\mathrm{k}_{3}$ & [46] \\
\hline $\mathrm{R} 4$ & $\mathrm{RH}+\mathrm{OH} \rightarrow \mathrm{iR}+\mathrm{H}_{2} \mathrm{O}$ & $\mathrm{k}_{4}$ & [46] \\
\hline R5 & $\mathrm{RH}+\mathrm{HO}_{2} \rightarrow \mathrm{nR}+\mathrm{H}_{2} \mathrm{O}_{2}$ & $\mathrm{k}_{5}$ & [66] \\
\hline R6 & $\mathrm{RH}+\mathrm{HO}_{2} \rightarrow \mathrm{iR}+\mathrm{H}_{2} \mathrm{O}_{2}$ & $\mathrm{k}_{6}$ & {$[66]$} \\
\hline R7 & $\mathrm{nR}+\mathrm{O}_{2} \rightleftharpoons \mathrm{nRO}_{2}$ & $\mathrm{k}_{7}, \mathrm{k}_{-7}$ & [30] \\
\hline R8 & $\mathrm{iR}+\mathrm{O}_{2} \rightleftharpoons \mathrm{iRO}_{2}$ & $\mathrm{k}_{8}, \mathrm{k}_{-8}$ & [30] \\
\hline R9 & $\mathrm{nR}+\mathrm{O}_{2} \rightleftharpoons \mathrm{QOOH}$ & $\mathrm{k}_{9}, \mathrm{k}_{-9}$ & [30] \\
\hline R10 & $\mathrm{nR}+\mathrm{O}_{2} \rightarrow \mathrm{C}_{3} \mathrm{H}_{6}+\mathrm{HO}_{2}$ & $\mathrm{k}_{10}$ & [30] \\
\hline R11 & $\mathrm{iR}+\mathrm{O}_{2} \rightarrow \mathrm{C}_{3} \mathrm{H}_{6}+\mathrm{HO}_{2}$ & $\mathrm{k}_{11}$ & {$[30]$} \\
\hline R12 & $\mathrm{nRO}_{2} \rightarrow \mathrm{C}_{3} \mathrm{H}_{6}+\mathrm{HO}_{2}$ & $\mathrm{k}_{12}$ & {$[30]$} \\
\hline $\mathrm{R} 13$ & $\mathrm{iRO}_{2} \rightarrow \mathrm{C}_{3} \mathrm{H}_{6}+\mathrm{HO}_{2}$ & $\mathrm{k}_{13}$ & [30] \\
\hline R14 & $\mathrm{nRO}_{2} \rightleftharpoons \mathrm{QOOH}$ & $\mathrm{k}_{14}, \mathrm{k}_{-14}$ & {$[30]$} \\
\hline R15 & $\mathrm{QOOH}+\mathrm{O}_{2} \rightleftharpoons \mathrm{O}_{2} \mathrm{QOOH}$ & $\mathrm{k}_{15}, \mathrm{k}_{-15}$ & {$[30]$} \\
\hline R16 & $\mathrm{O}_{2} \mathrm{QOOH} \rightarrow \mathrm{OQ}^{\prime} \mathrm{OOH}+\mathrm{OH}$ & $\mathrm{k}_{16}$ & [30] \\
\hline R17 & $\mathrm{OQ}^{\prime} \mathrm{OOH} \rightarrow \mathrm{OQ}^{\prime} \mathrm{O}+\mathrm{OH}$ & $\mathrm{k}_{17}$ & [30] \\
\hline R18 & $\mathrm{OQ}^{\prime} \mathrm{O} \rightarrow \mathrm{CH}_{2} \mathrm{CHO}+\mathrm{CH}_{2} \mathrm{O}$ & $\mathrm{k}_{18}$ & [30] \\
\hline R19 & $\mathrm{CH}_{2} \mathrm{CHO}+\mathrm{O}_{2} \rightarrow \mathrm{CH}_{2} \mathrm{O}+\mathrm{CO}+\mathrm{OH}$ & $\mathrm{k}_{19}$ & [67] \\
\hline R20 & $\mathrm{CH}_{2} \mathrm{O}+\mathrm{OH} \rightarrow \mathrm{HCO}+\mathrm{H}_{2} \mathrm{O}$ & $\mathrm{k}_{20}$ & [68] \\
\hline R21 & $\mathrm{CH}_{2} \mathrm{O}+\mathrm{O}_{2} \rightarrow \mathrm{HCO}+\mathrm{HO}_{2}$ & $\mathrm{k}_{21}$ & [69] \\
\hline
\end{tabular}




\begin{tabular}{llll}
$\mathrm{R} 22$ & $\mathrm{HCO}+\mathrm{O}_{2} \rightarrow \mathrm{CO}+\mathrm{HO}_{2}$ & $\mathrm{k}_{22}$ & {$[70]$} \\
$\mathrm{R} 23$ & $\mathrm{H}_{2} \mathrm{O}_{2}+\mathrm{OH} \rightarrow \mathrm{H}_{2} \mathrm{O}+\mathrm{HO}_{2}$ & $\mathrm{k}_{23}$ & {$[71]$} \\
$\mathrm{R} 24$ & $\mathrm{HO}_{2}+\mathrm{HO}_{2} \rightarrow \mathrm{H}_{2} \mathrm{O}_{2}+\mathrm{O}_{2}$ & $\mathrm{k}_{24}$ & {$[71]$} \\
$\mathrm{R} 25$ & $\mathrm{H}_{2} \mathrm{O}_{2} \rightarrow 2 \mathrm{OH}$ & $\mathrm{k}_{25}$ & {$[71]$} \\
$\mathrm{R} 26$ & $\mathrm{nRO}_{2}+\mathrm{CH}_{2} \mathrm{O} \rightarrow \mathrm{nROOH}+\mathrm{HCO}$ & $\mathrm{k}_{26}$ & {$[46]$} \\
$\mathrm{R} 27$ & $\mathrm{nRO}_{2}+\mathrm{HO}_{2} \rightarrow \mathrm{nROOH}+\mathrm{O}_{2}$ & $\mathrm{k}_{27}$ & {$[46]$} \\
\hline
\end{tabular}

Table 2: Arrhenius rate coefficient parameters for reactions required to calculate the first stage ignition delay using equation (51). The parameters come from the 10 atm PLOG fits for $n$-propyl pathway from Goldsmith et al. [30], from the detailed model of Healey et al. [59] for propane $+\mathrm{OH}$ and butane and the detailed model by Mehl et al. [3] for pentane and heptane.

\begin{tabular}{|c|c|c|c|c|}
\hline Reaction & Fuel & $\begin{array}{c}\text { A } \\
\left(\mathrm{cm}^{\left.3 / \mathrm{mol}^{-} \mathrm{s}\right)}\right. \\
\text { or s }^{-1}\end{array}$ & $\mathbf{n}$ & $\begin{array}{c}E_{a} \\
(\mathrm{kcal} / \mathrm{mol})\end{array}$ \\
\hline \multirow[t]{4}{*}{$\mathrm{RH}+\mathrm{OH} \rightarrow \mathrm{R}+\mathrm{H}_{2} \mathrm{O}$} & Heptane & $4.9 \mathrm{E}+06$ & 2.0 & -0.59 \\
\hline & Pentane & $9.3 \mathrm{E}+07$ & 1.61 & -0.035 \\
\hline & Butane & $9.3 \mathrm{E}+07$ & 1.61 & -0.035 \\
\hline & Propane & $1.0 \mathrm{E}+10$ & 0.97 & 1.59 \\
\hline \multirow[t]{4}{*}{$\mathrm{RO}_{2} \rightleftharpoons \mathrm{QOOH}^{\mathrm{a}}$} & Heptane & $2.5 \mathrm{E}+10$ & 0.0 & 20.5 \\
\hline & Pentane & $2.5 \mathrm{E}+10$ & 0.0 & 20.8 \\
\hline & Butane & $3.8 \mathrm{E}+10$ & 0.0 & 24.4 \\
\hline & Propane & 1.01 & 3.38 & 18.9 \\
\hline \multirow[t]{3}{*}{$\mathrm{RO}_{2} \rightarrow$ alkene $+\mathrm{HO}_{2}$} & Heptane & $20.0 \mathrm{E}+42$ & -9.4 & 42.5 \\
\hline & Pentane & $20.0 \mathrm{E}+42$ & -9.4 & 42.5 \\
\hline & Butane & $20.0 \mathrm{E}+42$ & -9.4 & 42.5 \\
\hline
\end{tabular}




\begin{tabular}{|c|c|c|c|c|}
\hline & Propane & $2.6 \mathrm{E}+16$ & -1.2 & 32.8 \\
\hline \multirow[t]{4}{*}{$\mathrm{QOOH}+\mathrm{O}_{2} \rightleftharpoons \mathrm{O}_{2} \mathrm{QOOH}^{\mathrm{a}}$} & Heptane & $7.5 \mathrm{E}+12$ & 0.0 & 0.0 \\
\hline & Pentane & $7.5 \mathrm{E}+12$ & 0.0 & 0.0 \\
\hline & Butane & $4.5 \mathrm{E}+12$ & 0.0 & 0.0 \\
\hline & Propane & $2.2 \mathrm{E}+27$ & -4.8 & 4.0 \\
\hline \multirow{4}{*}{$\mathrm{O}_{2} \mathrm{QOOH} \rightarrow \mathrm{OQ}^{\prime} \mathrm{OOH}+\mathrm{OH}$} & Heptane & $1.2 \mathrm{E}+10$ & 0.0 & 17.5 \\
\hline & Pentane & $1.2 \mathrm{E}+10$ & 0.0 & 17.5 \\
\hline & Butane & $2 \mathrm{E}+11$ & 0.0 & 26.4 \\
\hline & Propane & $4.5 \mathrm{E}+11$ & -0.5 & 18.4 \\
\hline \multirow[t]{4}{*}{$\mathrm{OQ}^{\prime} \mathrm{OOH} \rightarrow \mathrm{OQ}^{\prime} \mathrm{O}+\mathrm{OH}$} & Heptane & $1.0 \mathrm{E}+16$ & 0.0 & 39.0 \\
\hline & Pentane & $1.5 \mathrm{E}+16$ & 0.0 & 42.0 \\
\hline & Butane & $1.5 \mathrm{E}+16$ & 0.0 & 41.6 \\
\hline & Propane & $5.2 \mathrm{E}+43$ & -8.7 & 51.5 \\
\hline
\end{tabular}

*Note: (a) The reverse rate coefficients were obtained from the respective thermodynamic parameters of the species and are provided in a separate file. 
Table 3: Critical temperature $\left(T_{\text {stage-1,max }}\right)$ calculated for stoichometric mixture of fuel in air. The range in $T_{\text {stage-1,max }}$ corresponds to $\gamma$ values of 0 and 1 respectively. For propane the fate of OQ'O is well understood and $\gamma=1$.

$$
T_{\text {stage-1,max }}(\mathrm{K})
$$

\begin{tabular}{cccc} 
Fuel & $P_{0}=1$ bar & $P_{0}=10$ bar & $P_{0}=50$ bar \\
\hline Propane & 650 & 690 & 760 \\
Butane & $680-710$ & $710-750$ & $740-810$ \\
Pentane & $760-800$ & $860-930$ & $930-1030$ \\
Heptane & $790-830$ & $890-950$ & $970-1070$ \\
\hline
\end{tabular}

Table 4: Overall activation energy $(\mathrm{kcal} / \mathrm{mol})$ for first stage ignition delay for different $\mathrm{n}$-alkanes for stoichometric mixture of fuel and air at $P_{0}=10$ bar.

\begin{tabular}{cccc}
\hline Fuel & $\begin{array}{c}\text { Activation } \\
\text { Energy } \\
\text { (Full model) }\end{array}$ & $\begin{array}{c}\text { Activation } \\
\text { Energy } \\
\text { Eq (56) }\end{array}$ & $\mathrm{E}_{\mathrm{a}(\mathrm{RO} \rightleftharpoons \mathrm{QOOH})}$ \\
\hline Butane & 35.0 & 32.6 & 24.4 \\
Pentane & 33.9 & 31.0 & 20.8 \\
Heptane & 28.6 & 29.3 & 20.5
\end{tabular}

*Note: The overall activation energy from the full model is obtained by linear least square fit of the simulated full model first stage ignition delay to the temperature $\left(\ln \left(\tau_{\mathrm{OQ}^{\prime} \text { OOHpeak }}\right)=\mathrm{A}+\mathrm{E} / \mathrm{RT}\right)$. The temperature range was limited to $\mathrm{T}<650 \mathrm{~K}$. 


\section{Figures}

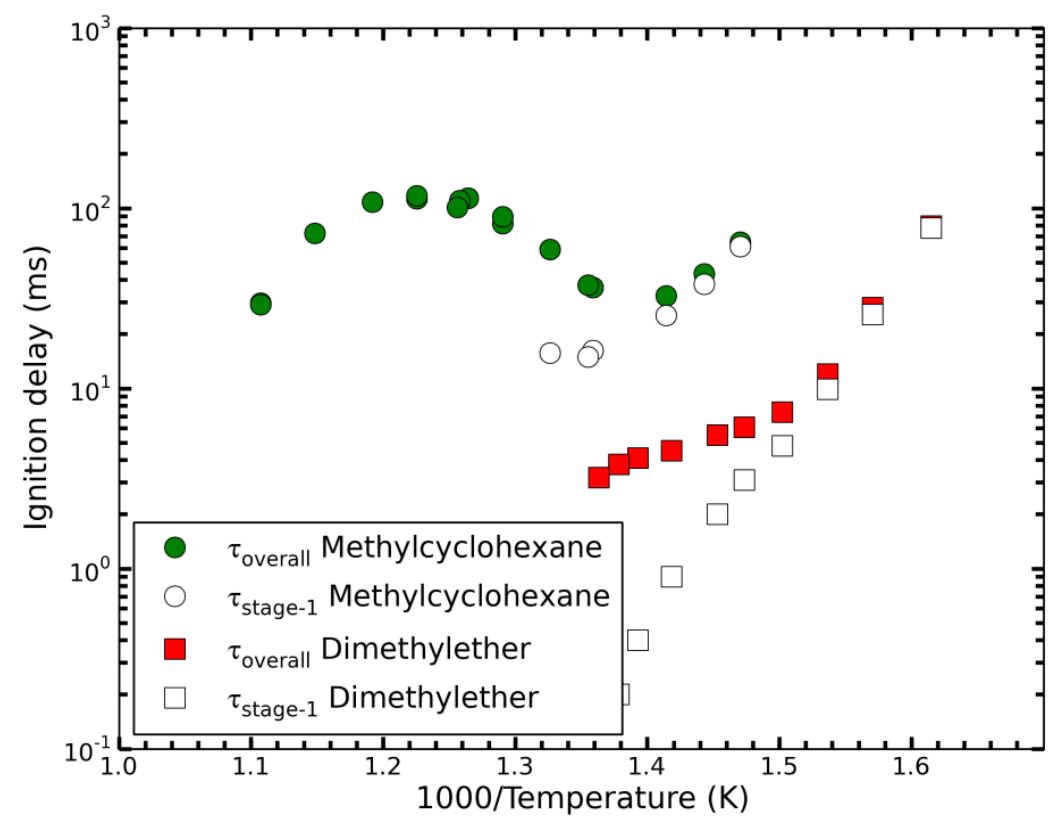

Figure 1: Experimental measured overall (filled symbols) and first-stage (open symbols) ignition delays in a rapid compression machine (RCM) for methylcyclohexane $(\mathrm{MCH})$ [50] and dimethylether (DME) [51] at $P_{0}=15$ bar, $\varphi(\mathrm{MCH})=$ 1 and $\varphi(\mathrm{DME})=0.75$. For low temperatures the measured first-stage ignition delay is almost equal to the overall measured ignition delay. For higher temperatures the later stages of ignition contribute more to the overall ignition delay. 


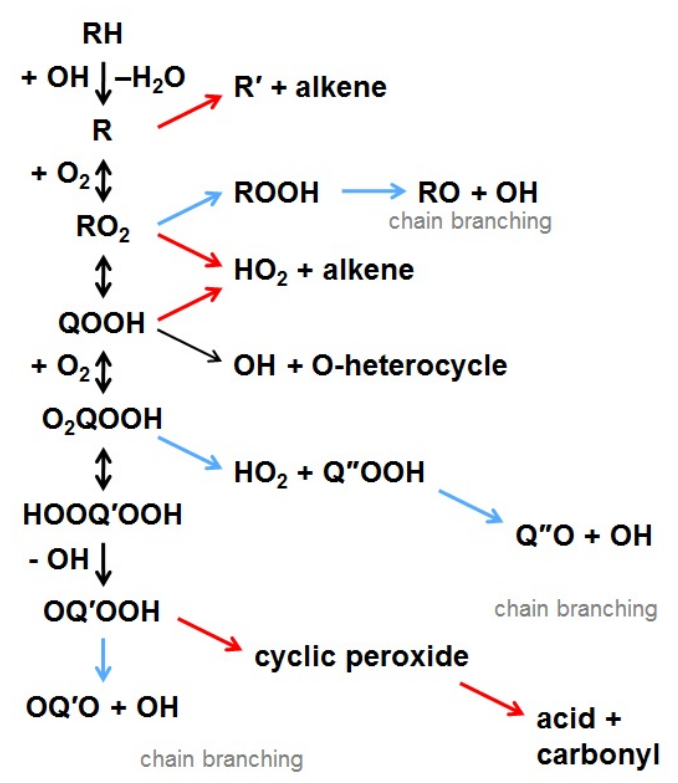

Figure 2: Schematic mechanism for the low temperature alkane oxidation and autoignition chemistry adapted from the work of Zádor et al. [52], including the Korcek reaction [24]. The pathways shown by a blue arrow lead to additional OH radicals (chain branching) while the pathways indicated by a red arrow lead to chain termination. Some of the intermediates may not live long enough to thermalize, they may not even be stationary points on the PES [30].

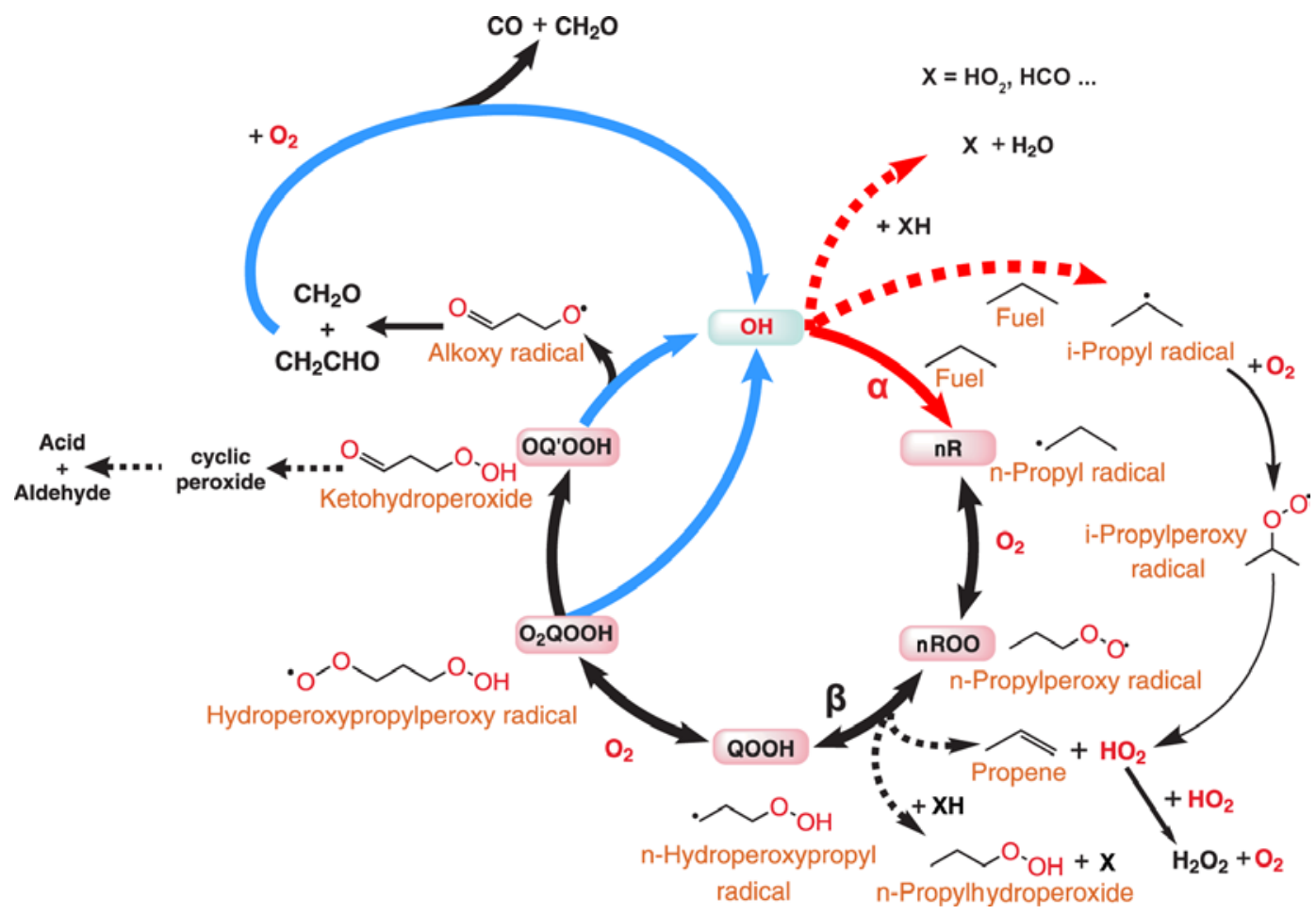

Figure 3: Schematic of major reaction pathways during the first-stage of propane ignition. Reactions shown in blue lead to formation of $\mathrm{OH}$ radicals while those in red consume $\mathrm{OH}$ radicals. The reactions shown by dotted lines divert radicals away from the main chain branching pathway and delay the first-stage ignition. During stage- $1 \mathrm{~A}, \mathrm{HO}_{2}$ radicals reacts with the fuel accelerating the chemistry, but later much of it recombines reducing the concentration of radicals. Note: For 
clarity some well-skipping pathways and reactions of $\mathrm{HO}_{2}$ are omitted from the figure.

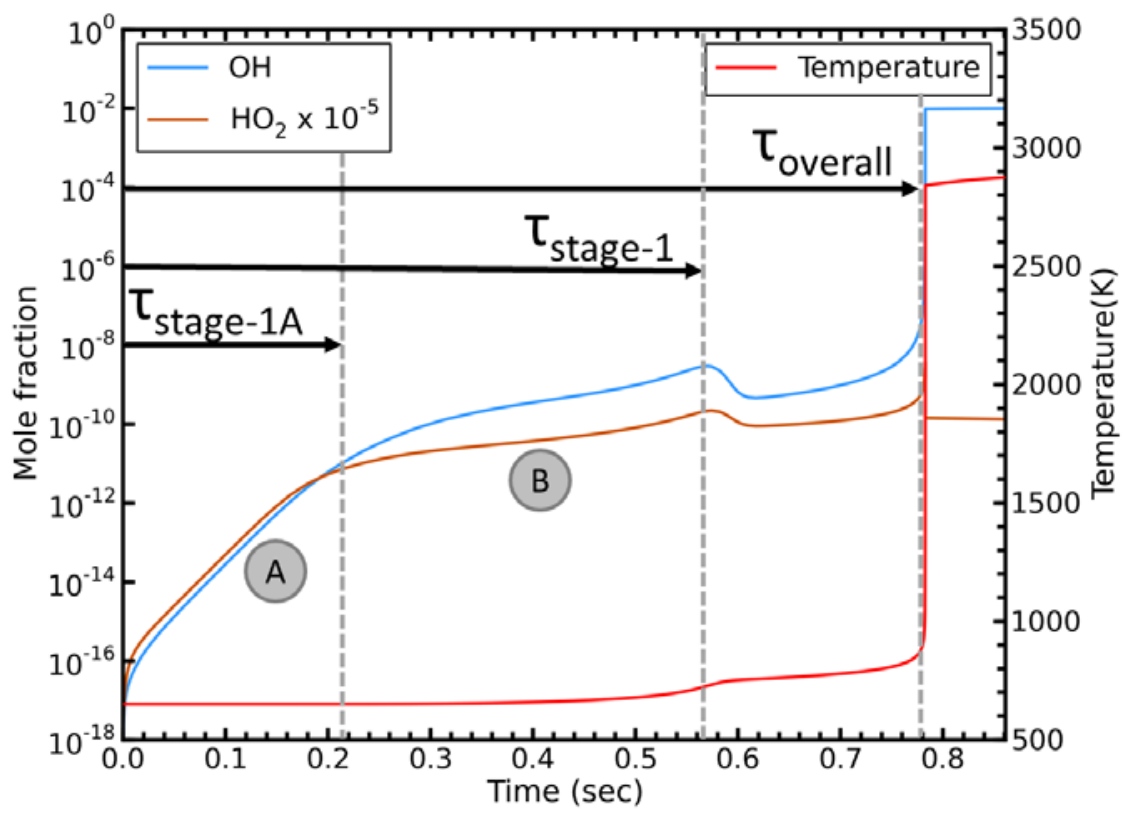

Figure 4: $\mathrm{OH}$ and $\mathrm{HO}_{2}$ mole fraction profile (on semi-log scale) and temperature profile for isochoric (constant-volume) adiabatic simulation for a stoichiometric mixture of propane and air initially at $P_{0}=10$ bar and $T_{0}=650 \mathrm{~K}$. $\tau_{\text {overall }}$ is the overall ignition delay of the fuel. $\tau_{\text {stage- } 1}$ is the first-stage ignition delay of the fuel, the time when the temperature (or pressure) of the system makes a small jump prior to the main ignition event. The first-stage ignition delay can be further divided into two stages $\mathrm{A}$ and $\mathrm{B}$ that are characterized by different time constants for the exponential rise of the $\mathrm{OH}$ concentration. $\tau_{\text {stage-1A }}$ is the time when the early exponential rise in $\mathrm{OH}$ concentration ends. 


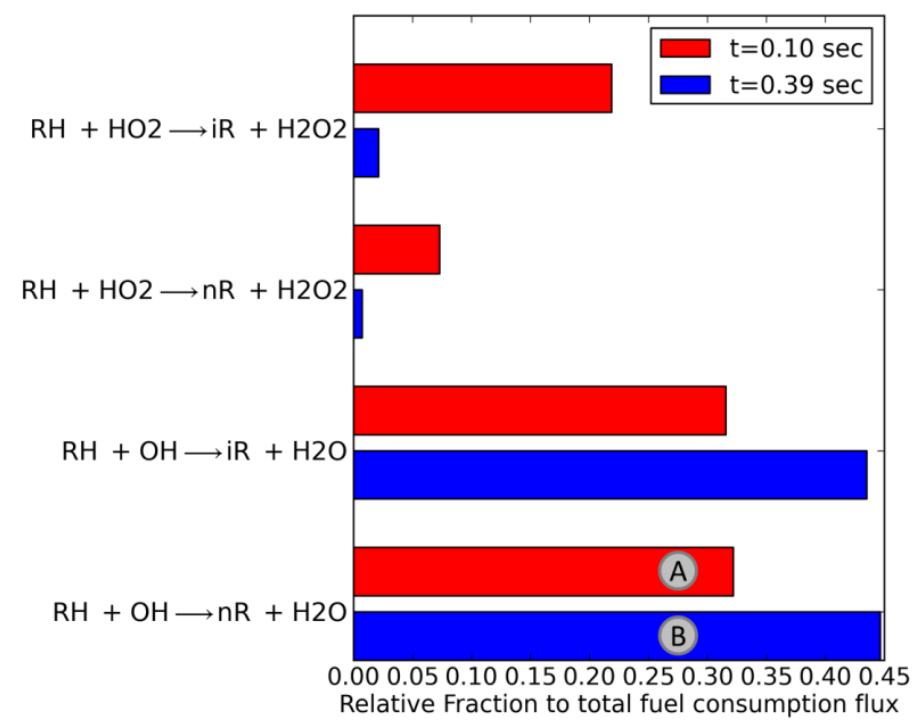

Figure 5: Fraction of propane consumed by each reaction during stage- $1 \mathrm{~A}(0.1 \mathrm{~s})$ and stage- $1 \mathrm{~B}(0.39 \mathrm{~s})$. $\mathrm{HO}_{2}$ reaction with the fuel is significant during stage-1A, but negligible during stage-1B.

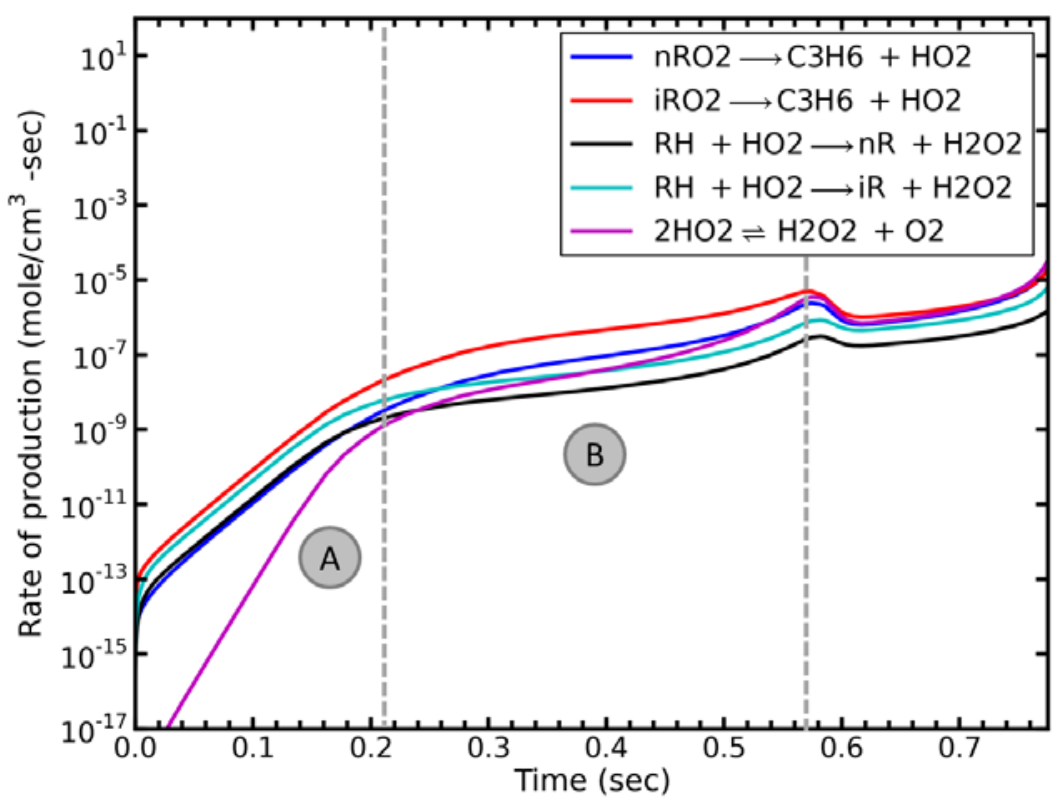

Figure 6: Magnitudes of the rates of important reactions producing or consuming $\mathrm{HO}_{2}$, for stoichiometric mixture of propane and air initially at $P_{0}=10$ bar and $T_{0}=650 \mathrm{~K}$. The transition from stage- $1 \mathrm{~A}$ to stage- $1 \mathrm{~B}$ occurs when $\mathrm{HO}_{2}$ recombination becomes comparable to other reactions. 


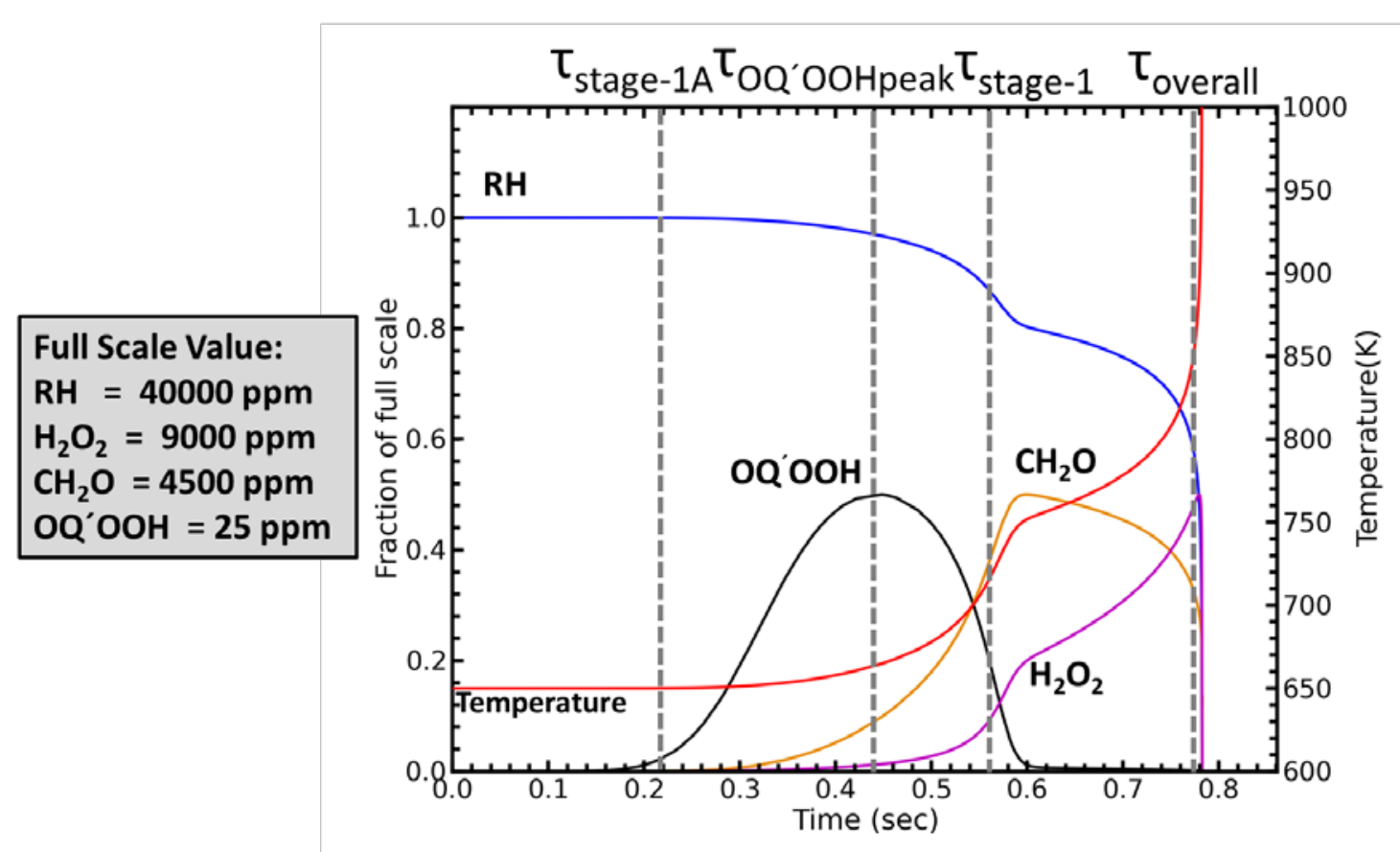

Figure 7: Evolution of key species during isochoric adiabatic reaction of stoichometric mixture of propane:air at $P_{0}=10$ bar and $T_{0}=650 \mathrm{~K}$. It should be noted that OQ'OOH peaks shortly before $\tau_{\text {stage- } 1}$. The full scale values of $\mathrm{H}_{2} \mathrm{O}_{2}, \mathrm{CH}_{2} \mathrm{O}$ and OQ'OOH were chosen to be of twice the maximum value reached in the simulation.

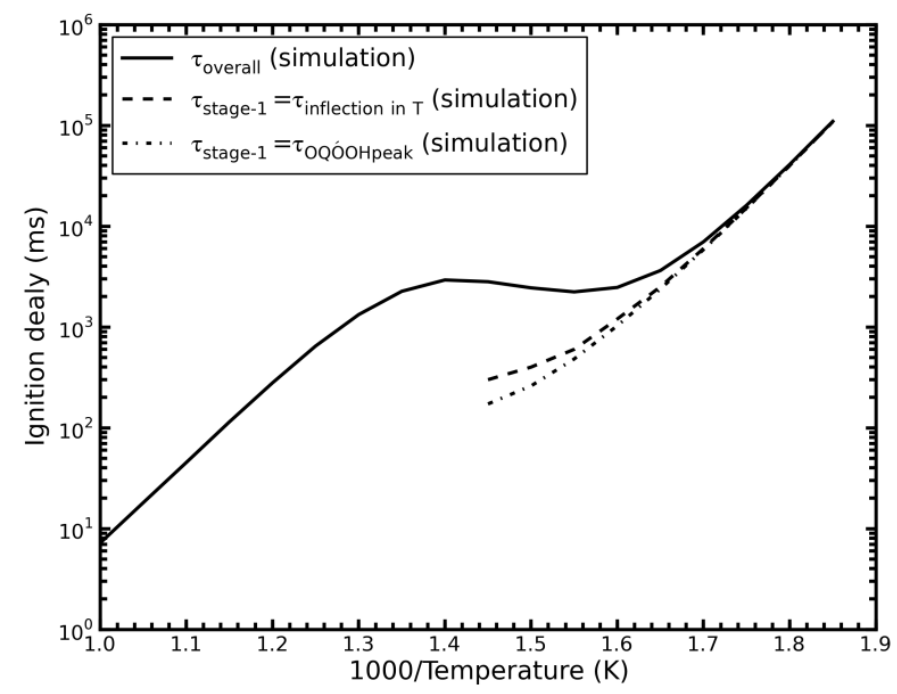

Figure 8: Arrhenius plot for adiabatic isochoric stoichometric mixture of propane in air initially at $P_{0}=10$ bar comparing

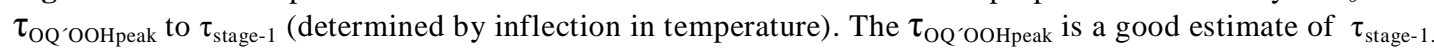



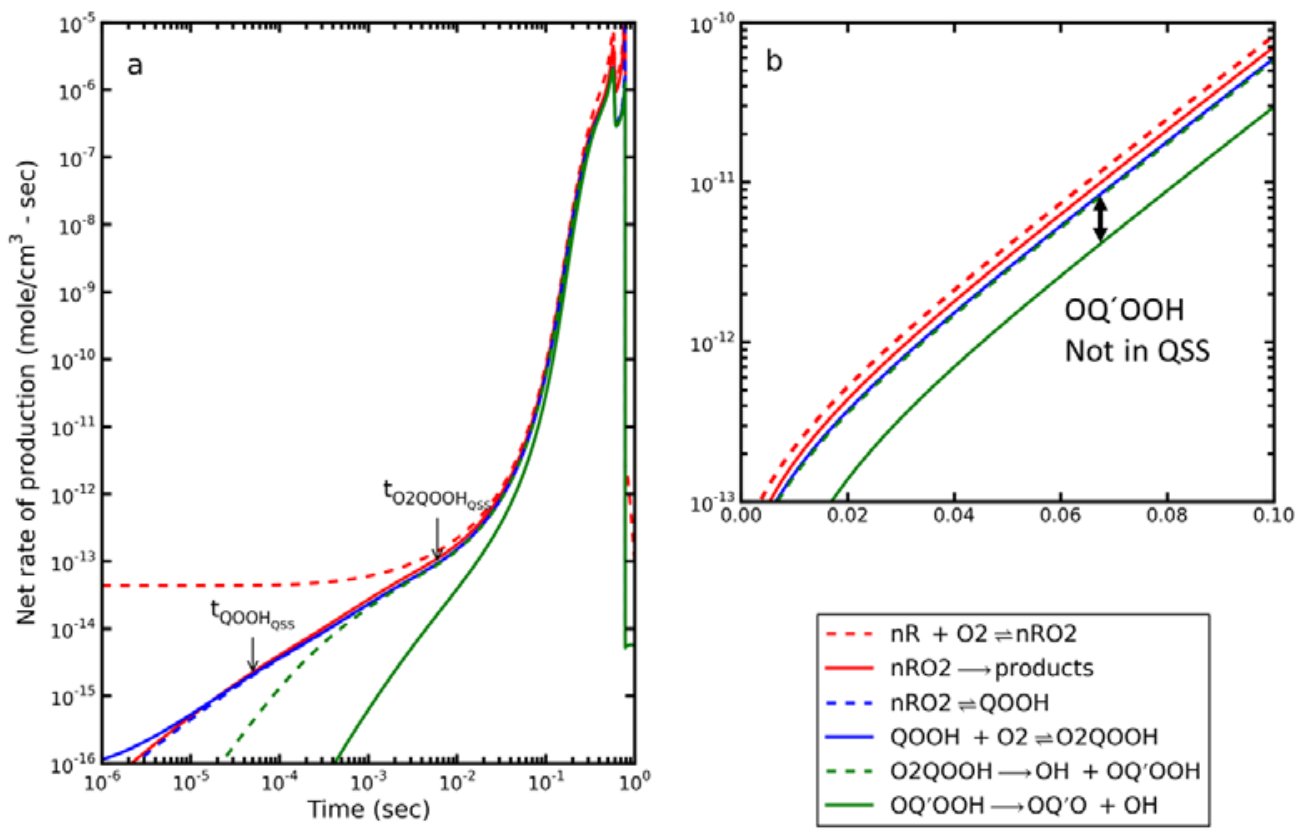

Figure 9: a) Net rate of production for reactions involved in $n$-propyl (nR) peroxy cycle, for adiabatic isochoric simulations $\left(P_{0}=\right.$ $10 \mathrm{bar}, T=650 \mathrm{~K}$ ) of stoichiometric mixture of propane and air using the full propane model. The arrows indicate the time when the species come into quasi-steady state, most species are in quasi-steady state after $\mathrm{t} \sim 5 \mathrm{~ms}$. b) Inset of plot $5 \mathrm{a}$ ) - the rate of $\mathrm{O}_{2} \mathrm{QOOH} \rightarrow \mathrm{OQ}^{\prime} \mathrm{OOH}+\mathrm{OH}$ and $\mathrm{OQ}^{\prime} \mathrm{OOH} \rightarrow \mathrm{OQ}^{\prime} \mathrm{O}+\mathrm{OH}$ are significantly different indicating OQ'OOH is not in quasisteady state. For reference $\tau_{\text {stage-1A, }} \tau_{\mathrm{OQ}} \mathrm{OOH}$ and $\tau_{\text {stage- } 1}$ are $\sim 0.2, \sim 0.44$ and $\sim 0.56$ s respectively

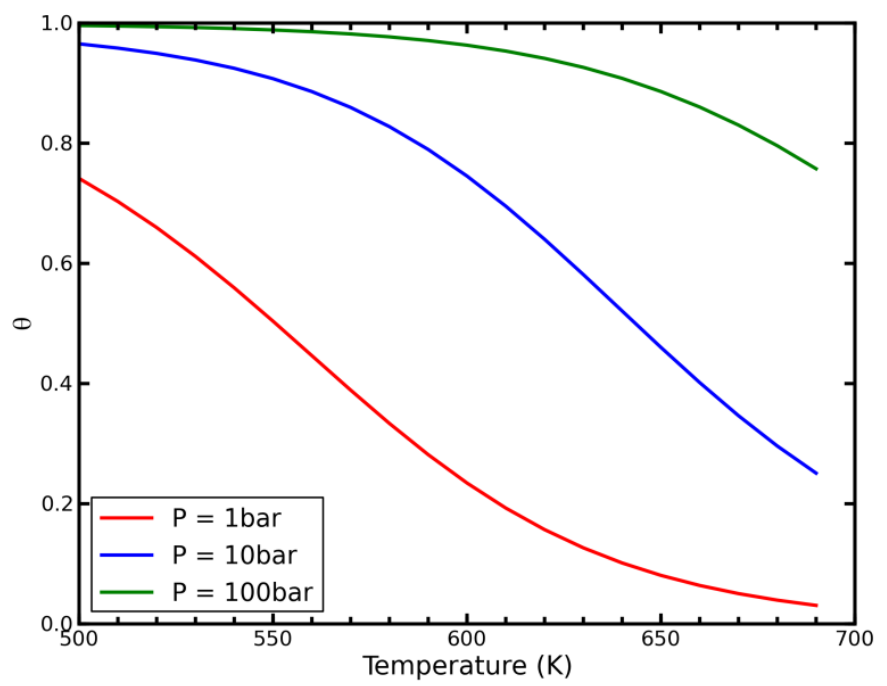

Figure 10: Effect of temperature on $\theta$ (equation (13)) at three different pressures for oxygen mole fraction of 0.2 . As the temperature increases, the fraction of $\mathrm{nRO}_{2}$ that participates in the chain branching sequence approaches zero. The fraction of $\mathrm{nRO}_{2}$ that participates in the chain branching sequence is higher at higher pressures. 


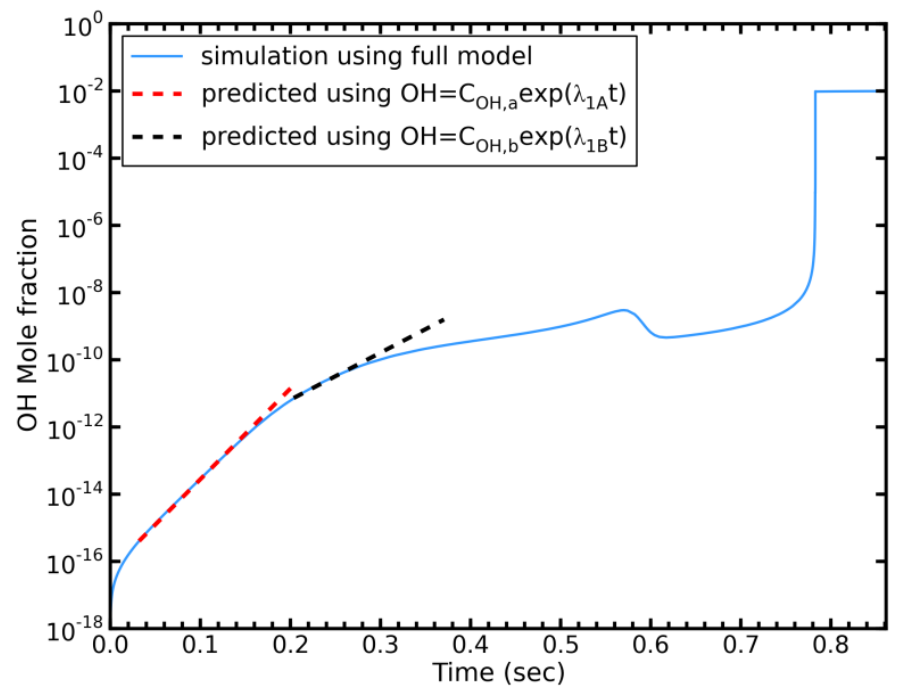

Figure 11: Comparison of the predicted and the simulated $\mathrm{OH}$ mole fraction profiles, for adiabatic isochoric simulations at $P=10$ bar, $T=650 \mathrm{~K}$ and stoichiometric mixture of propane: air using the full model. The red line corresponds to the stage-1A prediction while the black line corresponds to the stage-1B prediction. The predictions are made using the equation $[\mathrm{OH}]=C_{\mathrm{OH}, \mathrm{X}} \exp \left(\lambda_{1 \mathrm{X}} t\right)$ where $\lambda_{1 \mathrm{~A}}=55.4 \mathrm{~s}^{-1}$ and $\lambda_{1 \mathrm{~B}}=25.3 \mathrm{~s}^{-1}$.

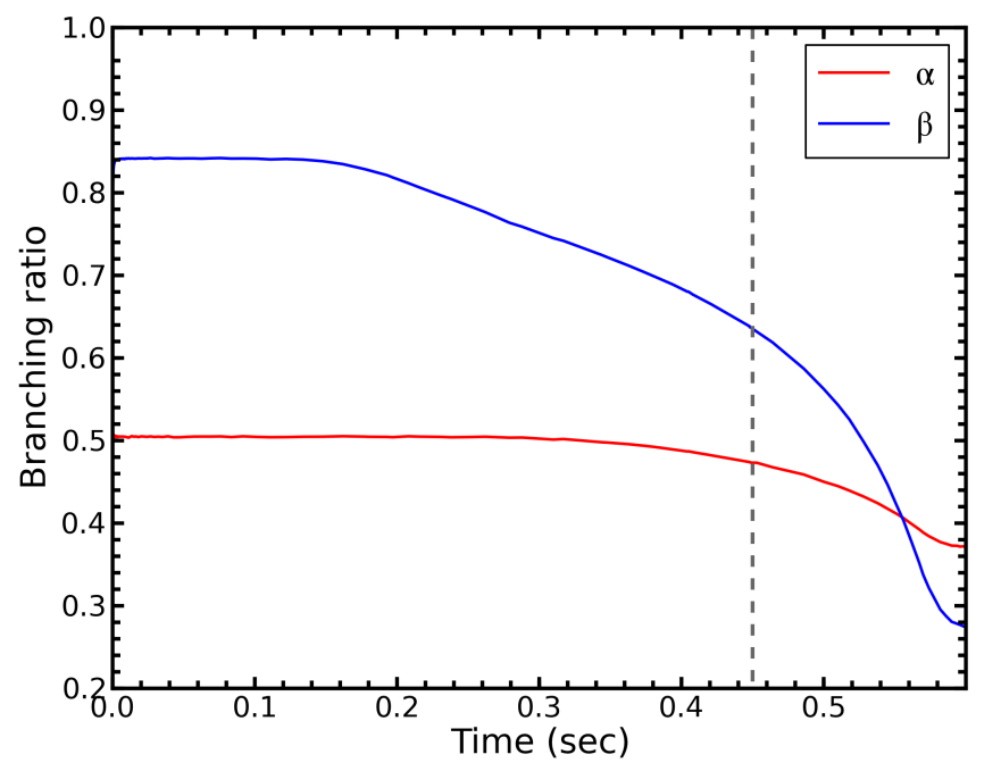

Figure 12: Simulated $\mathrm{OH}$ loss terms $\alpha$ and $\beta$ as function of time for stoichiometric mixture of propane at $T_{0}=650 \mathrm{~K}$ and $P_{0}=10$ bar under adiabatic conditions. The dashed grey line indicates the time when OQ'OOH peaks in the simulation. 


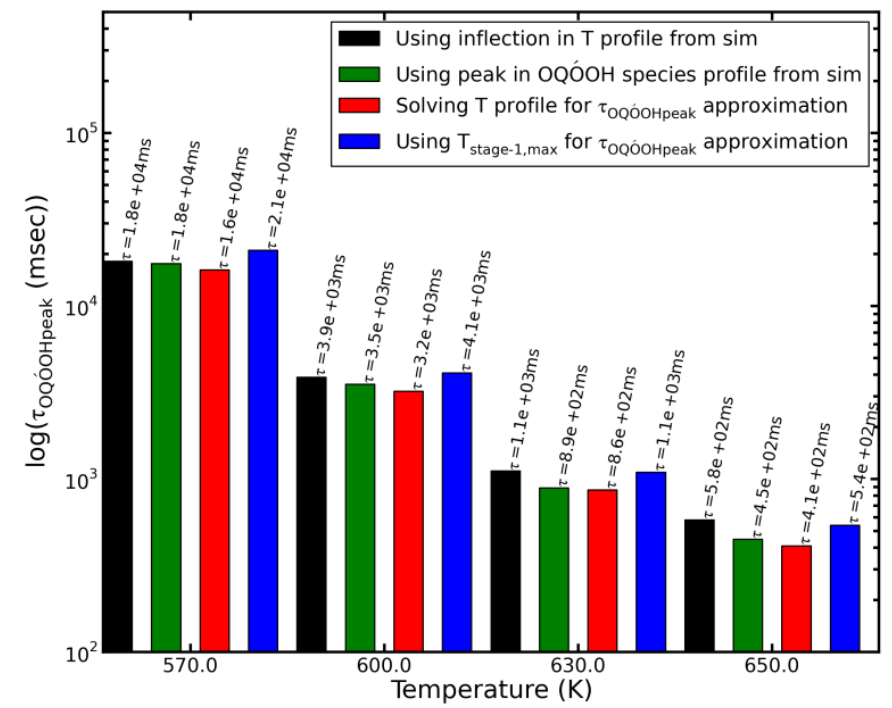

Figure 13: Comparison of the first-stage ignition delays $\left(\tau_{\mathrm{OQ}^{\prime} \mathrm{OOHpeak}}\right)$ obtained from 1$)$ the time of the inflection point in the temperature profile from full model simulation, 2) the time of the OQ'OOH peak in the full model simulation 3) the time for $f_{\mathrm{OH}}=1$ predicted from the solution to equations (31)-(36) and 4) the time for $f_{\mathrm{OH}}=1$ predicted by equation (41) for adiabatic, isochoric simulations of stoichiometric mixtures of propane and air, $P_{0}=10$ bar. 


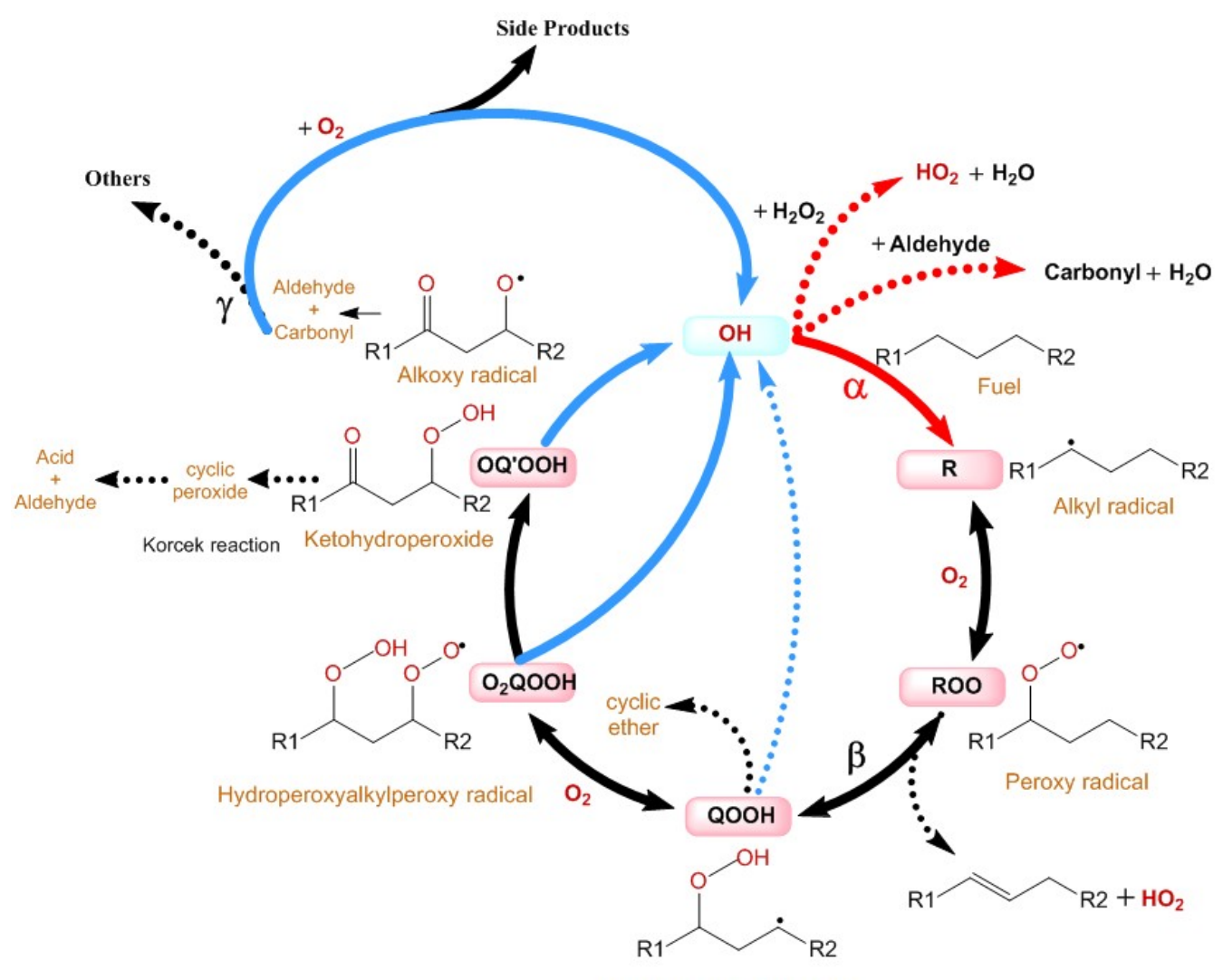

Hydroperoxyalkyl radical

Figure 14: Schematic of an long $n$-alkane fuel undergoing low temperature peroxy chemistry. As the carbon chain increases every site can be treated as an equivalent site. The blue arrows are $\mathrm{OH}$ formation reactions while the red arrows show loss of $\mathrm{OH}$ radicals. The dotted arrows are reactions that compete with low temperature branching reactions and delay the first stage ignition of the fuel.

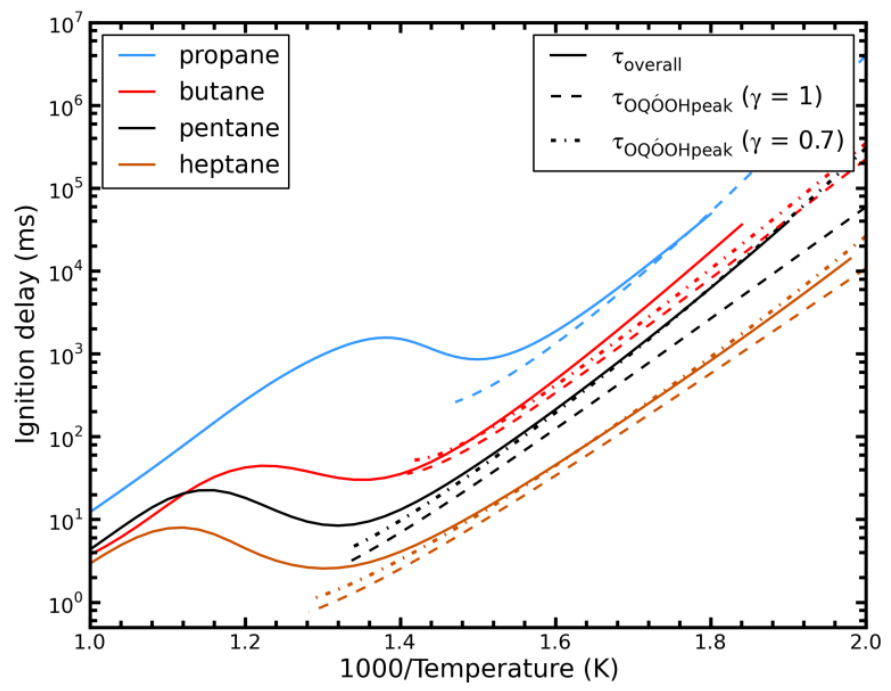

Figure 15: Comparison of the numerically simulated full-model adiabatic isochoric overall ignition delays with the first 
stage ignition delay predicted by Eqs. (50)-(52), for different n-alkanes with initial conditions $P_{0}=10$ bar and $\Phi=1$ in air. The parameters are tabulated in Table 2 and

Table 3. The value of $\gamma$ is uncertain for fuels larger than propane, here we plot results using $\gamma=1$ and $\gamma=0.7$. 